\title{
Zur Verwendung der Trennungskasus im Tscheremissischen
}

\section{EINLEITUNG}

Wer sich nach den modernen Grammatiken der tscheremissischen Schriftsprachen ein Bild vom tscheremissischen Kasussystem gemacht hat, dem kann der Titel meiner Untersuchung befremdlich erscheinen, denn die Grammatiken nennen keinen einzigen Trennungskasus. Viele Sprachlehren der Schriftsprachen aus den zwanziger und dreissiger Jahren unseres Jahrhunderts vertraten jedoch einen anderen Standpunkt: sie kannten einen auf $\gamma \hat{\partial} \hat{c}$ ausgehenden Trennungskasus; derselbe Kasus wird auch in den Deklinationen vieler westlicher Erforscher des T'scheremissichen erwähnt (s. ausführlicher Alhoniemi, MSFOu 142, 12-14). Dass das Morphem $\gamma \hat{a} c ̌$ aus der Gruppe der Kasusendungen ausgeschlossen und den Postpositionen zugerechnet wird, lässt sich durch morphologische Kriterien begründen: es kann an die Genitivform treten und braucht die Vokalharmonie nicht zu befolgen. In syntaktischer Hinsicht hat dieses Morphem jedoch die typischen Funktionen eines fiu. Trennungskasus, wie aus den folgenden Ausführungen hervorgeht.

Zusätzlich zum Morphem $\gamma \hat{\partial} c ̌$ verfügt das Tscheremissische noch über andere typische Trennungskasus-Elemente. In meiner oben erwähnten Abhandlung habe ich nachgewiesen, dass es im Tscheremissischen ca. 30 Wortstämme gibt, an die von der eigentlichen Deklination abweichende, morphologisch unproduktive Lokalkasusendungen treten. Als Trennungskasusmorphem begegnet in diesen Stämmen das Element $\check{c}$, das funktional mit dem Element $\gamma \hat{\partial} \check{c}$ zusammengehört, wie jeder beliebige von jenen Stämmen gebildete unproduk- 
tive Kasus mit dem entsprechenden produktiven; auch der auf $\breve{c}$ endende Kasus ist irgendwie in den Deklinationen einiger früherer Grammatiker erwähnt (Alhoniemi, MSFOu $142,13-14,30-31)$.

Ausser diesen Elementen tritt jedoch in einem Teil des Sprachgebietes ein auch vom morphologischen Standpunkt als lebendiger Kasus anzusehender Ablativ auf, der die Endung leč hat. Es handelt sich hier um die Trennungskasusentsprechung des Dativs. Er wird in keiner der beiden heutigen Schriftsprachen verwendet; in ihnen begegnen nur zwei pronominalstämmige Adverben auf leč mit äusserst begrenztem Gebrauch.

In einigen Dialekten sowie in der östlichen Schriftsprache hat sich eine unproduktive $\check{c}$-Kasusform, $\delta \check{c}$, jedoch gleichsam für eine Sonderaufgabe selbständig gemacht: sie hat dieselben Trennungskasusverhältnisse anzuzeigen, die mit den leč-Kasus in den Dialekten ausgedrückt werden, wo dieses Suffix auftritt. Über den kasusendungsartigen Sondergebrauch auch dieses Elementes sowie über die im gesamten Sprachgebiet bekannte postpositionale Verwendung gibt meine Darstellung ein detaillierteres Bild. (S. als allgemeinen Überblick Alhoniemi, Sananjalka 10, 71-76.)

Die vorliegende Untersuchung ist Teil einer grösseren Forschungsarbeit, die sich mit der Verwendung der Kasus im Tscheremissischen beschäftigt. Dieser Arbeit ging u.a. meine Dissertation über die Verwendung der Wohin-Kasus im Tscheremissischen aus dem Jahre 1967 voran. In der letztgenannten Untersuchung suchte ich die Funktionen der Wohin-Kasus möglichst weitgehend nach dem mechanischen Distributionsprinzip zu klären, indem ich nämlich verschiedene Gruppen bei den Verwendungsfällen der Wohin-Kasus aufstellte, die davon ausgingen, wie die Wohin-Kasus in ihren Kontexten durch andere Kasus ersetzt werden können. Den zentralsten Verwendungsbereich der Wohin-Kasus, wo der Lokalkasus durch keinen anderen Kasus ersetzt werden kann, behandelte ich dann in zwei Teilen. Der erste Teil enthielt ein umfangreiches Material mit sehr wenigen Kommentaren; sowohl die strukturellen als auch die semantischen Kommen- 
tare, durch die ich eine Synthese anstrebte, befanden sich am Ende der Arbeit. Die Semantik, die nach den strukturalistischen Lehren nach Möglichkeit zu vermeiden war, konnte in diesem Stadium endlich zu Wort kommen: hier musste sie schliesslich herangezogen werden.

Das Ziel dieser Untersuchung gleicht dem meiner früheren Arbeit über die Wohin-Kasus: ich möchte einmal die Oppositionen der Verwendung der verschiedenen Trennungskasusmorpheme im Tscheremissischen klären und zum anderen die Funktionen der Trennungskasus überhaupt darstellen. Meine Methode ist diesmal jedoch eine ganz andere.

Ich versuche in dieser Arbeit die Verwendung der Trennungskasus zu klären, indem ich vom semantischen Beziehungsfeld der Ausdrücke ausgehe. Die Untersuchung ist stark von verschiedenen Theorien der Kasusgrammatik beeinflusst worden. Meine Ergebnisse entsprechen jedoch nicht dem Geist dieser Theorien.

Die ursprüngliche Aufgabe der Trennungskasus liegt zweifellos in der Bezeichnung des Ausgangspunktes, und offenbar ist deren Verwendung im Zusammenhang mit Verben der Bewegung am primärsten. Doch bereits im Zusammenhang mit der Überprüfung von deren Kontexten lässt sich eine Frage stellen, deren Beantwortung offenbar nicht immer eindeutig klar ist: welchen Ausgangspunkt drückt der Trennungskasus in erster Linie aus, den einer mobilen Entität oder den der Bewegung selbst? Meines Erachtens muss der Trennungskasus im tscheremissischen Satztyp "X geht von A aus bzw. weg» allgemein - wie man es traditionell auch getan hat - zunächst in Beziehung gesetzt werden zu dem zweiten Nomen des Satzes, d.h. A ist als Aufenthaltsort von $\mathrm{X}$ zu untersuchen, mit welchem die Verbindung von $\mathrm{X}$ infolge des Prozesses unterbrochen wird bzw. aufhört. Der Trennungskasus im Satztyp "X läuft von $A_{1}$ nach $A_{2}$ »z.B. drückt jedoch nicht mehr nur den Ort aus, von wo $\mathrm{X}$ sich entfernt, sondern er kann auch den Anfangspunkt der durch das Verb ausgedrückten Handlung bezeichnen. Das ist meines Erachtens gerade in solchen Fällen der Fall, wo die Veränderungskasus eine deutlich terminative Bedeutung haben, d.h. 
wenn der Satz so auszulegen ist: "X läuft von A (angefangen) bis (hin nach) B». In solchen Sätzen muss denn auch in erster Linie das Verhältnis zwischen Trennungskasus und Verb untersucht werden.

Diese Auffassung, wonach also einige Nomina des Satzes vor allem in Beziehung zu den anderen Nomina des Satzes stehen, andere Nomina wiederum vor allem zu Verben, unterscheidet sich deutlich z.B. von der Fillmoreschen Kasusgrammatik, wonach alle Nomina speziell von dem Standpunkt aus zu betrachten sind, dass sie in Relation zum Verb stehen.

Ausser den Fällen aber, wo die Trennungskasusform entweder durch Vermittlung des Verbs an ein anderes bestimmtes Nominalglied des Satzes tritt oder aber direkt an das Verb, vertreten die Trennungskasusformen sehr oft eine lockerer zum Satz gehörende Bestimmung. Das gilt etwa für den lokalen Trennungskasus im folgenden Satztyp: $X$ saka $Y: m$

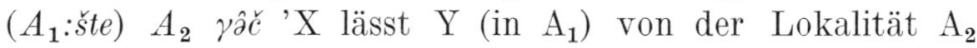
herunterhängen' (konkretes Beispiel S.106). Da sowohl das Verb 'hängen' als auch das semantisch in kausativer Beziehung dazu stehende '(herunter)hängen lassen' ihrem Charakter nach Ruheverben sind, haben sie Wo-Kasus als normale feste Bestimmungen. Der Trennungskasus, der die Lokalität ausdrückt, von wo aus das Hängen verursacht wird, ist im Satz das sekundäre Glied.

Am Anfang meiner Darstellung behandle ich die festeren Bestimmungen des Satzes. Dem Ende entgegen gehe ich i.a. auf Satzglieder über, die lockerer und sekundärer sind. Dennoch war es meines Erachtens nicht immer zweckmässig, die einzelnen Bestimmungen nach dem Aspekt ihrer Lockerheit in verschiedene Kapitel zu teilen: Abschnitt 8 z.B. enthält sowohl Verbal- als auch Satzbestimmungen.

Einige meiner Auslegungen über die Verwendung der Trennungskasus sind zweifelsohne in gewissem Umfang hypothetisch. Ich hoffe jedoch, dass sie auch dann, falls sie später durch bessere ersetzt werden, der Forschung Impulse gegeben haben. 


\section{DIE TRENNUNGSKASUSFORM ALS GLIED EINES PRÄDIKATIVEN VERHÄLTNISSES}

\subsection{Das Verhältnis ist total}

In den folgenden tscheremissischen Beispielen wird durch das Nominalprädikat der Zustand des Denotats des Subjekts

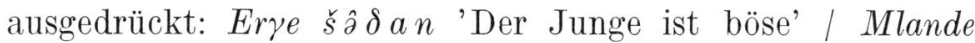
užar 'Die Erde ist grün'. Anstelle des Nominalprädikats kann jedoch in Ausdrücken mit entsprechender Bedeutung auch ein verbales Prädikat stehen: Erye š $\hat{z} \delta e s ̌ k a$ 'Der Junge ist

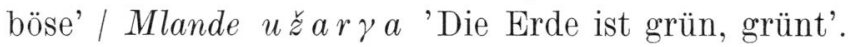

Die angeführten Beispiele drücken einen statischen Zustand aus. Entsprechende Mittel werden jedoch auch in solchen Sätzen verwendet, wo es sich um die Veränderung eines Zustandes handelt. Einerseits kann also ausschliesslich ein dynamisches Verb der Zustandsveränderung verwendet werden:

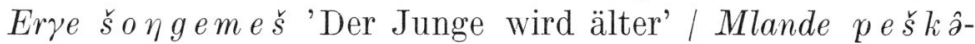
$\delta$ emes 'Die Erde wird härter'. In diesen Fällen enthält die Bedeutung der Verben eine doppelte Information: die Verben weisen einmal auf den Vorgang der Veränderung hin, doch teilen sie andererseits auch den Zustand mit, der das Ergebnis der Veränderung ausmacht. Zweifellos könnte man auch Ausdrücken diesen Typs noch ein prädikatives Nominalglied hinzufügen, doch bliebe diesem nur die Aufgabe, die Bedeutung des Verbs zu verstärken.

Auf der anderen Seite gibt es jedoch auch solche Sätze der Zustandsveränderung, in denen das nominale prädikative

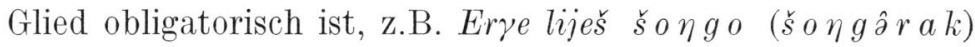
'Der Junge wird alt (älter)' / Mlande liješ p e š $k \hat{\partial} \delta e$ 'Die Erde wird hart'. In diesen Fällen informiert das Verb gleichsam nur über den dynamischen Charakter des Ausdruckes; das Nominalglied hat den Zustand auszudrücken, der das Ergebnis der Veränderung ist. Wie aus den Beispielen hervorgeht, kann das prädikative Nomen auch in derartigen Ausdrücken im Nominativ stehen. Üblicher ist allerdings, dass das prädikative Nomen im Verwandlungssatz in einem anderen Kasus als dem des Subjekts oder Objekts steht, z.B. im Lativ, wie in dem Satz Mlande $p e s ̌ s ̧ \hat{\partial} \delta e \breve{s}$ toleš 'Die 
Erde wird hart', im Illativ wie in dem Satz Mare in $\beta a$ $l i \delta \hat{\partial} s$ lektân 'Der Mann wurde invalide', im Dativ wie

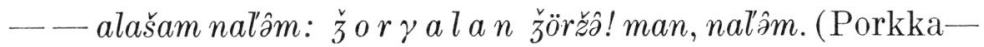
Genetz, 50 M-i) '- - einen Wallach kauft' ich: Zum Zelter taug' er! sprach ich ihn kaufend', im Genitiv wie $\breve{s} u l \delta \hat{z} n$

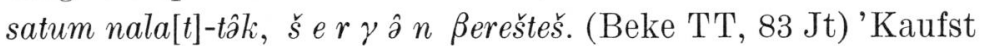
du billig die Ware, so wird sie teuer.' (Über prädikative Wohin-Kasus ausführlicher Alhoniemi, MSFOu 142, 276300, über den prädikativen Genitiv Kangasmaa-Minn, MSFOu 146, 62-82.)

Oben wurde erwähnt, dass es in einigen Fällen in der Sprache zwei ziemlich gleichbedeutende Ausdrucksmittel nebeneinander gibt: zum einen das blosse Verb, zum andern ein Gefüge von Verb und Nomen. Der Sprachbenutzer hat jedoch durchaus nicht immer die Möglichkeit der Wahl: wenn die Zustandsveränderung z.B. so geartet ist, dass dadurch das Denotat des Subjekts in eine andere Klasse übergeht, ist oft die einzige Möglichkeit, ein Verb und ein damit verbundenes Prädikativadverbial zu verwenden, z.B. Tuঠo ija ške saßârna 'Er verwandelt sich in einen Teufel'; ein Verb mit der Bedeutung 'zum Teufel werden' ist kaum vorhanden.

Der durch das Verb oder das prädikative Nomen ausgedrückte Zustand gilt im intransitiven Satz dem Denotat des Subjekts, im transitiven entsprechend dem des Objekts,

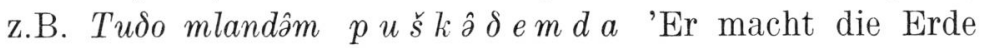

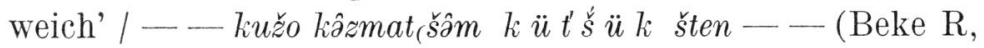
725 B) ' - - den langen Dienst kurz machend - - '. Diese transitiven Sätze unterscheiden sich in ihrer Tiefenstruktur von den früher behandelten intransitiven Beispielen lediglich insofern, als darin ausser der Zustandsveränderung auch der Urheber dieser Veränderung ausgedrückt wird. Die Bedeutung solcher Sätze ist folgendermassen zu analysieren: tuঠo âšta 'er verursacht' + mlande puškâdemeš 'die Erde wird weich'.

In allen angeführten Beispielen kann man die Bedeutungsbereiche der in prädikativem Verhältnis stehenden Nominalglieder als identisch ansehen, z.B. im Satz Erre š o $\eta g$ o liješ

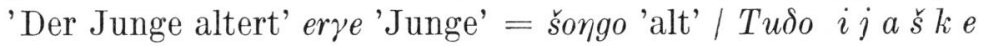




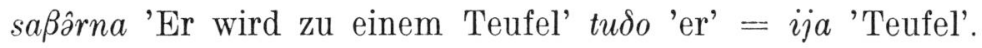
Ein solches prädikatives Verhältnis kann als total bezeichnet werden (vgl. Sadeniemi, Tietolipas 18, 25-36); der Gegensatz dazu ist das partiale prädikative Verhältnis, von dem im folgenden Kapitel die Rede sein wird.

Als zweites Glied des totalen prädikativen Verhältnisses kann in einigen, eine Zustandsveränderung ausdrückenden Konstruktionen auch der Trennungskasus auftreten. Meistens begegnet der Trennungskasus in einem Satztyp, der die Veränderung »aus X wird Y (gemacht)» ausdrückt; allgemein könnte anstelle eines solchen Trennungskasus-Ausdrucks ein Satz verwendet werden, wo statt des Trennungskasus ein Wort im Kasus des Subjekts (oder Objekts) steht mit einer Wohin-Kasusform als zweitem Glied, die Konstruktion also "X wird zu Y (gemacht)". Die Trennungskasusform tritt im überwiegenden Teil meiner Beispiele bei den Verben lijam 'werden', âštem 'machen' oder lâštem 'machen' auf, wie jedoch gegen Ende des folgenden Belegmaterials ersichtlich wird, können auch andere Verben in einigen Fällen als Prädikat in derartigen Konstruktionen stehen. Als Trennungskasus erscheint im gesamten Sprachgebiet der Elativ auf $\gamma \hat{a} c$; aus dem B-Dialekt liegen jedoch neben den $\gamma \hat{\partial} \hat{c}$-Belegen auch einige Kontexte mit dem leč-Trennungskasus vor sowie ein Kontext, wo als prädikativer Trennungskasus der unproduktive $\check{c}$-Kasus vorzukommen scheint.

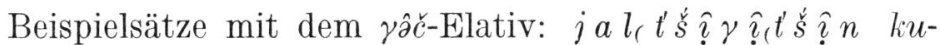

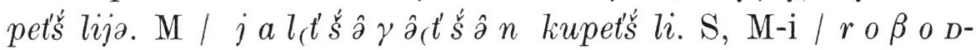

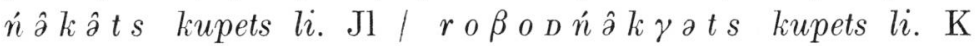
(Wichmann R, 20) 'Aus dem Arbeiter wurde ein Kaufmann.'

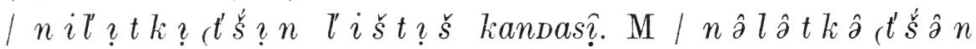

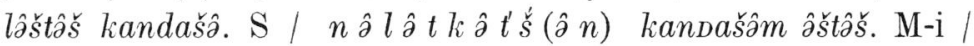

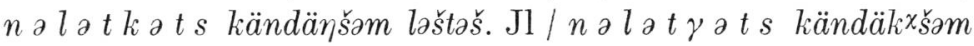
əšstəs. K (Wichmann R, 27) 'Aus vier machte er acht.' ।

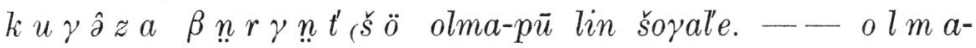
$p \bar{u} \check{s} a \dot{n}$ (d' $d^{\prime} \dot{z} a \grave{s} k \hat{\partial} t^{\prime} \dot{s}$ nöröp li. (Beke T I, 644 C̆) 'Aus dem Blut des Alten entstand ein Apfelbaum. - - Aus den Spänen (Sing.) des Apfelbaumes wurde ein Brunnen.' / u s a n k e t's usmak lit. (Beke T III, 419 Up) 'Aus Klugen 
(Sing.) werden Narren (Sing.).' / imńi-tarßâltâš olo, manât,

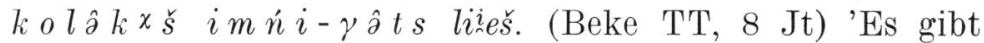
auch, sagt man, einen Pferd-tar $\beta \partial ̂ l t a ̂ s$, er entsteht aus einem verreckten Pferd.' / $t i m \hat{\jmath} n d \hat{\partial} r a-\gamma$ a $t s$ a n lin šandześ

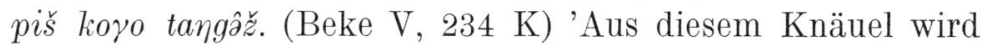

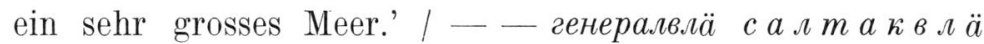

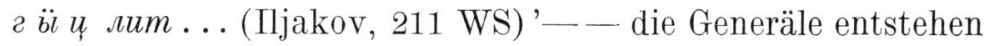
aus Soldaten...' / Bara solašte kalâk tsâla pâtat, $\hat{\partial} r \beta e$ $z \hat{\partial} \gamma \hat{\partial} t s$ kušso uko. (Beke T I, $135 \mathrm{Jt}$ ) 'Im Dorfe kommen (dann) die Leute alle um, keines der Kinder wächst heran [eigtl. von Kindern gibt es keine wachsenden, d.h. es werden keine Kinder geboren].' I sokâr liịmöngö mariiňe nalân

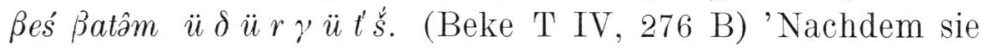
[die Frau] erblindet war, nahm ihr Mann ein anderes Mädchen zur Frau.'

Wie gesagt, gibt es in einigen entsprechenden Kontexten des B-Dialektes auch leč-Kasus; in allen Fällen tritt die Endung leč an belebte Nomina, z.B. ademe pušenge ššskendžâm

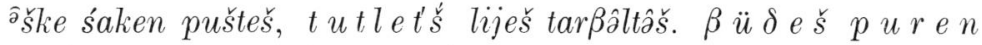

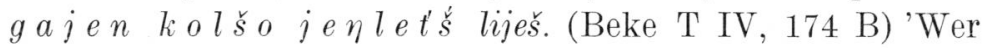
sich auf einen Baum erhängt und Selbstmord begeht (eigtl. wenn man sich tötet), wird auch ein tarßâltâš. Auch im Wasser ertrunkene (eig. hineingefallen gestorbene) Menschen (Sing.) werden zu tarkâltâs.'

In erster Linie in diesen Zusammenhang dürfte auch die folgende Wendung gehören, die bedeutet 'jemand wird nichts od. ist zu nichts nutze'; diese Wendung ist nur im B-Dialekt belegt, und alle von mir verzeichneten Beispiele haben den leč-Kasus: $t \hat{\partial}$ er $\gamma \hat{\partial} m l$ e t’śs o lijmaš dartšat uke ulmaš. (Paasonen-Siro T, 7 B, s. auch Beke T IV, 410, 412, 413 B) 'Aus diesem Jungen scheint nichts zu werden und er scheint keine Neigung zu haben.'

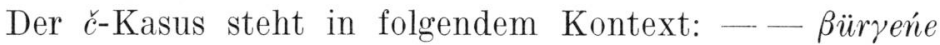

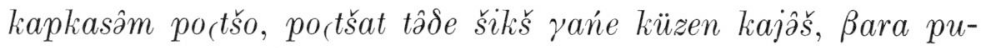

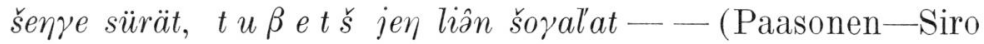
T, 237 B) ' — - er öffnete den kupfernen Deckel, er öffnete und dieser [das Mythenwesen šerrit] erhob sich wie Rauch, wurde dann wie ein Baum, aus diesem ein Mann und _- - 
Die Trennungskasusform kann auch in einer Konstruktion auftreten, wo das prädikative Verhältnis dreigliedrig ist, mit anderen Worten im Satztypus "X wird aus Y zu Z (gemacht)». In diesen Ausdrücken ist der Trennungskasus obligatorisch; als Trennungskasus tritt regelmässig der $\gamma \partial \hat{\partial}$-Elativ auf. Viele Belege weisen als Prädikat lijam 'zu etwas werden' auf; in allen diesen Fällen sind die beiden anderen Glieder des prädikativen Verhältnisses durch dieselben Formmittel ausgedrückt wie das Subjekt, z.B. Pikej $\gamma \hat{a} c \hat{z} n$ Marja liâm. (Genetz, 33 P) 'Aus Pikej bin ich zur Marja umgewandelt.'

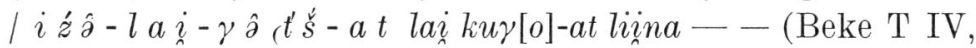
298 B) 'Aus klein[en Kindern] sind wir Erwachsene (eigtl.

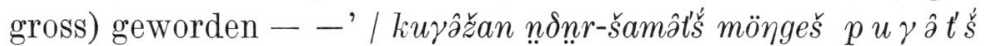

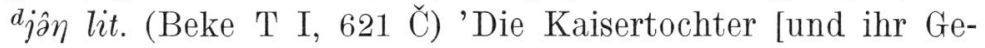
folge] verwandeln sich (aus Bäumen) wieder in Menschen.' /

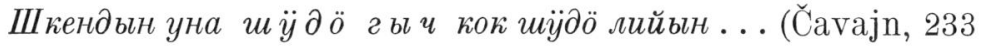
OS). 'Deine eigenen Bienenstöcke haben sich von hundert auf zweihundert vermehrt...'

Im Zusammenhang mit den Verben saßârnem 'sich verwandeln' und saßârem 'verwandeln' wird das entsprechende prädikative Verhältnis dagegen durch die folgenden Formen wiedergegeben: Nominativ od. Personalendung des Verbs oder aber Akkusativ + $\gamma \partial \hat{\partial}$-Elativ + Illativ, Beispiele: $k u$ -

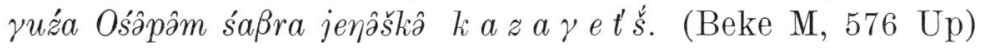
'Der Alte verwandelt Josef aus einer Ziege in einen Menschen.' / ošan-Gâts ân turakâš šuku sayurnat, tura [k]-

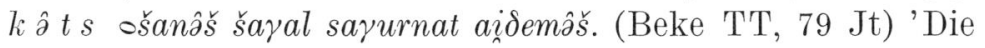
Gescheiten werden öfters zu Narren, aus Narren werden wenig gescheite Menschen.'

Schliesslich steht in zwei Texten aus den Ostdialekten der prädikative Trennungskasus auch in Verbindung mit dem Verb kodam 'bleiben'. Überall handelt es sich um das Abnehmen einer Anzahl von etwas zu etwas. In zweifacher Hinsicht sind die Kontexte auffallend. Als prädikativer Trennungskasus erscheint zwar auch in diesen Zusammenhängen der $\gamma$ วิč-Elativ, doch als Wohin-Kasus begegnet der eš-Lativ. Dies ist eine Ausnahme, da ein verbaler Ausdruck, mit dem ein Trennungskasus zur Bezeichnung des Ausgangspunktes 
einer Bewegung, eines Zustandes u.dgl.m. verbunden ist, ausdrücklich eine illativische Wohin-Kasus-Bestimmung erhält (Alhoniemi, MSFOu 142, 233, 290-291). Andererseits weist die Oberflächenstruktur dieser Beispiele überhaupt kein Subjekt auf: jene Entität, deren Anzahl verändert wird, drückt man durch den Trennungs- und den Wohin-Kasus aus, die Anzahl selbst durch nominativische Adjektivattribute jener Veränderungskasus, z.B. taj šojaklet maneš. š ü d ö p ir a ga č an bič pireš kodeš mańe. (Sebeok-Ingemann, 64 B) 'Du lügst, sagt [der Vater]. Von den [zuerst von dir genannten] hundert Wölfen blieben fünf, sagte er.' / $l a t k o k$

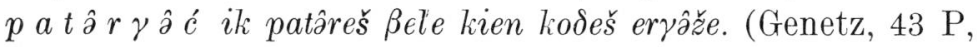
derselbe Beleg zweimal auf dieser Seite) 'Der Knabe blieb da liegen und von den zwölf Kräften hat er nur eine Kraft nach.'

\subsection{Das Verhältnis ist partial}

In den oben angeführten Belegen für Trennungskasus ist die gemeinsame semantische Komponente der Prädikatsverben überall 'sich verwandeln' oder 'verwandeln'; in den Kontexten handelt es sich stets um eine totale Veränderung: jemand oder etwas wird ganzheitlich zu etwas anderem.

Das folgende Beispiel entspricht stark den oben zitierten; auch das Prädikatsverb lautet hier lâštem 'tun', ein Verb also, das auch in einigen Belegen des vorangehenden

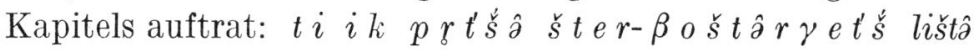
stanâm-—(Beke M, 414 Up) 'Aus dieser einzelnen Rute mache einen Webstuhl _- - '. Der Satzzusammenhang entspricht jedoch offenbar nicht genau den oben behandelten. Der weitere Textzusammenhang zeigt nämlich, dass durch die Trennungskasusform in diesem Satz in erster Linie das Material bezeichnet wird, woraus der Webstuhl hergestellt werden sollte. Der Herstellungsprozess setzt keine totale Veränderung voraus: es ist nicht unbedingt nötig, dass eine Rute ganzheitlich in einen Webstuhl verwandelt wird; wesentlich ist nur, dass bei der Herstellung des Webstuhls Rutenmaterial verwendet worden ist. Ein derartiges Verhältnis 
wird man als partiales prädikatives Verhältnis bezeichnen können: der Trennungskasus gibt an, aus welchem Material jemand oder etwas besteht, der Bedeutungsbereich der Trennungskasusform ist - oder kann es wenigstens sein grösser als jener des zweiten Gliedes im prädikativen Verhältnis. Andererseits ist der Veränderungsvorgang in Sätzen mit einem materiellen Trennungskasus oft anders geartet: die Veränderung betrifft gleichsam die äussere Gestalt der sich verwandelnden Entität, nicht deren inneres Wesen. Weitere Belege für materielle Trennungskasus, die vor allem

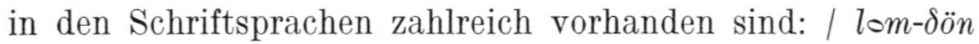
$(l \circ m \gamma \circ t s)$ jenam lašten. (Wichmann R, $24 \mathrm{Jl})$ 'Aus Schnee hat er den Menschen gemacht.' / $T$ в г а й ур жм а г и и ыиштыме киндым кочкын - - (Ončyko 6/1963, 93 OS) 'Er ass aus solchem Roggen gemachtes Brot - - / Тӥрыснек тудо марийже кап-кыл гы и ыиталтын... (Ončyko 6/1963, 26 OS) 'Sie [die Frau] ist ganz aus dem Körper

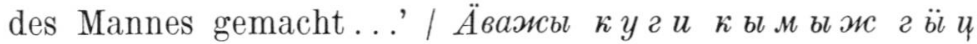
плетымы пешырым кычыкта. (Iljakov, 19 WS) 'Seine Mutter

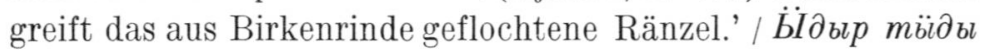

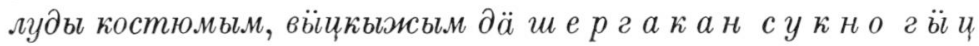
ыргыктылмым чиэн - - (Iljakov, 142 WS) 'Das Mädchen hatte ein graues Kleid an, aus dünnem und teurem Stoff angefertigt - - / - - ззи снаряд гильза гй й йштымы — - ламna - - (Iljakov, $266 \mathrm{WS})^{\prime}$ - - aus einer kleinen Granatenhülse gemachte - - Lampe - - '.

Der Unterschied zwischen den von mir als total und partial bezeichneten prädikativen Trennungskasus ist wie gesagt vielfach recht gering. Der folgende Trennungskasus kann z.B. entweder als totales oder als partiales Prädikativum verstanden werden: $И$ юмо айдемын ӧрдымлужо а ыч удрамашым ыитен.(Ončyko 6/1963, 26 OS) 'Und Gott machte die Frau aus der Rippe des Mannes.' Um einen totalen prädikativen Elativ würde es sich handeln, falls die präzisierte Bedeutung des Ausdruckes lautet 'Und Gott schuf die Frau, indem er eine Rippe des Mannes in eine Frau verwandelte.' Ein partiales Prädikativum würde wiederum voraussetzen, dass das Beispiel folgendermassen verstanden wird: 'Und 
Gott schuf die Frau, wobei er die Rippe des Mannes als Material verwendete.'

Zwischen dem totalen und partialen prädikativen Trennungskasus kann man jedoch mittels der distributiven Methode auch einen formalen Unterschied erhalten. Die partiale prädikative Elativform kann nämlich — anders als die totale - ersetzt werden durch einen instrumentalen Postpositionsausdruck mit dene 'mit'. Bereits in einem der oben stehenden Belege findet sich neben dem Elativ eine solche Postpositionskonstruktion; erwähnt sei, dass in den Varianten für diesen Belegsatz in den Dialekten M, S, M-i und K lediglich die Postpositionskonstruktion erscheint. Zwei weitere Beispiele: kunam $t i \beta$ ošt $\hat{\partial} r \delta$ en $\hat{\partial}$ lišta stanâm - - (Beke M, 414 Up; vgl. das erste Beispiel oben) 'Macht er aus dieser Rute

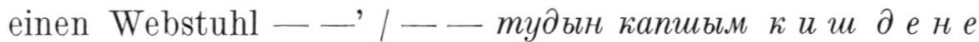
веле ыиштеныт улмаи. (Ončyko 6/1963, 93 OS)'- - sein [des Heiligen] Körper war nur aus Harz gemacht.'

\section{DIE TRENNUNGSKASUSFORM ALS GLIED EINES LOKALEN VERHÄLTNISSES}

Abstrahiert bedeutet das lokale Verhältnis: „Die Entität $\mathrm{X}$ ist in der Lokalität A». Das statische lokale Verhältnis wird im Tscheremissischen, wie in den fiu. Sprachen allgemein, vor allem mit Hilfe der Wo-Kasus ausgedrückt, z.B.

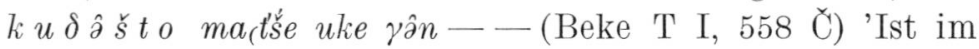
Hause keine Katze - - '. Statt der Lokalkasusformen werden jedoch zum selben Zweck auch vielerlei lokale Adverben und Postpositionskonstruktionen verwendet, z.B. Mikâš ulmažâ $\beta$ eś $\beta$ ere. (Beke M, 188 Up) 'Mikâš war anderswo.'

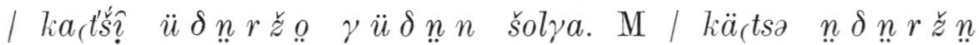

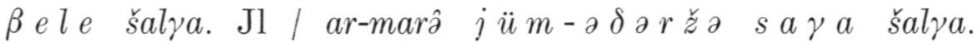
K (Wichmann R, 110) 'Der Bräutigam steht neben seiner Braut'. Dasselbe Verhältnis lässt sich jedoch auch durch einige andere Formmittel wiedergeben, u.a. mit Hilfe des Objekts,

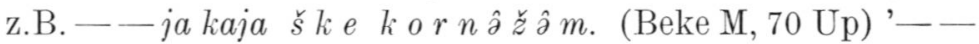
der Teufel geht seines Weges.'

Die Kontexte, die den Prozess "X kommt nach A» aus- 
drücken, bezeichnen den Beginn eines bestimmten lokalen Verhältnisses. Die Lokalität, in deren Bereich die Entität gelangt, wird normalerweise durch lokale Wohin-Kasus ausgedrückt, in manchen Sonderfällen auch durch den Dativ, z.B. ——kaja kn $\beta$ ar $\beta$ ujô̌k o. (Beke T I, 638-639 C̆) '_- - er geht an den Brückenkopf.' / jo r a l a n śürat, t'šuš poremda. (Beke T III, 305 Us) 'Man streicht [Ameisenbutter] auf Wunden (Sing.), [die] sie rasch heilt.' Auch statt der Wohin-Kasus können viele lokale Adverben und Postpositionskonstruktionen verwendet werden. Das Besondere ist, dass in ziemlich vielen Fällen die Bedeutungsopposition zwischen Wohin- und Wo-Kasus bei diesen erstarrten Elementen geschwunden ist; vgl. z.B. die folgenden Kontexte mit den im vorangehenden Abschnitt dargestellten: aštaren

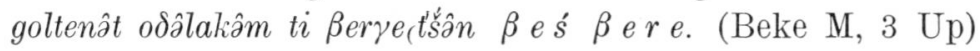
'Sie vertrieben die Wotjaken von diesem Platze auf einen anderen Platz.' / aźźam a t’am kü $\delta$ ṇn šindı̣̌s?m. M /

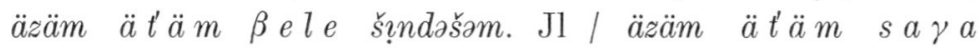
šrndašəm. K (Wichmann R, 109) 'Ich setzte das Kind neben meinen Vater.' Auch statt eines lokalen Adverbials mit lativischer Bedeutung kann mitunter das Objekt verwendet werden. In den folgenden Sätzen z.B. steht ein "Lokalobjekt» bei Verben, die normalerweise eine lokale lativische Bestimmung erhalten: po $\beta$ oskam šind żât, kajat. (Beke M, 137 Up) 'Sie setzen sich auf den verdeckten Wagen, fahren.' /

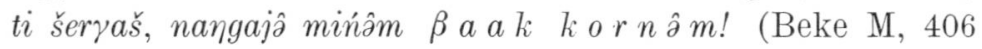
Up) 'Ring, bringe mich auf den Weg [zum] ßaak Teich!'

Die Kontexte, in denen der Prozess " $X$ entfernt sich aus A» ausgedrückt wird, bezeichnen ihrerseits das Ende eines bestimmten lokalen Verhältnisses. Die Lokalität, aus der sich die Entität entfernt, wird allgemein durch den Trennungskasus wiedergegeben, z.B. $k$ às et $s$ tı̣n tolâts? (Wichmann R, $425 \mathrm{~K}$ ) 'Woher kamst du?' Es gibt auch Adverben und Postpositionen mit Trennungskasusbedeutung. Auffallend ist jedoch, dass diese Elemente sehr allgemein ein deutlich erkennbares, den Trennungskasuscharakter anzeigendes $\gamma \hat{a} c$ oder $\breve{c}$ enthalten, worauf u.a. beruht, dass diese sprachlichen Elemente sich der Form nach deutlich von den Adverben 
und Postpositionen mit Wo- und Wohin-Bedeutung unterscheiden. Die auf $-(\hat{\partial}) n$ endenden Adverben folgender Art scheinen jedoch mit dieser Feststellung in Widerspruch zu

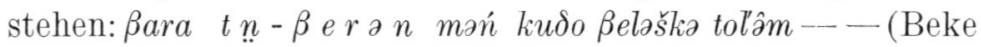
T I, 9 Jo) 'Dann reiste ich (von dort) heimwärts ——' / tö r nn n

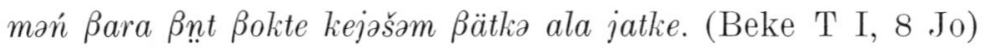
'Von dort fuhr ich zu Wasser bis Wjatka.' Zu beachten ist

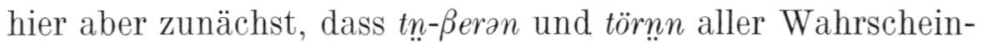
lichkeit nach ein und dieselbe Form ist; das $\ddot{o}$ hat sich in der letzten Form wahrscheinlich durch die Verschmelzung von $\beta$ mit $e$ entwickelt. Im folgenden Kontext erscheinen beide Formen nebeneinander: —— $\beta$ ara $t \ddot{o r} n n$ n $(t n-\beta$ er ən $)$ Buঠopešt alaškâ kandâšt. (Beke T I, $15 \mathrm{~J} 0$ ) '- - dann schickte (eigtl. brachte) man mich nach Budapest.' Andererseits wird sich die Form tn- $\beta$ eran aus dem deutlichen Trennungskasus

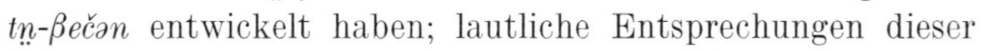
Form begegnen verbreitet in den tscheremissischen Dialekten in der Bedeutung 'von dort' oder 'von da her'. Der Wandel $\check{c}>r$ könnte wiederum in Verbindung stehen mit der im Tscheremissischen auftretenden Erscheinung des sog. Rhotazismus (s. z.B. Wichmann, FUF 9, 114-119).

Alle oben genannten Zitate vertreten denselben Dialekt von Jo. In einem anderen J-Dialekt, in Jt, begegnen wiederum aus Pronominalstämmen gebildete, auf $\beta$ erâm ausgehende

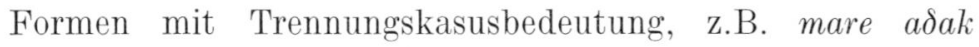

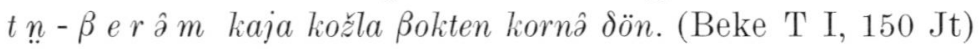
'Der Mann geht von dort wieder seines Weges durch den

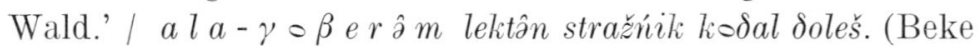
T I, $305 \mathrm{Jt}$ ) 'Da fährt (von irgendwoher) ein Polizist vor und geht hinaus [zu ihm].'

Diese Formen gehören etymologisch sichtlich mit den oben behandelten $\beta$ erən-Formen zusammen. Bei den auf $-m$ ausgehenden Formen ist die Loslösung von der Bečân-Ausgangsform nur noch weitergegangen. Die Formen mit $r$ sind im Sprachbewusstsein zweifellos verbunden worden mit den Formen von $\beta$ er- 'Platz'. $\beta$ erâm ist sicherlich das Ergebnis einer bestimmten Volksetymologie: statt der hinsichtlich der Bedeutung des Trennungskasus unmotivierten Form ßerân 
wurde gleichsam die Akkusativform in Gebrauch genommen.

Die Verwendung der als Akkusativ verstandenen Form ßerâm anstelle des Trennungskasus wird wiederum unterstützt durch andere Fälle, wo ebenfalls der Akkusativ den Trennungskasus ersetzt. Das Verb lektam 'los-, weggehen' z.B., das allerdings meistens eine lokale Trennungskasusbestimmung erhält, kann mitunter auch mit einem die Lokalität bezeichnenden Objekt auftreten. Im folgenden Zitat z.B. steht einmal das Objekt und zum andern die Elativbestimmung in aufeinanderfolgenden Sätzen: lekna ol a m. o l a-

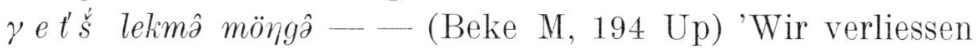
die Stadt. Als wir die Stadt verliessen - - '. Andererseits begegnen von einigen die Richtung angebenden Wörtern erstarrte Kasusformen mit Trennungskasusbedeutung (s. S. $26-27)$.

In dieser Darstellung beschränke ich mich jedoch auf die nähere Betrachtung nur jener Kontexte, in denen die Lokalität speziell durch ein für den Trennungskasus typisches

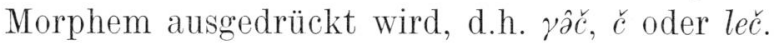

Das lokale Verhältnis ist seinem Charakter nach unbelebt (-Anim). Dies wird im Tscheremissischen auch in der Oberflächenstruktur der Sprache sichtbar. Von belebten Wesen werden nämlich allgemein in lokaler Funktion keine eigentlichen Lokalkasusformen gebildet (in den Dialekttexten finden sich zwar einige Ausnahmen von dieser Regel). Falls ein belebtes Wesen manchmal als Lokalität aufzufassen ist, wird von dem diesbezüglichen Wort i.a. eine Postpositionskonstruktion verwendet. Statt maskaš(ke) 'in den Bär' oder maskašte 'im Bär' zu sagen, benutzt man z.B. die Ausdrücke maska

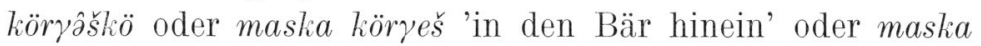

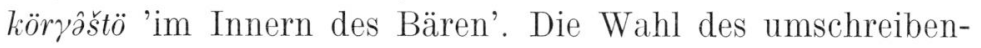
den Ausdruckes wird verständlich, wenn man bedenkt, dass die Bedeutung der Postposition immer konkreter ist verglichen mit dem entsprechenden Kasus (s. z.B. Lyons, Introduction, 304); die mit einer Lokalkasusendung versehene Postposition hat im Tscheremissischen relativ wenig andere Aufgaben als die Lokalität anzuzeigen.

Diese suppletive Situation zwischen den Kasusendungen 
und den Postpositionen hat dazu geführt, dass in den Formenlehren der tscher. Schriftsprachen allgemein überhaupt keine Lokalkasus von Wörtern -Anim angeführt werden (s. z.B. Savatkova-Učajev, 807-808). Diese Entscheidung befremdet deshalb, weil ja die Lokalkasus auch der Wörter +Anim in anderen als lokalen Funktionen verwendet werden, z.B. als Prädikativ-Adverbiale. Wie erwähnt (S. 5) kennt man in den Formenlehren der Schriftsprachen überhaupt keine Trennungskasus. Man kann deshalb nicht sehen, wie sich die Autoren der Grammatiken zur Verwendung der Trennungskasusmorpheme bei +Anim-Wörtern verhielten. Jedenfalls existiert im Tscheremissischen neben den erwähn-

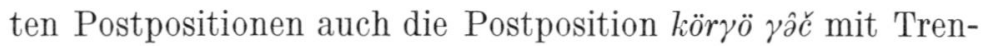
nungskasusbedeutung (s. Marijsko-russkij slovaŕ, 231). Ich habe anhand der Texte jedoch nicht feststellen können, dass sie speziell bei +Anim-Wörtern stünde (s. z.B. Beke T IV, 168, 266, 269, 271 B). Andererseits finden sich im Material einige Texte, wo das Morphem $\gamma \hat{\partial} c$ an ein +Anim-Wort tritt, z.B. Borân $\beta$ [orânit'ś] naleš korakâm, lukteš korakket'śs

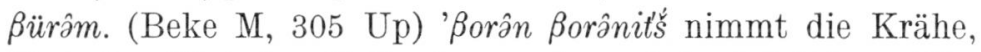

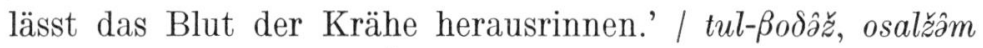

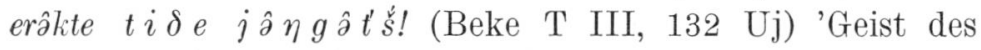
Feuers, verjage den Bösen aus diesem Mann!' Insgesamt sind die Fälle, wo ein +Anim-Wort als Lokaladverbial mit Trennungskasusbedeutung steht, in meinem Material jedoch zahlenmässig so gering, dass aufgrund dessen keine sicheren Schlussfolgerungen gezogen werden können.

3.1. Der Trennungskasus bei einem Verb des lokalen Übergangs

\subsubsection{Der Trennungskasus drückt die Lokalität aus}

In den Kontexten, wo der Trennungskasus bei einem Verb der lokalen Verschiebung steht, ist die lokale Verwendung des Trennungskasus am typischsten. Die Kontexte drücken i.a. den Übergang von Lokalität A zu Lokalität -A aus; die Lokalität A wird mittels des Trennungskasus angegeben. 
Wenn auch ausgedrückt werden soll, wohin der Übergang geschieht, schematisch der Übergang von $\mathrm{A}_{1} \mathrm{zu} \mathrm{A}_{2}$, muss ein Adverbial mit Wohin-Kasus-Bedeutung hinzugefügt werden.

Verben, die den lokalen Übergang bezeichnen, gibt es im Tscheremissischen ausserordentlich viel, wie allgemein auch in anderen Sprachen. Und das deshalb, weil die Übergangsverben oft nicht nur diesen Übergang ausdrücken, sondern gleichzeitig auch vieles andere, z.B. die Richtung des Vorgangs ( $\beta$ olem 'fallen', küzem 'steigen, klettern'), die Art und Weise (jortem 'traben', kudalam 'laufen', čoneštem 'fliegen'), die Annäherung an ein Ziel (pörtâlam 'zurückkehren', lišemam 's. nähern'), die Entfernung von einem Punkt (čaknem 'sich zurückziehen', torlem 'sich entfernen'), ein Vermeiden hinsichtlich eines Punktes (koranam 'ausweichen', šâlam 'fliehen') usw. Die Bedeutung des Verbs kann auch einen Hinweis auf die Beschaffenheit dessen enthalten, der oder das an dem Übergang teilnimmt, z.B. jojem 'strömen' weist hin auf eine Materie in flüssigem Zustand, pörðam 's. drehen' wiederum auf einen bestimmten Gegenstand oder ein Wesen. Die gemeinsame Bedeutungskomponente all dieser Verben in den Kontexten, wo eine lokale Trennungskasusbestimmung damit zusammenhängt, ist jedoch der Übergang, die Verschiebung.

Die Übergangsverben, die in transitiven Sätzen stehen, unterscheiden sich von den intransitiven darin, dass sie noch eine zweite gemeinsame Bedeutungskomponente aufweisen, nämlich die des Verursachens. In einigen Fällen bilden die intransitiven und die transitiven Verben ein Paar, getrennt lediglich durch diese Bedeutungskomponente des Verursachens. Z.B. kann man $\beta$ olem 'fallen, herabsinken, sich herabsenken' und Boltem 'fallenlassen, senken' folgendermassen in Bedeutungskomponenten einteilen:

Bolem = ÜBERGANG + ÜBERGANGSRICHTUNG: HINUNTER + ÜBERGANGSART: NICHT GENAUER DEFINIERT

Boltem = vERURSACHEN + ÜBERGANG + ÜBERGANGSRICHTUNG: HINUNTER + ÜBERGANGSART: NICHT GENAUER DEFINIERT 
In den meisten Fällen ist die Analyse der transitiven Verben komplizierter als der intransitiven, da ein Teil der semantischen Merkmale zum Verursachen gehören kann, ein anderer dagegen mit zum Übergang. Das Verb üžam 'einladen, rufen (jmd von irgendwoher)' z.B. sagt ausdrücklich, dass die Übergangsbewegung mit Hilfe von Wörtern erreicht wird, während z.B. das Verb kudalâktem 'laufen lassen' nichts über die Veranlassung des Übergangs aussagt, während es dagegen die Art und Weise des Übergangs genau wiedergibt.

Ich beabsichtige in dieser Untersuchung keine detaillierte Analyse der Bedeutungskomponenten der Verben durchzuführen; bei der Einteilung meiner Darstellung in Kapitel habe ich jedoch ausdrücklich einige Bedeutungskomponenten der Verben berücksichtigt.

Mein Material enthält über hundert Übergangsverben, die eine lokale Trennungskasusbestimmung erhalten; die Anzahl der lokalen Trennungskasusbelege übersteigt tausend. Mit Ausnahme dreier unten (s.S. ) angeführter Sätze begegnet

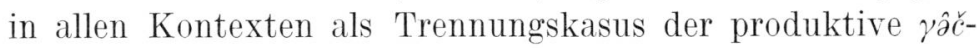
oder der unproduktive $\check{c}$-Elativ. Beispiele für Trennungskasusbestimmungen bei typischen Übergangsverben: $\ddot{u} \delta \hat{r} r$

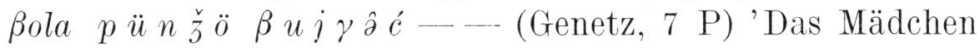
steigt herab vom Gipfel der Fichte - - / $t \bar{u} \gamma u \beta a$ $\delta e\left(t^{\prime} \dot{s}\right.$ àn lektân gajat. (Beke T IV, $432 \mathrm{~B}$ ) 'Sie verlassen die (eigtl. diese) Frau und machen sich auf den Weg.' I - -

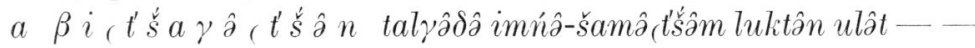
(Wichmann V, $163 \mathrm{~S}$ ) '- - aus dem Stall aber haben sie

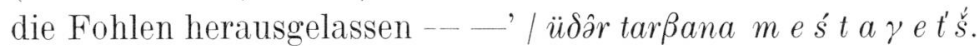
(Beke M, 345 Up) 'Das Mädchen bewegt sich von ihrer Stelle.' / šiǩš Bel kuza imńi djol nômalts. (Beke T I, 345 Jt) 'Die Hufe (eigtl. unter dem Fuss) der Pferde wirbeln (Sing.) Staubwolken (eigtl. Rauch) auf.' / koti to ma $\gamma$ ə(t s a n šaleš kâń - (Beke V, $28 \mathrm{~K}$ ) 'Läuft die Katze von

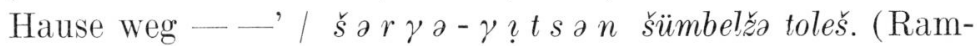
stedt, $193 \mathrm{~K}$ ) 'Aus dem Walde kommt der Bruder zurück.' /

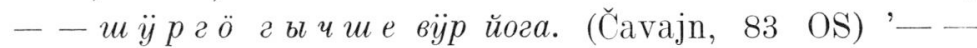

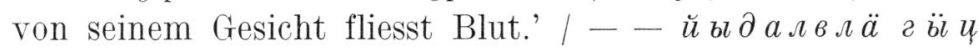
рокым пачкен - - (Iljakov, 22 WS)' - - er schüttete den 
Sand aus den Birkenrindenschuhen _- _.' ${ }^{1}$

Es gibt auch viel solche Beispiele, wo mit dem Verb neben dem Trennungskasus gleichzeitig ein Wohin-Kasus verbunden ist; in fast allen Fällen erscheint eine Illativform als

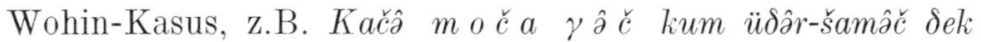
tolân - - (Porkka-Genetz, 2 M-i) 'Der Freier kam aus der Badestube zu den drei Mädchen _- ' Lazâr kaja $k u \gamma u$ za $\delta$ e $t^{\prime} \dot{s}$ terkâž̂̀. (Beke M, 231 Up) 'Lazâr geht vom

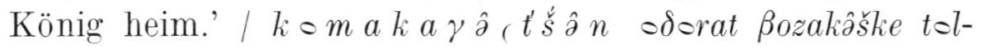
šolâm. (Beke T I, $384 \mathrm{JOk}$ ) 'Man scharrt die Glut aus dem Ofen [und legt sie] in (eigtl. auf) den Herd.' / m ? $\dot{n} s$ a $\gamma a^{-}$

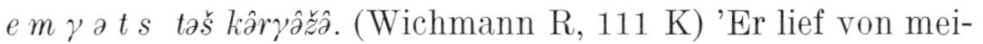

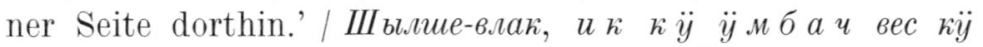
ӱмбак йолыитым иуен тошкалын - - (Čavajn, 146 OS) 'Die Flüchtenden, von einem Stein auf den anderen tretend, ihre Füsse setzend _- -

Der nächste Beleg gehört zu jenen, auf die am Ende der vorangehenden Fussnote verwiesen wurde; er enthält kein Objekt, sondern dieses ist gleichsam in der Bedeutung des Verbums 'schiessen' beinhaltet: - - дӓ шоссе кок векы пуш-

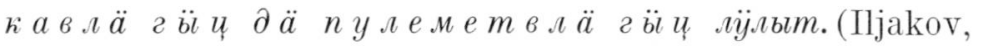
279 WS) '__ - und sie schiessen aus Kanonen und Maschinengewehren auf beide Seiten der Hauptstrasse'. Andererseits wiederum ist das folgende Beispiel nur oberflächlich gesehen transitiv: an sich bildet hier das Verb gemeinsam mit dem Oberflächenobjekt das Prädikat, das dem intransitiven Verb

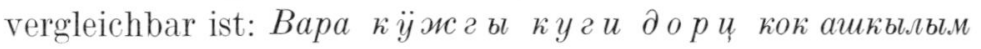

${ }^{1}$ Im Tscheremissischen sind intransitive Sätze üblich, in denen das Subjekt nicht ausgedrückt wird sowie solche transitiven Sätze, in denen entweder das Subjekt oder das Objekt oder sogar beide aus dem weiteren Kontext erschlossen werden müssen, z.B. kušk $\hat{\jmath}$ pura šülà

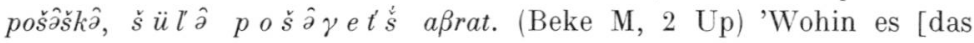
Vieh] aufs Haferfeld geht, treibt man [eigtl. treiben sie] es vom Haferfeld weg.' Die Erscheinung gehört natürlich der Oberflächenstruktur der Sprache an; solche Beispiele müssen so analysiert werden, als wären jene wesentlichen Satzglieder in ihnen ausgedrückt.

Andererseits verfügt das Tscheremissische wie auch viele anderen Sprachen ebenfalls über solche Verben, die gleichsam ein Objekt in sich enthalten können (s. genauer z.B. S. 58). 
в̈іштен - - (Iljakov, 92 WS) 'Dann nahm er zwei Schritte von der dicken Birke her —- '.

An sich kann das Bedeutungsmerkmal des Übergehens in bestimmten Kontexten auch für Verben gelten, die auf den ersten Blick nicht wie Übergangsverben wirken. So ist es z.B. bei den Verben šinžam 'normal: sich hinsetzen' und čijem 'normal: anziehen'; in den folgenden Zitaten treten sie als Übergangsverben auf, die gleichzeitig sowohl eine Trennungs- als auch eine Wohin-Kasusbestimmung erhalten haben:

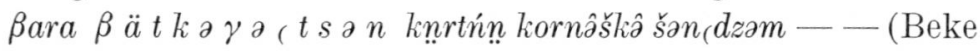
T I, 8 Jo) 'In Wjatka setzte ich mich (dann) auf die Eisen-

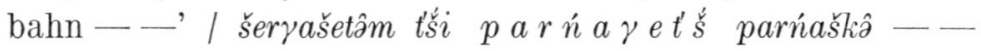
(Beke M, 174 Up) 'Stecke deinen Ring von einem Finger auf den anderen - - '.

Weitere Belege, wo neben dem Trennungskasus gleichzeitig der Wohin-Kasus auftritt, sind zu finden in meiner Untersuchung Alhoniemi, MSFOu 142. Die äusserst zahlreichen Beispiele enthalten nur drei solche Kontexte, wo als Wohin-Kasus der Lativ auftritt (s. a.a.O. 100, 144, 148 und 257).

In einigen Fällen kann das Verb, das den Übergang angibt, gleichzeitig auch den Zustand ausdrücken, in den die betreffenden Entitäten nun übergehen; solche Verben sind z.B.

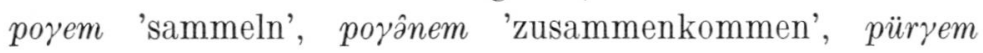
'spritzen', šalanem 'sich auflösen', šalatem 'zerstreuen'. Besonders anzumerken ist, dass das Zusammenkommen und Sammeln, das Auseinandergehen und Verstreuen auch an einem solchen Ort geschehen kann, der gewissermassen der Teil einer durch die Trennungskasusbestimmung ausgedrückten grösseren Lokalität ist. Auch in diesen Fällen vollzieht jedoch wenigstens ein Teil der in Frage stehenden Entität oder der Entitäten die Übergangsbewegung, und die Trennungskasusbestimmung kommt wie auch bei den anderen Übergangsausdrücken zur Anwendung. Andere Beispiele:

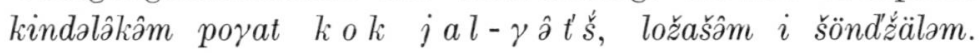
(Beke R, 63 B) 'Man sammelt für Brot in den beiden Dör-

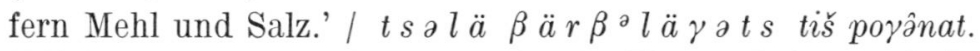
(Wichmann R, $434 \mathrm{Jl}$; entsprechende Konstruktion auch in den Varianten des Satzes in anderen Dialekten) 'Von überall 


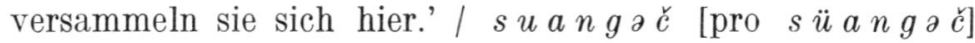
jenblak šalanaš tünal möngö- - (Sebeok-Ingemann, 70 B) 'Nachdem sich die Menschen nach der Hochzeit allmählich zerstreuen - -'.

Die mit den Übergangsverben stehenden lokalen Trennungskasusbestimmungen sind, wie ich früher erwähnte, fast

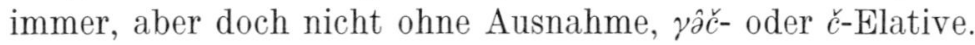
Unter mehr als tausend Elativen finden sich nämlich drei leč-Ablativbelege, die offenbar lokal verwendet sind; in allen Fällen ist die Endung leč mit einem Pronomen verbunden. Bei den von Wichmann aufgezeichneten einzelnen Sätzen steht in einer Variante aus dem Dialekt von Sernur zunächst

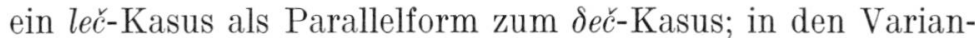
ten aller anderen Dialekte desselben Beispielsatzes begegnet

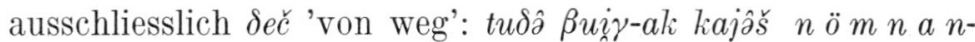
$d e t^{\prime} \dot{s}$ ( $n \ddot{o} m n$ a $\left.n l e t t^{\prime}\right)^{2}$. (Wichmann R, $384 \mathrm{~S}$ ) 'Er ist ganz von uns gegangen.' Die übrigen beiden leč-Trennungskasus sind aus einem Uj-Text; erwähnt sei, dass in diesem Dialekt in habitiver Verwendung ausschliesslich der $\delta e c ̌-K a s u s ~ a u f-$ tritt (s. S. 60). Die folgenden leč-Kasus sind somit also die einzigen, die in den Texten dieses Dialekts auftreten: mo ttš $a$ -

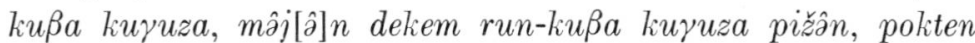

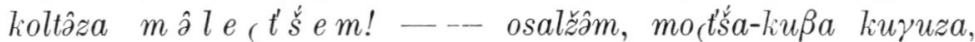
pokten koltâza mâle (t'śem! (Beke T III, $138 \mathrm{Uj}$ ) 'Alte, Alter des Badehauses, ich bekam einen Schnupfen (eigtl. ich wurde von der Rotz-Alten, dem [Rotz]-Alten angesteckt), verjagt [ihn] mir! — - Geister (eigtl. die Alte, der Alte) des Badehauses, vertreibt den Bösen von mir!' In dem entsprechenden Satzzusammenhang kann im gleichen Dialekt auch ein deutlicher lokaler Trennungskasus auftreten, z.B. - osalžâm poktâl kolto âr $\beta$ ez $z \quad \beta a t ' s !$ (Beke T III, $183 \mathrm{Uj}$ ) '_ — befreie das Kind vom Bösen (eig. vertreibe den Bösen aus dem Kind)!'

\subsubsection{Der Trennungskasus drückt die Richtung aus}

In einigen Fällen können die Adverben und Postpositionen im Trennungskasus mit unbestimmter Bedeutung so verstanden werden, dass sie entweder den eigentlichen Ort oder die 
Richtung wiedergeben, von wo aus der Übergang geschieht,

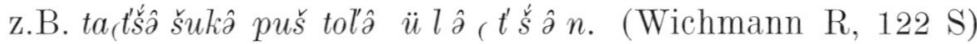
'Heute kamen viel Boote von unten [d.h. vom Unterlauf des Flusses] oder von unten her [d.h. vom Unterlauf des Flusses her].' Wenn man speziell die Richtung ausdrücken will, kann

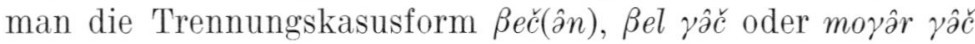
verwenden, jeweils 'von her' bedeutend, z.B.: O а ы ч волгыдо ок пуро. (Ončyko 6/1963, 66 OS) 'Von der Seite

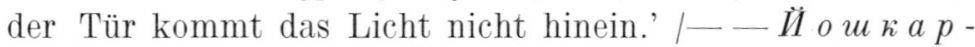
Ола мона ыр р ӓи й Йыл векыла автомашина кыдалын. (Iljakov, 163 WS) '_- aus der Richtung von J.-O. in die Richtung der Wolga fuhr das Auto.'

Zusätzlich zu diesen lexikalischen Mitteln kann jedoch auch ein besonderes unselbständiges Morphem zum Ausdruck des Trennungskasus der Richtung verwendet werden: -la, das an die Endung des lokalen Trennungskasus tritt. Z.B. ta tt'ša šukâ

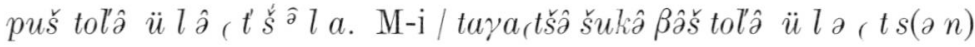
( $\ddot{u} l$ a $t s-l \ddot{a}$ ). K (Wichmann R, 122) 'Heute kamen viele Boote von unten herauf.' / Кернак, урем вес мучаш г в ч л а изирак капан ӥдыр толеш. (Čavajn, 131 OS) 'Wirklich, vom anderen Ende der Strasse her kommt ein kleines

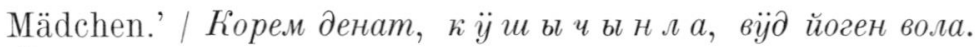
(Čavajn, 145 OS) 'Die Schlucht entlang, von oben her, fliesst das Wasser.' Der Trennungskasus der Richtung kann manchmal auch gleichzeitig mit dem die eigentliche Lokalität ausdrückenden Trennungskasus stehen: Kлавий чодра а ви ч вес вел г ич и а толеш - - (Čavajn, 204 OS) 'K. kommt aus dem Wald von der anderen Seite [der Bühne] _- ' . Ein Satz wie der zuletzt zitierte vertritt deutlich zwei eigene Sätze der Tiefenstruktur: 'K. kommt aus dem [auf der Bühne errichteten] Wald' — 'K. kommt von der anderen Seite [der Bühne]'.

Auch der Trennungskasus der Richtung kann in einigen Kontexten durch die Akkusativform ersetzt werden (vgl. S. 11); so verwendet begegnen zumindest Belâm 'Seite (Akk.)'

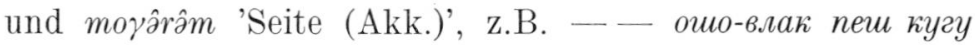
тӥшка дене толыт... - Кудо в ельм? (Čavajn, 124 $\mathrm{OS})$ '- - die Weissen kommen mit einer richtig grossen 


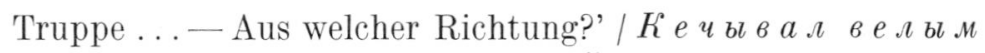
пеш талын Деникин армий толеш. (Čavajn, 118 OS) 'Aus dem Süden kommt sehr schnell die Armee von D.'

Die eine Richtung ausdrückenden Trennungskasus können zweifellos auch in vielen anderen Zusammenhängen denn als Bestimmungen von Verben der Bewegung auftreten. Trennungskasus, die semantisch ebensogut als Indikator der Lokalität wie auch der Richtung interpretiert werden können, finden sich mehrere z.B. in Kapitel 12. Die einzige Trennungskasusform, die nicht zu Kapitel 3.1.2 gehört, die jedoch auch das Richtungsmorphem -la aufweist, steht jedoch in Kapitel 3.7 (s. S. 47); dieses einzige Beispiel veranlasste mich aber nicht zu einem eigenen Unterkapitel.

Vergleichshalber sei erwähnt, dass der 'Wohin-Kasus der Richtung' prinzipiell auf die gleiche Weise gebildet wird: das Morphem -la tritt an die Illativendung (s. Alhoniemi, MSFOu $142,267-270)$.

\subsection{Der Trennungskasus bei einem Verb des Verschwindens}

Alle oben behandelten Beispiele drücken also die Verlagerung einer Entität von einer Lokalität an eine andere aus. Die Bedeutung der Verben, die als Bezugswörter der Trennungskasusformen in jenen Kontexten stehen, enthält stets die Komponente des Übergangs. Der Trennungskasus steht aber auch oft bei solchen Verben, deren Bedeutung statt der Komponente des Übergangs das Merkmal des Verschwindens trägt. Die Trennungskasusform drückt in jenen Fällen die Lokalität aus, von bzw. aus der sich etwas entfernt, so dass sich die diesbezügliche Entität nach dem Prozess nirgends mehr befindet oder aber im Prozess des Verschwindens aus der durch den Trennungskasus wiedergegebenen Lokalität in einen anderen Zustand übergeht, z.B. unsichtbar wird. Typische Verben mit der Bedeutungskomponente des Verschwindens sind z.B. jomam 'verschwinden', kolem 'sterben', kürâltam 'abnehmen, geringer werden'; in einigen Fällen kann jedoch das z.B. den Verschwindenden bezeichnende Wort bereits auch einen Hinweis auf den Prozess des Verschwin- 
dens enthalten, z.B. bei kolâšo 'gestorben, sterbend; Toter, Sterbender' u.a. dann kann als Prädikat ein andersartiges Verb auftreten.

Die lokalen Trennungskasusbestimmungen bei den Verben des Verschwindens sind der Form nach immer Elative. Z.B.

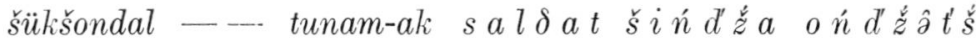
jomân. (Beke R, 60 B) 'šükšondal — - verschwand zugleich vor den Augen des Soldaten.' / kurnâž kußject'šşšs tolân

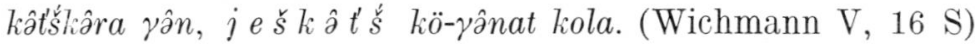
'Wenn ein Rabe auf den Hof kommt und krächzt, stirbt einer von der Familie.' / uškalem jomo pa se $\gamma \hat{\jmath} t^{\prime} \dot{s}$. (Beke T IV, 182 B) 'Meine Kuh ist vom Feld verschwunden.' / omo

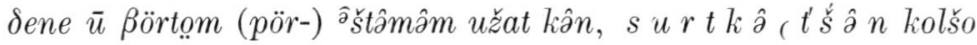
lektě̌, manât. (Beke T IV, 385 B) 'Wenn man (2. P. Sing.) im Traum ein neues Haus bauen sieht, wird man einen Toten aus dem Hause tragen (eigtl. wird ein Toter hinausgehen), sagt man.' In Kontexten entsprechender Art kann jedoch auch der Wo-Kasus in Frage kommen; im folgenden Zitat steht in ganz ähnlichem Zusammenhang der Wo- und Woher-

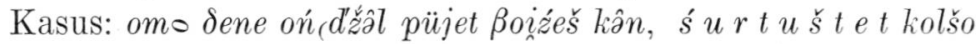

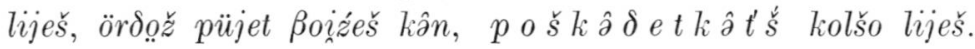
(Beke T IV, 166 B) 'Wenn dir im Traum der vordere Zahn (d.h. Schneidezahn) ausfällt, wird es in deinem Haus einen Toten geben; wenn dir der Seiten-(Backen-)zahn ausfällt, wird es bei deinem Nachbarn einen Toten geben.' Weitere Beispiele für die Verwendung des Trennungskasus: $k$ a šä $n^{\eta} g$ a $t s$

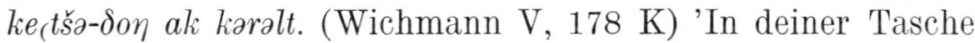
werden die Sonnenblumenkerne nicht weniger.' I - - омо пашаш ноймашым $к$ а $n$ г ьи ч әркын ӱштылеш. (Onс̌уko 6/1963, 47 OS) '— — der Schlaf entfernt allmählich aus dem Körper die durch die Arbeit entstandene Ermüdung.' Кьиак пиитәм, тйьи и йамәи! - манәи. (Grigorjev, 101 WS) 'Wohin ich [ein Ei] lege, da verschwindet es, spricht [das Huhn].'

\subsection{Der Trennungskasus bei einem Verb des Entstehens}

In allen oben behandelten Fällen, ob es in den Kontexten um den Übergang oder das Verschwinden geht, denkt man 
sich X vor dem Prozess in A; der Prozess zeigt den Weggang von X aus A an. Die lokale Trennungskasusbestimmung kann aber mitunter auch bei Verben stehen, deren zentrale Bedeutungskomponente das Erscheinen ist. Diese Verben zeichnen sich oft dadurch aus, dass ihre lokale Bestimmung entweder in einem Wo- oder Wohin- oder Woher-Kasus besteht. Der Wo-Kasus drückt wie üblich aus, wo das Erscheinen geschieht, der Wohin-Kasus bezeichnet den Ort, wo infolge des Erscheinens die neue Entität hingelangt. Die Information der Ausdrücke mit Trennungskasus-Bestimmung ist komplizierter: durch sie wird nämlich ausgedrückt, dass die entstehende Entität nach ihrem Entstehen nicht an dem durch die Lokalitätsbestimmung mitgeteilten Ort verbleibt, sondern sich entfernt oder sich auch ausserhalb dieses Ortes verbreitet. Somit wird in diesen Beispielen das Gewicht nicht so sehr auf das Erscheinen gelegt als vielmehr auf den danach folgenden Vorgang. In den Texten findet man nur relativ wenig Belege für Trennungskasusbestimmungen bei Verben, die ein konkretes Entstehen oder Erscheinen bedeuten; in den betreffenden Beispielen erscheint allgemein der Elativ als

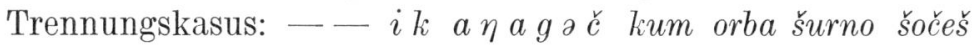
- - (Sebeok-Ingemann 60 B) '- - auf einem Ackerstreifen wachsen drei Fuhren Getreide —-' 1 - - sadalan berčən mo ̌́ag ə ̌̌ šuko kana požar lieš, moča əštalteš büt bokteran, surtteč bitle metar pelke. (Sebeok-Ingemann, 87 B) '_- darum [weil] durch die Sauna oft ein Feuer entsteht, baut man sie am Wasser, fünfzig Meter entfernt vom Haus.' / Икћань в ӓр г ӥ ц кӥн сэк иућь олма лин? (Grigorjev, 12 WS) 'Wer bekam auf der gleich grossen Fläche die meisten Äpfel?'

In einem Kontext hätte jedoch der Übersetzung nach der lokale leč-Kasus beim Verb šočam 'entstehen' gestanden. Das aus einem Lied stammende Zitat ist jedoch schwer auszulegen, und schon die Verwendung des Bindestrichs scheint darauf hinzudeuten, dass der Trennungskasus eher - vielleicht nach dem Muster der Komparativausdrücke - zum folgenden Nomen gehört und irgendwie dessen Bedeutung verstärkt: šočân moštâdâmâ šoptârřâa lop ple e č-lopeš šočeš - (Porkka-Genetz, 46 M-i) 'Verkümmerte Johannisbeeren aus 
dem Sumpfe, im Sumpfe sie wachsen ——_.

Falls das Wort, das etwas Erscheinendes bezeichnet, eine abstrakte Bedeutung hat, sieht auch die Trennungskasusbestimmung häufig so aus: sie kann z.B. die Rede oder ein Ereignis bezeichnen. Auf jeden Fall gehören die Beispiele folgender Art eng zu den oben angeführten: $m u t k e t^{\prime} \dot{s}$ mut lekteš - (Beke T III, 408 Up, s. auch z.B. Beke T I, 374 JOk) 'Worte ergeben Worte (eigtl. aus dem Wort kommt em Wort heraus) _- ' / Изижын пикшыже волен мемнан изи коремланрак мотор мландышке. - - Туше ч ын лийьн "Изи Kорамас!" (Čavajn, 19 OS) 'Der Pfeil des kleinen [Bruders] fiel in unser schönes Land mit kleinen Talschlüchten - - Daraus entstand der Name Klein-Koramas.' / K в и ә и ти пьикәдйи ияр лиэи - - (Grigorjev, 138 WS) 'Woher diese Durchfallkrankheit kommt - -

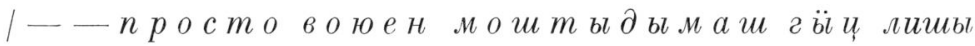
ямдымашвлӓ-- - (Iljakov, $256 \mathrm{WS}$ )' - — die einfach durch die Ungeschicktheit der Kriegsführung verursachten Ver-

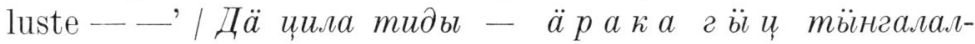
тын! (Iljakov, 103 WS) 'Und all dies [Unheil] kam vom Schnaps!'

3.4. Der Trennungskasus bei einem Verb der Trennung oder der Loslösung

In den obigen Kapiteln wurden Fälle behandelt, wo der Trennungskasus den Ort bezeichnet, von bzw. aus dem sich etwas entfernt. Eine ähnliche Aufgabe kann die Trennungskasusform in den Satzzusammenhängen haben, wo als Prädikat ein Verb steht, das ein Loslösen oder Trennen bezeichnet. Als Trennungskasus begegnen auch in diesen Kontexten im gesamten Sprachgebiet der $\gamma \hat{\partial} \check{c}^{-}$und $\check{c}$-Elativ. Aus OS liegen jedoch einige Belege vor, wo der $\delta e c$-Trennungskasus so verwendet wird, dass man ihn kaum aus der lokalen Bedeutung 'von her' dieses Morphems verstehen kann (s. Beispiel 4). Beispiele: ožnâ miń $i$-kana kožlaštâ jam muštaršâm $p u n d \hat{s} s k e t \dot{s}$. (Beke M, 68 Up) 'Ich machte einmal im Walde den Teufel aus einem Holzstumpfe los.' / tâ saldat odo 
$\bar{u}-j e \eta \partial n \quad k \hat{\partial} \delta a t^{\prime} \dot{s}$ ( $̌$ e porśân üštüm ruঠen nalân - (Beke R, 59-60 B) 'Dieser wotjakische Soldat löste von der Hüfte der jungen Frau ihren Seidengürtel - $/ t$ n $\delta$ n n

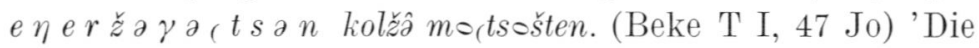
Fische fielen [eigtl. lösten sich] von der (eigtl. seiner) Angel.'/ - - ил ии деч ойырлымо ок шу иктынат - - (Čavajn, 62 OS) ' - - aus dem Leben zu scheiden ist niemandem angenehm —- '.

$\mathrm{Zu}$ beachten ist aber, dass die Ausgangssituation für einen Prozess, der den Vorgang "X löst sich aus A» mitteilt, nicht unbedingt " $\mathrm{X}$ ist in $\mathrm{A}$ " lautet, sondern eventuell auch " $\mathrm{X}$ ist befestigt in $\mathrm{A}$ ", "X ist bei/an $\mathrm{A}$ " oder " $\mathrm{X}$ ist mit $\mathrm{A}$ ». (Vgl. Bartens, Kaasussyntaksi, 121.) Hier einige Belege; zu beachten ist wiederum der $\delta e c ̌$-Kasus in den OS-Belegen: --. -

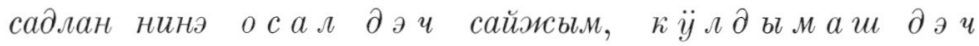
кӥлэиььм ойрэн моштат. (Izi bolševik-vlak, 5 OS) '- deshalb können sie das Böse vom Guten unterscheiden, das Unnötige vom Nötigen.' / Ӓнят викок тӥ̈дым земля а й и айыраш ак кел ьъльн?' (Iljakov, 80 WS) 'Vielleicht hätte man ihn nicht direkt dem Lande entfremden sollen [indem man ihn in die Schule schickte]?'

Eine eigene Gruppe unter diesen Trennungskasusbestimmungen, die man als kontaktive Trennungskasus bezeichnen könnte, bilden jene, wo die Loslösung eines Teils aus einem Ganzen zum Ausdruck gebracht wird. Damit hängen wiederum jene Kontexte eng zusammen, in denen die Wahl von etwas oder jemandem aus einer Gesamtheit beschrieben wird. In meinen Belegen für diesen Typ steht überall der $\gamma \hat{\partial} c$ oder $\check{c}$-Elativ, auch dann, wenn die Ganzheit durch ein +Anim - Wort bezeichnet wird. Beispiele: - - $\beta u \beta e r ~ \gamma u \gamma u z a n$

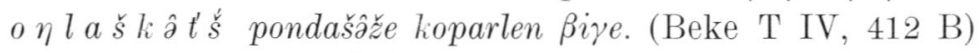
'_— der Bart des $\beta$ - der-Alten trennte sich gänzlich vom Kinn desselben.' / $i k$ š or $\hat{\partial}[k]-k \hat{\partial} t s \quad k o[k]$ koßaštâm nikktô[n] nalaš ok li - (Beke TT, 75 Jt) 'Dem Schaf kann man die Haut nicht zweimal abziehen-—' / $i k$ ü $\breve{s} k \hat{z}$

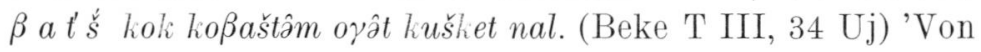
einem Ochsen kann man nicht zwei Häute (Sing.) abziehen (eigtl. zieht man nicht zwei Häute ab).' / —— южыит 
вохтыр муча г зи ийырлат да южышто пӧрдынпӧрдын волат. (Čavajn, 95 OS) '- - manche [Blätter] lösen sich von den Zweig-Enden und fallen, sich im Winde

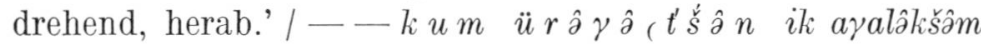
sajlen —- (Paasonen-Siro T, 52 B) '- - aus drei Herden für ein Pflügen das taugliche wählen —- -

Im folgenden Kontext handelt es sich meines Erachtens um eine bildliche, übertragene Loslösung eines Teils vom

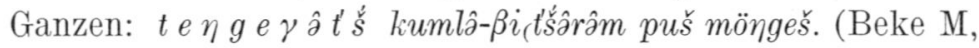
118 Up) 'Vom Rubel hat er [mir] zehn Kopeken herausgegeben.'

Die Loslösung ist ein Vorgang, der oft vom Standpunkt beider am Prozess beteiligten Seiten betrachtet werden kann: von derselben Handlung kann man ebensogut den Ausdruck 'den Fisch von der Angel losmachen' wie 'die Angel vom Fisch losmachen' verwenden. Die sich entfernende oder zu entfernende Seite wird allgemein im intransitiven Satz mit dem Subjekt oder im transitiven Satz mit dem Objekt ausgedrückt. Das ist z.B. im folgenden Kontext der Fall, der überhaupt jenen sehr nahesteht, wo ein typisches Verb des

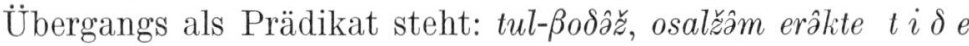
$j \hat{\partial} \eta g \hat{\partial} t^{\prime} \dot{s} !$ (Beke T III, $132 \mathrm{Uj}$ ) 'Geist des Feuers, verjage [eigtl. reinige] den Bösen aus diesem Mann!' Aber auch die entgegengesetzte Verwendung ist nicht unmöglich, wie die folgenden Beispiele zeigen; das erste Beispiel stammt übrigens von derselben Seite wie das zuletzt zitierte: $\beta \ddot{u} t-\beta$ odâz, ške o sal $\gamma \hat{\partial}$ ( $t^{\prime} \dot{s} \hat{\partial} n$ erâkte — - (Beke T III, $132 \mathrm{Uj}$ ) 'Geist des Wassers, reinige ihn (du selbst) vom Bösen - - ' / tul$a \beta a$ o s a l $\gamma \hat{\partial} t^{\prime} \dot{s}$ erâktâ! (Wichmann V, 54 S) 'Mutter Feuer, reinige [uns] vom Bösen!' / T и ярдым а ш ша н им а и

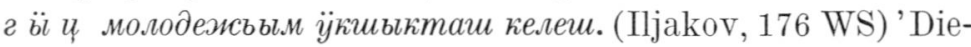
sem untauglichen Gedanken muss die Jugend entfremdet werden.' / Неушты ти кого войнаат тӥ̈дым фор м али зм г в̈ и лищен кердде? (Iljakov, 305 WS) 'Ob dieser grosse Krieg ihn vom Formalismus hat heilen können?' / - — колхозниквлӓн вуйыитылым религи озны й предрассудкывлӓ г ӥ ч ирыктаи келеи. (Iljakov, 102 WS)' - - die Köpfe der Kolchosemitglieder müssen von religiösen Vorurteilen gerei- 


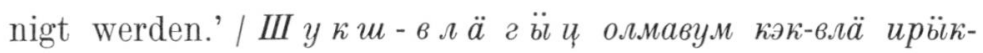
mäm. (Grigorjev, 16 WS) 'Die Vögel reinigen die Apfelbäume von Raupen.'

Ungeachtet des Formenunterschiedes drücken all diese Beispiele denselben Prozess aus wie die früher behandelten Kontexte: die Verbindung zwischen zwei Entitäten wird unterbrochen. Ausserdem ist in den Ausdrücken noch eine zusätzliche Information enthalten: die Verben 'heilen', 'retten', 'reinigen', 'befreien' usw. bezeichnen den auf den Prozess folgenden kontaktlosen Zustand als positiv.

Es gibt noch Ausdrücke anderen Typs, in denen die Trennung oder die Loslösung von etwas bezeichnet wird. Schon in einigen oben zitierten Belegen sind beide sich trennenden Glieder +Anim. Doch sind diese beiden Partner in den behandelten Kontexten nicht gleichwertig. Wenn ausgedrückt wird, dass jemand aus einer Gruppe ausgewählt wird, ist die Gruppe gleichsam die Gesamtheit, von der ein Teil abgetrennt wird. Wenn dagegen z.B. gesagt wird, dass der Mensch vom Formalismus geheilt wird, dann ist der Mensch die primäre Entität, aus deren Zusammenhang etwas entfernt wird.

Es können auch zwei gleichberechtigte Wesen oder Gruppen von Wesen sein, die sich trennen. Die Ausgangssituation ist dann immer "X ist in der Gesellschaft oder im Zusammenhang von A»; auf übertragener Ebene auch "X ist $\mathrm{A}$ zugetan».

In allen bisher behandelten kontaktiven Kontexten fanden lokale Trennungskasus Verwendung; die einzigen Ausnahmen bildeten einige $\delta e c ̌$-Kasus in OS. In den nun zur Sprache kommenden Kontexten, wo es also um die Trennung zweier belebter Wesen oder Gruppen von Wesen geht, werden dagegen im gesamten Sprachgebiet jene Trennungskasus verwendet, die die diesbezügliche Sprachform zum Ausdruck habitiv-kognitiver Beziehungen verwendet. Zusätzlich sei angemerkt, dass in jenen Kontexten, wo es um eine Trennung auf geistiger Ebene geht, das Wort für 'Herz' oder 'Seele' statt 'Mensch' verwendet werden kann. Da sich die tscheremissischen Schriftsprachen und Dialekte sogar in fünf 3 
verschiedene Verwendungsgebiete der habitiv-kognitiven Trennungskasus aufteilen, behandle ich auch die diesbezüglichen kontaktiven Trennungskasus in fünf Teilen (über die Vertretungstypen s. näher S. 53-54).

\section{Der leč-Vertretungstyp}

Mit Ausnahme eines Liedes aus B, auf das ich weiter unten zu sprechen komme, ist die leč-Vertretung im Belegmaterial die ausschliessliche: kunam urßeźlalak a $t^{\prime} a \breve{s} t l$ et $t^{\prime}$ ojarlen kajen-l?̣t - - (Beke T IV, 138 M) 'Als die Kinder [im Walde] von ihrem Vater Abschied genommen hatten —- / saltak

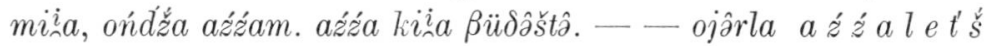
—- (Beke M, 75 Up) 'Der Soldat geht hin, schaut das Kind an. Das Kind liegt im Wasser. - - Er entfernt sich vom

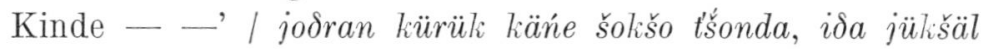
mâle t' $n a$ ! (Beke T IV, 357 B) 'So warm wie der - -(?) Pelz, ist euer Herz (eigtl. eure Seele), es möge [nur] gegen uns nie erkalten.'

Der einheitliche $l e \check{c}$-Stand wird durch zwei Varianten desselben Liedes aus B gestört, in denen der $\delta e c ̌$-Kasus steht; angemerkt sei, dass in einer dritten, ebenfalls aus dem BDialekt aufgezeichneten Variante desselben Liedes jedoch

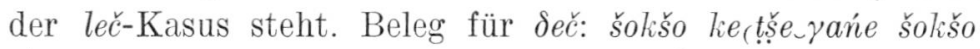

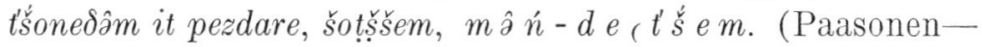
Siro T, 124 B) 'Deiner der heissen Sonne gleich heissen Seele darfst du, mein Verwandter, nicht zulassen mich zu verachten.' (Ein anderer $\delta e c$-Kasus in der Quelle Wichmann V, 432 B, ein leč-Kasus in der Quelle Paasonen-Siro T, 124 B.)

\section{Der Vertretungstyp lě̌ $\sim \delta e \check{c}$}

Es gibt wenig hierhergehörende Beispiele; Belege mit dem

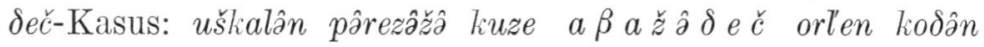
lomâžeš - - (Porkka-Genetz, 32 M-i) 'Wie das Kalb der Kuh, von der Mutter getrennt, brüllt - - / šokšâ kinde

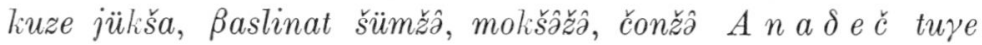
jükšâžâ! (Porkka-Genetz, 33 M-i) 'Wie das heisse Brot erkaltet, so mögen auch Wassilis Herz, Leber und Seele für Anna gleichgültig werden!' 
3. Der $\delta e c ̌-V e r t r e t u n g s t y p$

Alle Belege - sie stammen aus OS - haben den $\delta e c ̌$-Kasus, z.B. $T$ ый де че $т$ мый нигунам ом ойырло ... (Čavajn, 251 OS) 'Von dir trenne ich mich nie ...'। _ _ ала м в й де чем иймет ййкшен? (С̆аvajn, 82 OS) '- - ist dein Herz vielleicht mir gegenüber erkaltet?' / Me, баптисmвлак, католик але христиан-влак деч ойыршемалтына - - (Ončyko 6/1963, 30 OS) 'Wir Baptisten haben uns von den Katholiken bzw. Christen getrennt - - '.

\section{Der Vertretungstyp lě́c $\sim \gamma \hat{\partial} \check{c}$}

In allen von mir verzeichneten Belegen tritt der $\gamma \hat{\partial} \check{c}$-Kasus auf; andererseits vertreten alle Belege denselben Jt-Dialekt,

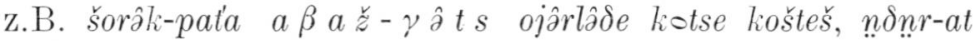
$m \hat{\partial} \hat{n}$ - a $\hat{t}$ s e $m$ tṇye-ok ojârlâde loošs̆o! (Beke TT, 25 Jt) 'So wie das Lamm des Schafes von seiner Mutter unzertrennlich einhergeht, so soll das Mädchen auch von mir unzertrennlich einhergehen!' | — — šeškâts, maneš, mare ž $\gamma \hat{\partial} t s$ djükix̌̌en. (Beke T I, 117 Jt) '- - deine Schwiegertochter (sagt er) liebt ihren Mann nicht mehr (eigtl. hat sich ihrem Mann entfremdet).'

\section{Der $\gamma \hat{\partial} \hat{c}$-Vertretungstyp}

In allen Beispielen steht der $\gamma \hat{\partial} \hat{c}$-Elativ; zu beachten ist, dass im folgenden Beleg ausser dem Trennungs- auch der Wohin-Kasus beim Verb des Trennens steht: Стройыда мӥлам пасна. Сола кӓташкь тӥ а ӥ ияда айырлем-..(Iljakov, 34 WS) 'Baut für mich extra [ein Haus]. Ich entferne mich von euch an den Rand des Dorfes -.-'.

\subsection{Der Trennungskasus bei einem Verb des Bleibens}

Die in dieses Kapitel gehörenden Trennungskasusbestimmungen stehen regelmässig bei intransitiven Verben. Die bei einem Verb des Bleibens stehenden Trennungskasusbestimmungen sind in manchen Teilen den im vorangehenden $\mathrm{Ka}$ pitel behandelten Fällen sehr eng verwandt. Ein eigenes Kapitel empfahl sich aber unter anderem deshalb, weil die 
Form der Bestimmungen in einigen Fällen hier eine andere ist als bei den Verben des Trennens und Loslösens.

Beispiele, in denen es darum geht, dass eine Entität von einem in Bewegung befindlichen Gegenstand oder aus der vergangenen Zeit zurückbleibt, sind in meinen Belegen nur

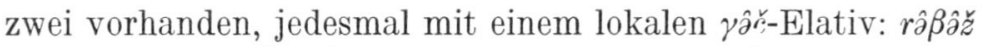

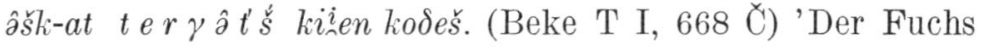
(selbst) [springt] aus dem Schlitten und bleibt [auf dem Wege]

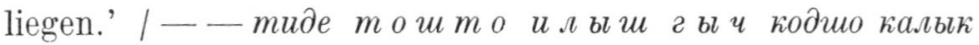
ойлымаи. (Ončyko 6/1963, 98 OS) '—— dies ist eine aus dem alten Leben erhaltene Volkssage.'

Es gibt nicht viel Kontexte, in denen ausgedrückt wird, dass etwas von etwas übrigbleibt oder von etwas fehlt; die Grenze zu den adnominalen Trennungskasus ist nicht immer klar, vgl. S. 120-121. Doch auch diese wenigen Belege vermögen zu zeigen, dass in diesen Zusammenhängen - anders als dort, wo es um die Trennung oder Loslösung aus einer Gesamtheit geht und regelmässig der $\gamma \hat{\partial} c$-Elativ steht - überwiegend die habitiven Kasus Verwendung finden. Beim 2. Vertretungstyp liegen allerdings auch Belege für den $\gamma \hat{\partial} c$-Elativ vor, der nicht zu den habitiven Kasus dieses Vertretungstyps gehört. Beispiele, geordnet nach Vertretungstypen:

1. Der leč-Vertretungstyp

ś ü a n l et'š ǚs-moklak[a]-at o[k] kot. (Beke T I, $377 \mathrm{JOk}$ ) 'Bei der Hochzeit fehlt nicht [einmal] der Schlegel.'

2. Der Vertretungstyp leč $\sim \delta e \check{c}$

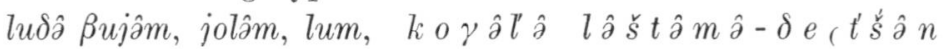
loot(šâžâm - - (Wichmann V, $28 \mathrm{~S}$ ) 'Den Kopf, die Füsse und die Knochen der Ente, welche bei der Zubereitung der Pastete übriggeblieben sind - - .

In den folgenden Zitaten, die aus von Porkka aufgezeichneten Gebeten stammen, werden in ganz gleichgearteten Kontexten alle möglichen Kasus verwendet, sowohl leč, deč als

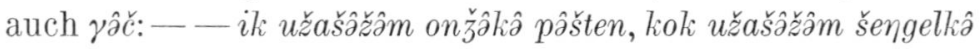

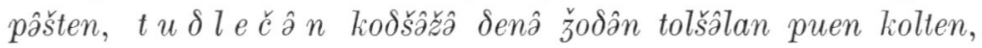

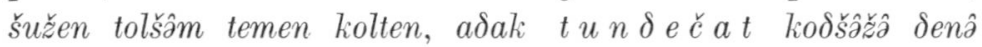




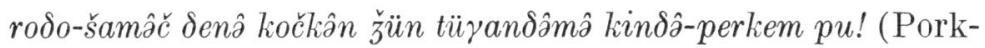
ka-Genetz, 19 M-i) '- - einen Teil [vom Getreide] vorlegen, zwei Teile [für die Zukunft] zurücklegen, mit dem, was davon übrig bleibt dem Bittenden helfen, den hungrig Gekommenen sättigen und von dem noch Übrigen mit den Verwandten essen und trinken!' / - $t u \delta \hat{\partial} \gamma \hat{\partial} \breve{c} \hat{\partial} n$ kot-

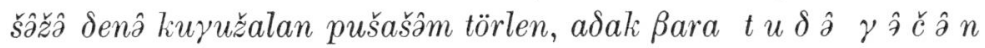

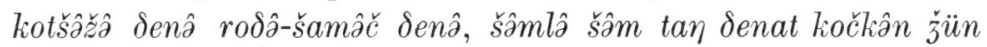

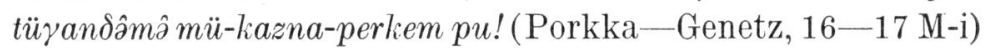
'_- von dem Übriggebliebenen den dem Kaiser zukommenden Tribut bezahlt haben, das noch Übergebliebene mit unseren Verwandten, mit 77 Freunden nicht aufessen und austrinken können!'

\section{Der $\delta e \check{c}$-Vertretungstyp}

Ик шагат коклаите кугу ӥштыган тйшка де ч и пудыраыл кийие орава-влаћ веле кодыч. (С̆аvајп, 102 OS) 'Nach einer Stunde waren von der grossen Lastkarawane nur die kaputten Wagen übriggeblieben.'

\section{Der Vertretungstyp leč $\sim \delta e \check{c}$}

konam malänem kol-ik $\bar{\imath} s u(l i)$, s a l t a klets kodâm. (Beke T I, 13 Jo) 'Als ich 21 Jahre alt war, machte ich mich vom Militärdienst frei (eig. blieb [zu Hause]).'

\section{Der $\gamma \hat{\partial} \check{c}$-Vertretungstyp}

Ляпииевын батальонжи гёи ик рота веле вет кодын. (Iljakov, 274 WS) 'Von L.s Bataillon blieb ja nur eine Kompanie übrig.'

Jene Kontexte, in denen vom Zurückbleiben eines belebten Wesens nach bzw. von einem belebten Wesen gesprochen wird, sind vollauf vergleichbar mit denen, in denen es um die Trennung oder Loslösung von jemandem geht (s. S. 34-35). Auch die Verwendung der Trennungskasus ist in beiden Fällen gleich; bei den Verben des Bleibens steht in diesen Kontexten regelmässig der habitive Trennungskasus. Beispiele nach Vertretungstypen (für Typ 4 liegt kein Beleg vor): 
1. Der leč-Vertretungstyp

miń $t$ utlet's om kot. (Beke M, 173 Up) 'Ich bleibe von ihm nicht weg [sondern möchte mitgehen].' / min soyâš

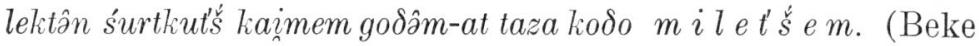
R, 386 B) 'Als ich von zu Hause in den Krieg ging, blieb sie auch gesund zu Hause.' Im letzten Zitat wird also auch der Zustand vom Denotat des Subjekts ausgedrückt, der im Augenblick der Trennung herrschte.

2. Der Vertretungstyp leč $\sim \delta e \breve{c}$

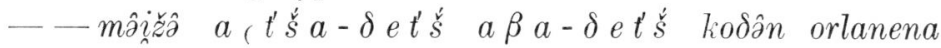
-- - (Wichmann V, $260 \mathrm{~S}$ ) '——auch wir, von unseren Eltern [als Waisen] zurückgelassen, haben Mühe ——'.

3. Der $\delta e c$-Vertretungstyp

- - ачиц деч вич ияи кодынам, а в ай деч лу иям... (Čavajn, 206 OS) '— - meinen Vater verlor ich (eigtl. von meinem Vater blieb ich Waise) mit fünf Jahren, meine Mutter (eigtl. von meiner Mutter) mit zehn Jahren . .'

5. Der $\gamma \hat{\partial} \hat{c}$-Vertretungstyp

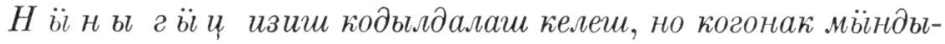
ран агыл - - (Iljakov, 329 WS) 'Man muss ein bisschen hinter ihnen zurückbleiben, aber nicht sehr weit —- '.

3.6. Der Trennungskasus bei einem Verb der habitiven Veränderung

Die meisten Verben des Übergangs, des Verschwindens und des Erscheinens können neben lokalen Veränderungen auch habitive Veränderungsereignisse ausdrücken (mehr über das habitive Verhältnis S. 52-). Im folgenden Kontext z.B. handelt es sich sowohl um eine lokale Veränderung die Entität X gelangt von der Lokalität A zur Lokalität -A - als auch um eine habitive Veränderung - die Entität X geht von -B bzw. von einem nicht ausgedrückten Besitzverhältnis auf B bzw. die Söhne des Denotats des Subjekts über:

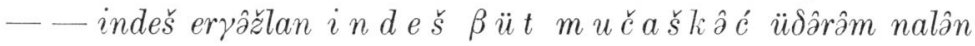


—— (Genetz, 57 P). ' - — für ihre neun Söhne hinter neun Flüssen Bräute finden — - '

Im oben zitierten Beispiel fungiert das Denotat des Subjekts gleichsam als aussenstehendes Agens, das für andere eine habitive Veränderung herbeiführt. Auch im folgenden Kontext, wo es allerdings gar keine Dativbestimmung gibt, ist die Situation entsprechend:

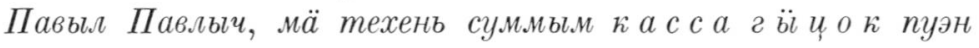
кердына - - (lljakov, 300 WS) 'P.P., wir können eine solche Summe aus der Kasse geben - - '.

In solchen habitiven Veränderungssätzen ist jedoch sehr häufig das Subjekt ein Glied des habitiven Verhältnisses, und hierin unterscheiden sich diese Ausdrücke wesentlich von den lokalen Veränderungssätzen. Im Satz Mare satum naleš 'Der Mann kauft Ware' z.B. vertritt mare neben dem Agens auch den habitiven Wohin-Kasus und im Satz Mare satum pua 'Der Mann gibt die Waren' steht das Subjekt zusätzlich zum Agens in der Funktion eines habitiven Trennungskasus. Habitive Veränderungsverben sind vor allem z.B. nalam 'kaufen, nehmen', polučajem 'bekommen', šolâštam 'stehlen'; puem 'geben', užalem 'verkaufen'1; die drei erstgenannten drücken aus, dass sich der Übergang in Richtung auf den Besitz des Denotats des Subjekts vollzieht, während dieser bei den beiden letztgenannten vom Besitz weg verläuft.

Wie in den obenstehenden Zitaten kann auch in solchen Beispielen, wo der lokale Trennungskasus bei einem habitiven Veränderungsverb steht, immer ebenfalls ein lokaler Übergang angenommen werden; allerdings kann es sein, dass das Fehlen von Beispielen anderen Typs auf die Einseitigkeit

\footnotetext{
${ }^{1}$ Anzumerken ist jedoch, dass wenigstens einige dieser Verben auch den rein lokalen Übergang ausdrücken können. Das Verb nalam z.B. bildet an sich ein Antonympaar sowohl mit dem habitiven als auch mit dem lokalen Übergangsverb, vgl. einerseits nalam 'nehmen (von jmdm)' - puem 'geben (jmdm)' und nalam 'nehmen (von etw.)' pâštem 'tun (wohin)'; ein Beispiel für die letztgenannte Verwendung des Verbums nalam: Клавий әркын кидиым и и р гӧ а ы и ие налеш - - (Čavajn, 197 OS) 'K. nimmt langsam ihre Hände von ihrem Gesicht - -’.
} 
des von mir ausgewerteten Textmaterials zurückgeht. Ein solcher Zweifel kann u.a. deshalb geäussert werden, weil die habitiven und kognitiven Kontexte eine an sich ziemlich organische Gesamtheit bilden; der in den kognitiven Belegen stehende lokale Trennungskasus setzt seinerseits nur selten einen lokalen Übergang voraus. ${ }^{1}$ Einige Beispiele für lokale Trennungskasusbestimmungen bei solchen Verben; die Bedeutung der Bestimmungen lässt uns die habitive Bedeutungskomponente des Gebens od. des Nehmens abstrahieren: $\ddot{u} \delta \ddot{u}-$ rüm nalat kân, p e l $\hat{\partial}$, $t^{\prime} \dot{s} \hat{\partial} n$ nal- - $a u l \gamma \hat{\partial}$, $t^{\prime} \dot{s} \hat{\partial} n$ nalat kân - - (Beke T IV, 394 B) 'Wenn du heiratest (eigtl. dir ein Mädchen nimmst), [so] nimm [es] von weither — - wenn du dir [eine Frau] aus dem [eigenen] Dorfe nimmst — -

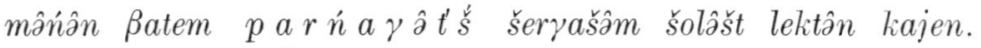
(Beke T I, 654 C) 'Meine Frau stahl [mir] den Ring vom Finger und ging fort.' / pi žma šset'ś oßerâm koltat kưuzalan. (Beke M, 248 Up) 'Vom Schlachtfeld schickt man dem König Nachricht.' | ШІколын физика каб ине тие г ыч фотоаппаратым йодын налын - - (Ončyko 6/1963, 70 OS) 'Er hätte aus dem Physikraum der Schule den Fotoapparat geliehen - - '.

Dass bei den Verben des Findens und Suchens in den finnisch-ugrischen Sprachen allgemein eine Lokalbestimmung im Trennungskasus steht, ist von der Forschung reichlich beachtet worden. Bei den Erklärungen dieser Erscheinung kam man meist zu der Ansicht, dass der Trennungskasus darauf beruht, dass sich im Erfassen des Geschehens von Finden oder Suchen zugleich das Entfernen des Gesuchten oder Gefundenen von der entsprechenden Stelle vereint (s. z.B. Hakulinen, SKRK ${ }^{3}$, 428). Meines Erachtens steht der lokale Trennungskasus gerade deshalb als Bestimmung bei diesen

\footnotetext{
${ }^{1}$ Erwähnt sei noch, dass z.B. im Finnischen der lokale Trennungskasus oft in Kontexten erscheint, die keinen lokalen Übergang ausdrücken können, z.B. Monet ovat ostaneet husilan Es p a njasta 'Viele haben eine Villa in Spanien gekauft' / Mies vuokrasi asunnon Helsingist $\ddot{a}$ 'Der Mann mietete eine Wohnung in Helsinki' / Maanviljelijä myi metsäpalstan ti e n v a r r elt a 'Der Landwirt verkaufte ein Stück Wald, das am Wege lag'.
} 
Verben, weil sich das habitive Verhältnis für das Denotat des Objekts verändert: das Gefundene geht in den Gewahrsam des Finders über. ${ }^{1}$ Die von mir durchgearbeiteten tscheremissischen Texte wiesen nur einige wenige Trennungskasusbestimmungen bei Verben des Findens und Suchens auf; dies wird u.a. darauf beruhen, dass das Verb muam 'finden' im Tscheremissischen etwas überraschend auch eine Lativbestimmung erhalten kann (s. Alhoniemi, MSFOu 142, 77). Belege für Trennungskasusbestimmungen: $k u \beta e\left(t^{\prime} \dot{s} \hat{\partial} n\right.$ muut'š tū šâlâm? (Beke T IV, 427 B) 'Wo verschafftest (eigtl. fandest) du [dir] dieses Fleisch?' / tī par emniam $k u s ̌ s e t^{\prime} \dot{s}$ mut's? (Beke T IV, $106 \mathrm{M}$ ) 'Wo fandest du dieses Paar Pferde

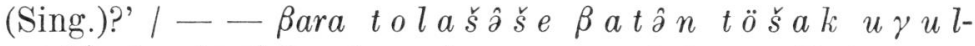
$\gamma \hat{a} t^{\prime} \dot{s}$ (šso kầ,t'śalân lü-paśkatam mun loktom. (Beke T I, $528 \mathrm{JOk})$ '- - ich suchte dann in der einen Ecke des Kissens (der leidenden Frau) den Knochensplitter, fand ihn und nahm ihn heraus.' / Bara mâjân on̉âskamân pöržâżö kas

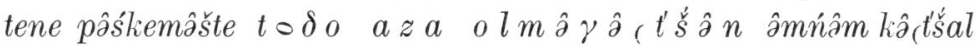
kaịmâž yodâm - - (Beke T I, 431 JOk) 'Als dann eines Abends der jüngere Bruder der Frau meines Schwagers im Finstern an der Begräbnisstätte dieses (eigtl. jenes) Kindes sein Pferd suchte - -

Auch die Verben jüam 'trinken', kočkam 'essen', jüktem 'zu trinken geben, tränken' und pukšem 'zu essen geben, füttern' sind offenbar in erster Linie zu den habitiven zu rechnen; die zwei erstgenannten Verben lassen sich zunächst mit nalam 'nehmen' zusammenstellen, die zwei letztgenannten mit puem 'geben'. Bei den beiden letzterwähnten kann auch ein habitiver Dativ stehen (s. letztes Beispiel). Die Verben jüam und kočkam gehören zu jenen, die im Innern transitiv sind, auch wenn sie in der Oberflächenstruktur objektlos auftreten; die Belege mit einem lokalen Trennungskasus beim

${ }^{1}$ Ausdrücke wie z.B. fi. Löysin (etsin) asunnon $k$ a u p ung is ta 'Ich fand (suchte) eine Wohnung in der Stadt' / Kullanhuuhtoja löysi y läjuoks u l t a hyvän huuhdontapaikan 'Der Goldwäscher fand am Oberlauf eine gute Stelle zum Goldwaschen' würden einen zu vielfachen Analogie-Erklärungen zwingen, wollte man an der Annahme des Übergangs festhalten, s. näher Alhoniemi, Sananjalka 17, 12-16. 
Verb weisen jedoch auch in der Oberflächenstruktur immer ein Objekt auf. ${ }^{1}$ Auch bei den Verben jüktem und pukšem kann das Wort fehlen, das ausdrücken würde, was zu trinken oder zu essen gegeben wird; der Trennungskasus weist jedoch stets ausdrücklich auf ein Element mit dieser Bedeutung hin. Andererseits ist zu beachten, dass der habitive Wohin-Kasus bei diesen Verben entweder durch den Dativ oder das Objekt vertreten sein kann; wie das mittlere der folgenden Beispiele zeigt, gehören sie zu jenen Verben, die im Tscheremissischen gleichzeitig zwei Objekte mit verschiedenen Funktionen erhalten können (genauer über diese Fälle s. Kangasmaa-

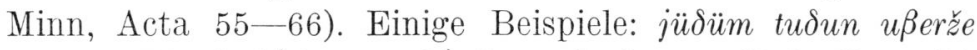

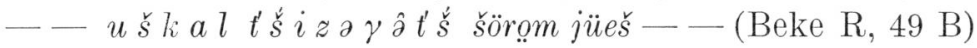
'Nachts saugt sein ußer — — aus dem Euter der Kühe die

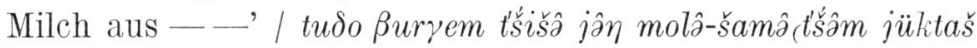

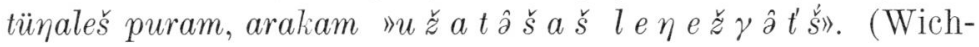
mann V, 65 M-i) 'Diese mit dem Anzug [des Verstorbenen] angetane Person beginnt die anderen Bier, Branntwein aus dem Begleitungseimer trinken zu lassen.' / - - molo kočašzz̆mbolaklan puǩsat tu b e č a n al'e piblak kočkat. (SebeokIngemann, 74 B) '_— dem Vieh füttern sie anderes Fressen daraus [aus dem Gefäss] oder die Hunde fressen es.'

3.7. Der Trennungskasus bei einem Verb der kognitiven Veränderung

Das folgende Beispiel erinnert sowohl strukturmässig als auch semantisch stark an die im vorangehenden Kapitel behandelten Kontexte: $О$ ндрикан $Р$ аманын нигна-

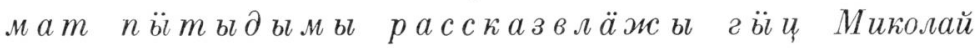
дӓ - - Bикторат иукым кералым илӓнышты нӓльныт. (Iljakov, 40 WS) 'Von den nie endenden Geschichten des R.O. übernahmen M. und V. viel Nötiges für sich selbst.' Das Zitat enthält also einmal einen lokalen Trennungskasus,

${ }^{1}$ Paavo Siro hat in seiner i.J. 1956 erschienenen Arbeit über die Verwendung der Lokalkasus im Finnischen den besonderen Charakter derartiger Verben bereits prinzipiell auf diese Weise analysiert (Siro, Lokalkasus, 66-67). 
zum andern einen Dativ, der in diesem Satz denselben Bezug hat wie die Subjekte. Aus der durch den Trennungskasus ausgedrückten Lokalität kommt den im Subjekt und Dativadverbial ausgedrückten Personen etwas zugute. ${ }^{1}$ Der Beleg bezeichnet jedoch weder einen lokalen Übergang noch eine Veränderung der Gewahrsamsverhältnisse, sondern die Vermittlung von Wissen an eine Person von irgendwoher. Ein Verhältnis, das ausdrückt, dass jemand etwas weiss, jemand etwas erfährt oder dass etwas z.B. durch Vergessen dem Wissen abhanden kommt, kann als kognitiv bezeichnet werden (mehr zum kognitiven Verhältnis S. 71-77).

Ein kognitives Verhältnis herrscht oft zwischen einem +Anim-Subjekt des Satzes und dem das Wissen ausdrückenden Objekt; allerdings kann das Objekt auch in der Bedeutung des Verbums enthalten sein. Im Satz Tudo $k n i \gamma a \gamma \hat{\partial} \breve{c}$ tunemân 'Er lernte aus dem Buch' z.B. enthält das Verb tunemaš das Objekt, die Bedeutung ist 'Lehre erhalten'; tuঠo 'er' vertritt auch in diesem Satz den kognitiven Wohin-Fall, und das kognitive Verhältnis herrscht also zwischen dem Subjekt des Satzes und dem im Verb enthaltenen Objekt.

Eine kognitive Verschiebung kann zwischen zwei belebten Wesen vorgehen, aber auch von einem belebten Wesen an einen Ort, wenn z.B. Kenntnisse irgendwo aufgezeichnet werden, oder von einem Ort auf ein belebtes Wesen, wie z.B. in den hier bereits zitierten Beispielen. In den Ausdrücken, in denen der Übergang eines Wissens von einer Lokalität in das Bewusstsein von jemandem mitgeteilt wird, wird also folgender Prozess ausgedrückt: "Kenntnis X kommt von Lokalität A zum Wesen C».

${ }^{1}$ Das Reflexivpronomen ške 'selbst' ist ein Kriterium, womit die Doppelrolle des Subjekts solcher sowohl kognitiver als auch habitiver Sätze nachgewiesen werden kann; durch seine Nominativform wird die Agens-Bedeutung des Subjekts verstärkt, durch seine Dativform dagegen die habitive und kognitive Funktion des Wohin-Kasus des Subjekts. Entsprechend verstärkt die bei einem Verb des Gebens stehende Nominativform des Reflexivpronomens die Agens-Bedeutung des Subjekts, der Trennungskasus wiederum dessen Charakter eines habitiven oder kognitiven Trennungskasus. 
In Sätzen der kognitiven Veränderung treten als lokale Trennungskasus im gesamten Sprachgebiet allgemein der $\gamma \hat{\partial} \breve{c}$ - und $\breve{c}$-Elativ auf. In einigen Belegen aus den Schriftsprachen, wo ein Verb des Bemerkens oder Erfahrens steht, kann allerdings auch der $\delta e c ̌$-Kasus als Trennungskasus vorkommen; dieses Morphem scheint in jenen Beispielen nicht die konkrete Bedeutung 'von weg' zu haben.

Die kognitiven Beispiele müssen in verschiedene Gruppen geteilt werden, da sich die einzelnen Kontexte etwas voneinander unterscheiden. Zunächst Belege für Kontexte, in denen ein Verb des Lernens, des In-Erfahrung-Bringens oder -Kommens, des Lesens, des Verstehens usw. steht. Der überwiegende Teil der Beispiele stammt aus den Schriftsprachen;

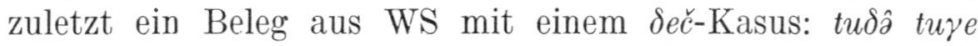

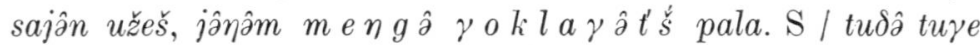

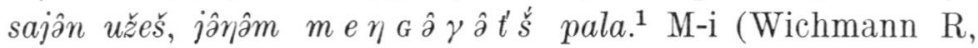
408) 'Er sieht [so] gut, [dass] er einen Menschen aus einer Entfernung von einem Werst erkennt.' / Мыйын шочмо кечем нерген куиеч паленда? - - Тендан трудов о й кни га ада г ы ч. (Ončyko 6/1963, 36 OS) 'Woher habt ihr meinen Geburtstag erfahren? - - Aus Ihrem Arbeitsbuch.' I Андрий ойлым а г ы ч мом ыніленам, тудым веле мый тыланда каласем... (Čavajn, 158 OS) 'Ich werde euch nur das sagen, was ich von A.s Rede verstand...'। А куше ч тидым ишнчет?' (Ončyko 6/1963, 84 OS) 'Aber woher weisst du das [hast du das erfahren]?' / Тӓланда, молода писательвлӓлан, Антон Антоновичьн "Туан сӓндалык» романжы гёи ц тыменяи келеш - (Iljakov, 135 WS) 'Ihr jungen Schriftsteller sollt aus A.A.s Roman „Vaterland» lernen.' / _- йымы кугижӓм колитаи

${ }^{1}$ Erwähnt sei, dass beim Verb palem 'kennen, erkennen' als Bestimmung in einem derartigen Zusammenhang ausser dem Trennungsoder Wo-Kasus auch der Wohin-Kasus stehen kann; das ist auch in der Variante dieses Zitates aus dem Dialekt K der Fall (s. Alhoniemi, MSFOu 142, 79-80). Das Verb palem ähnelt also in dieser Hinsicht - wie ja auch semantisch - dem Verb muam 'finden' (s. S. 40-41). Beim Verb palem kann auch eine ganz anders geartete Trennungskasusbestimmung stehen, s. S. 111. 


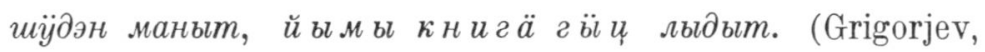
70 WS) ' — — [die Priester] heissen [einen] dem göttlichen Gebieter zu gehorchen, sie lesen aus göttlichen Büchern.'/ $Ю$ ю л ӓ дор и ын стариина ыцнылла - хозавлӓ шкевлӓ веле ылыт. (Iljakov, 341 WS) 'An den Stimmen erkennt der Kompanie-Älteste — nur die Hausherren selbst sind [da].'

Ein eigenes Ganzes bilden jene Kontexte, in denen als Prädikat ein Verb des Sprechens, Singens oder einer ähnlichen Lauterzeugung steht. Hier drückt der Trennungskasus jeweils den Ort aus, wo der Ton bzw. die Stimme erzeugt wird, die ein belebtes Wesen erfassen soll, z.B. $k \circ \beta a z ̌ e ~ k o^{-}$ maka ümba, $t$ śs ola: olam. poro! (Beke T I, 630 C) 'Die Alte antwortet vom Ofen herab: "Ich bin [zu Hause],

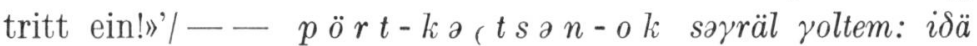

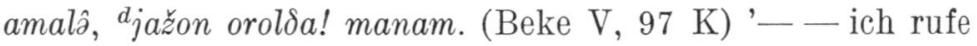
aus dem Haus: "Schlaft nicht, wachet gut!» sage ich.' | Пеленда ведрам налза.. . Тиде - колхозын радиоуз ел е гы и бригадир Иван Степанович кутыра. (Ončyko 6/1963, 79 OS) '"Nehmt die Eimer mit»... Das ist der Brigadier der Kolchose, I.S., der aus der Radiozentrale spricht [über Lautsprecher].' / Леонтьев - - с ие н н а г ӥ и антирелигиозный мырывлӓм мырен - - (Iljakov, 77 WS) 'L. _ — sang von der Bühne antireligiöse Lieder — - ' Дӓ тӥнь мам попет, әргым? - Ц ылан а в̈ ц Наста юкиылм nуа. (Iljakov, 283 WS) 'Und was sagst du, mein Sohn? - Aus der Speisekammer spricht N. [eigtl. lässt ihre Stimme (hören)].' /

Die Verben der Sinneswahrnehmung lassen sich je nach dem Anteil des Betreffenden am Vorgang in drei Gruppen teilen. In meinem tscheremissischen Material hatte ich im Zusammenhang mit der Trennungskasusbestimmung fast ausschliesslich nur visuale und auditive Verben; das syntaktische Verhalten der anderen Verben der Sinneswahrnehmung kann jedoch als entsprechend angenommen werden. Die Verben mit der Bedeutung 'zuhören', 'beobachten', 'betrachten' und 'untersuchen, prüfen' setzen beim Subjekt Aktivität voraus; von den habitiven Verben würden ihnen die des Nehmens entsprechen. Die Verben des Hörens, Sehens, 
Unterscheidens wiederum weisen auf ein passiveres Subjekt hin; bei den habitiven Verben entsprechen ihnen die des Bekommens. Die Verben mit der Bedeutung 'gehört werden, zu hören sein', 'gesehen werden, zu sehen sein' und 'unterschieden werden, zu unterscheiden sein' geben gleichsam die lokalen Möglichkeiten der Wahrnehmbarkeit der Entität wieder.

Alle Trennungskasus bei den in diesen Zusammenhang gehörenden Verben der Sinneswahrnehmung sollen den Ort ausdrücken, von dem der Impuls bzw. Reiz ausgeht, den der Gesichts- oder Gehörssinn wahrnehmen soll. Zu beachten ist, dass bei den Verben der Sinneswahrnehmung auch ganz andere Trennungskasus stehen können (s. S. 107-108). Belege; bei den Elativen wiederum einige $\delta e c ̌$-Kasus aus der

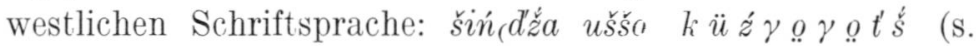
$k \ddot{u} z \dot{z} o \quad \delta e n)$ on (dza, tutlan koješ. (Beke T IV, 182 B) 'Der mit Augen Sehende sieht aus einem Spiegel (od. mit einen Spiegel), [die (gestohlene) Kuh] erscheint ihm.' / _- -

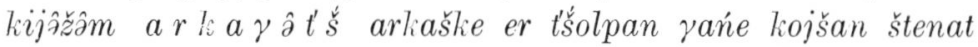
-.. (Paasonen-Siro T, 59 B) '— die Öffnung [im Bienenstock] von Berg zu Berg dem Morgenstern gleich. [für die Bienen] sichtbar machen - - / lat-kok me $\eta g \partial^{-}$ $\gamma$ a ( $t^{\prime} \dot{s}$ an šušken tolmâžo šokta. (Beke T IV, 62 M) 'Aus [einer Entfernung] von zwölf Werst hört man [bereits], wie er sausend kommt.' / Авай, мый тыланда радиом иыннен кодем, вара те тӥрлӧ уверым Й ош кар-Ола г ьч ч а т,

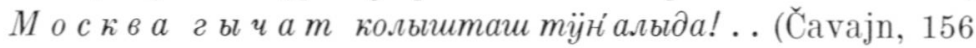
OS) 'Mütterchen, ich stelle euch ein Radio auf, dann könnt ihr verschiedene Nachrichten aus J.-O. wie auch aus M.

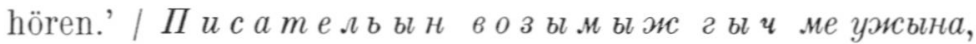
кузе ий гыч ийыи ял илыи, а тидын дене пьрля, ен'-влакынат илыиыит вашталт толеш. (Ončyko 6/1963, 100 OS) 'Aus dem Text des Schriftstellers sehen wir, wie sich das Leben des Dorfes von Jahr zu Jahr und damit auch das Leben der Menschen ändert.' / Коридор кок велны икманяр амасавлӓ кӥран чиашты доно о и стен н а гёи ц айырлалтыныт. (Iljakov, 111 WS) 'Zu beiden Seiten des Flurs unterschieden sich ihrer braunen Farbe wegen einige Türen in der Wand.' 
1-—но Марк Степановичын тыр ау жиланен

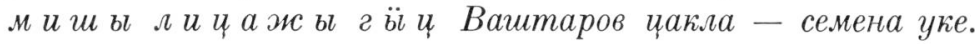
(Iljakov, 293 WS) '- - aber V. bemerkt am besorgten Gesicht von M.S. - es gibt kein Saatgetreide.' / T

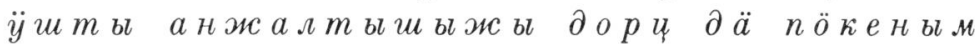

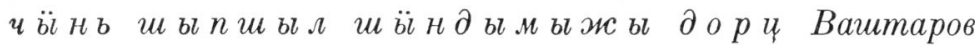
цакла, что кытырымаш шанавӥл гань агыл, а кӥъыртышан suau сӧpa. (Iljakov, 176 WS) 'Aus (an) seinem kalten Blick und dem erregten Verrücken des Stuhles sieht V., dass das Gespräch nicht wie ein Regenbogen sein wird, sondern Gewitter verspricht.'

Im folgenden Beispiel tritt eine auf -la endende, die Richtung ausdrückende Trennungskasusform auf (vgl. S. 26-27):

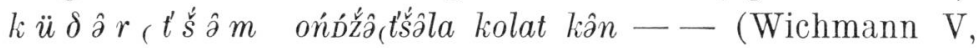
$18 \mathrm{M}-\mathrm{i})$ 'Wenn du vor [dir] den Donner hörst — - '.

In einigen Fällen kann man an eine Verbindung denken zwischen dem Gegenstand der Wahrnehmung und der Lokalität, woher dieses Wahrnehmungsobjekt stammt. Das gilt z.B. für Kontexte, wo vom Verstehen der Sprache oder Schrift die Rede ist; die Schrift kann z.B. darin als Ort aufgefasst werden, an dem etwas "hinterlegt» ist, was man beim Lesen zu verstehen sucht; andererseits kann man sich die Schrift selbst als Gegenstand der Wahrnehmung denken. Im Tscheremissischen kann in solchen Fällen der Trennungskasus gleichsam in zwei Rollen verwendet werden, einmal als Objekt, ein andermal als Ortsadverbial. ${ }^{1}$ Hier zwei Beispiele; im einen - aus OS stammend - ist wieder der $\delta e c ̌-$

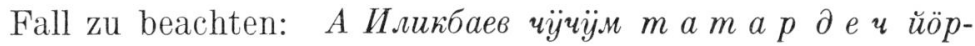
иынат ойыраи ок ли. (Ončyko 6/1963, 65 OS) 'Aber mein Onkel I. kann das Tatarische nicht gut verstehen.' / - но нигыщеак сирмаи гй̈ч айырлен ак керд. (Iljakov,

1 Vergleichshalber sei erwähnt, dass man in den entsprechenden Kontexten des Finnischen den Ausdruck saada selvää jostakin verwenden würde. Zwischen den Ausdrücken im Finnischen und Tscheremissischen besteht also in der Oberflächenstruktur ein Unterschied; im Finnischen fungiert selvää in der Oberflächenstruktur als Objekt, so dass sich der finnische Ausdruck der Form nach nicht vom typischen transitiven Satz unterscheidet. 
104 WS) '- - aber er kann auf keine Weise die Schrift entziffern.'

Mit einer derartigen Verwendung des Trennungskasus hat man offenbar eine Verwendung des Elativs zu verbinden, die in einer interessanten Nominalkonstruktion des Tscheremissischen begegnet. In dieser Konstruktion tritt als Prädikat eine Verbalform auf, wo die Elativendung $\gamma \partial \hat{c} c$ allgemein direkt an den Verbstamm tritt (auf diesen Umstand hat Erkki Itkonen aufmerksam gemacht, s. Vir. 1960, 317); die Konstruktion steht bei den Verben šoktem 'zu hören sein' und kojam 'zu sehen sein'.

Schon im nächsten Beispiel findet sich als Bestimmung des Verbums šoktem eine Nominalform diesen Typs. Dieser Beleg steht den normalen Verwendungsweisen des Verbs šoktem jedoch noch recht nahe ('etwas ist von irgendwoher zu hören'). Der Trennungskasus drückt in diesem Beispiel anstatt der eigentlichen Lokalität nur die Tätigkeit aus, von der der Schallreiz ausgeht - unter den obigen Beispielen findet sich eine entsprechende lokale Trennungskasusbestimmung bei einem visualen Verb -; der Reiz ist wie üblich durch ein eigenes Subjekt des Verbs šoktem ausgedrückt: —- - $i^{i} a-$

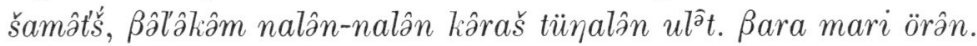

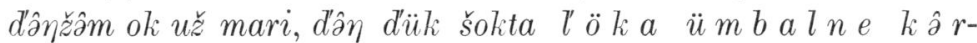
$\gamma \hat{\partial}\left(t^{\prime} \dot{s} \hat{a} n\right.$. (Beke T I, 540 Č) '- - die Kobolde ergriffen den Badequast und begannen [den Mann] zu schlagen. Das überraschte (dann) den Tscheremissen. Der Tscheremisse sah niemanden. Eine menschliche Stimme war (eigtl. ist) auf der Schwitzbank (während des Schlagens) vernehmbar [eigtl. eine menschliche Stimme ist auf den Pritschen vom Schlagen zu hören].'

Entsprechend wie bei den oben zitierten Beispielen für das Verb ojârem 'verstehen, herausbekommen' kann aber ein blosses Verbalnomen im Trennungskasus gleichzeitig ausdrücken, von welcher Tätigkeit ein Reiz für eine Gehörsoder Gesichtswahrnehmung ausgeht sowie welche Tätigkeit da gehört oder gesehen wird. Das ist z.B. im folgenden Beleg der Fall: tombalne mor $\gamma$ ât'šs šoktaš tnn nale. (Beke T I, 567 $\breve{C})$. 'Da hörten wir plötzlich in einiger Entfernung Gesang 
[eigtl. begann Gesang hörbar zu sein, (der gesungen wurde) weiter weg].'

In diesem Beispiel wird das Agens der Nominalform nicht ausgedrückt; das Agens der nominalen Verbform kann jedoch auch durch ein eigenes Wort ausgedrückt werden. Das Besondere ist aber, dass es in der Oberflächenstruktur nicht wie üblich mit der Nominalform verbunden wird, sondern das grammatische Subjekt des herrschenden Verbs šoktem oder kojam wird. Dies zeigt sich u.a. an der Pluralität des Prädikats, also des Verbs šoktem oder kojam, in jenen Kontexten, wo die durch die Nominalform ausgedrückte Tätigkeit mehrere Täter hat. ${ }^{1}$ Z.B. tutlak mündṇrkọ kajen-ḷ̨t $i$ ni $\gamma u s ̌ t-a t$ o $\gamma \approx t$ šokto $i l$ ? $\gamma$ ? $t^{\prime} \dot{s}$. (Beke T IV, $138 \mathrm{~B}$ ) 'Sie gingen weit weg, und keine Kunde berichtet (eigtl. es ist nichts zu hören), [ob] sie [noch] leben.' / Умбалне кичкыме имне дене к а й г ы и койыт. (Ončyko 6/1963, 55 OS) 'In der Ferne sind die mit Pferdewagen Fahrenden zu sehen [wörtlich: die mit angeschirrtem Pferd Fahrenden].' / Тушеч грузовой автомашина тол г и и коеш. (Ončyko 6/1963, 71 OS) 'Von dort sieht man einen Lastwagen kommen.' / Ялт лиинаћ, нельгн тошкальи, омылымо шон'го қугыза - орол ко и т г и и коеш. (Ončyko 6/1963, 58 OS) 'Ganz nahe ist, schweren Schrittes gehend, der aufpassende Alte — man sieht den Wärter umhergehen.' / Лачак кӥшнӧ, вуй мучаите, Ужкар-канде пыл лон гаште, - Яндар ййкан чылдырий, M у р а ы ч шокта ић турий. (Čavajn, 31 OS) 'Ganz oben, in der grünblauen Wolke, hört man die Singlerche mit klarer Stimme singen.'

In einem meiner Belege tritt in entsprechendem Kontext die Endung des Trennungskasus statt an den Verbalstamm an das me-Verbalnomen: - - тумо йымалне м утлан ы-

\footnotetext{
${ }^{1}$ Hinsichtlich dieser Eigenschaft der Oberflächenstruktur ähneln die tscheremissischen Beispiele jenen der finnischen Sprache, wo beim Verb näkyä oder kuulua eine Partizipialkonstruktion steht; die Form des Prädikatsteils ist in den finnischen Konstruktionen jedoch eine ganz andere, z.B. tytöt näkyvät, kuuluvat laulavan 'man sieht, hört die Mädchen singen'.
} 
м ы г ы ч а m шокта - - (Čavajn, 126 OS) '- - man hört, wie unter der Eiche gesprochen wird - - '.

3.8. Der Trennungskasus in Nominalsätzen sowie in Sätzen mit 'sein'

In Ausdrücken, die die Verschiebung einer Entität von einem Ort bezeichnen, tritt als Prädikat i.a. ein sog. Veränderungsverb auf. In einigen Fällen kann das Veränderungsverb jedoch in der Oberflächenstruktur unausgedrückt bleiben. In solchen elliptischen Ausdrücken kann z.B. die Interjektion als Prädikat fungieren oder z.B. die Akkusativform darauf hinweisen, dass das nichtausgedrückte Verb speziell transitiv ist. Einige Beispiele für verblose Übergangssätze:

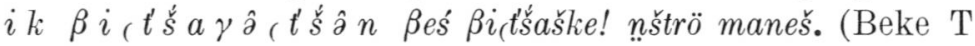
IV, 10 M) 'Aus dem einen Stall in den anderen Stall! sagt

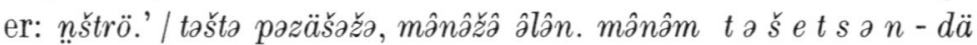
tokâžâ tolân Bara. (Ramstedt, $173 \mathrm{~K}$ ) 'Dort ist sein Nest: ein Ei war darin. Das Ei heraus und er kommt nach Hause zurück.' / kaja, kaja, ik kußan deke mien pura - Ku $\beta$ el ć kumbalke? joঠeš kußa. (Genetz, $15 \mathrm{P})$ 'Er geht und geht, kommt zu einem Weibe und tritt hinein — - . Das Weib fragt: Woher und wohin?' Diese Ausdrücke sind typisch: durch den Trennungskasus wird der Ort ausgedrückt, von wo etwas nach ausserhalb dieses Ortes gerät.

Ein entsprechender lokaler $\gamma \hat{\partial} \check{c}$ - oder $\check{c}$-Trennungskasus begegnet aber auch in einigen solchen verblosen Sätzen, die nicht elliptisch sind, sowie in solchen, die als Prädikat das

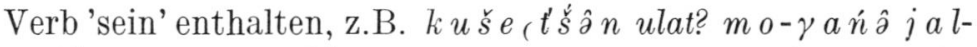

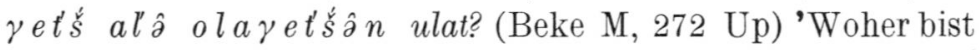
du? Aus welchem Dorf oder Ort (eigtl. Stadt) bist du?' / tiń išit'ś

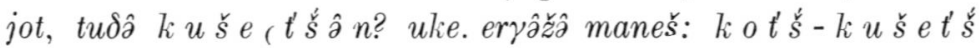
li.ẑे —-(Beke M, 393 Up) 'Hast du [den Mann] nicht gefragt, woher er [ist]? Nein. Ihr Sohn sagt: Woher er auch

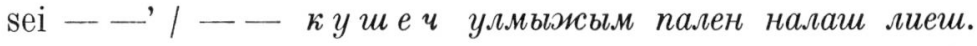
(Ončyko 6/1963, 68 OS) '- — man muss erfahren, woher sie

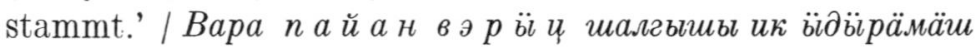
Ләниным лӥән колтән. (Grigorjev, 66 WS) 'Dann erschoss 
ein aus einem reichen Ort stammendes Mädchen Lenin.' / IIIачьнжы кого Й ил дор цин ыллам. (Iljakov, 206 WS) 'Ich bin am Ufer der grossen Wolga geboren [= zu Hause].' ।

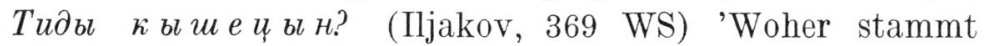

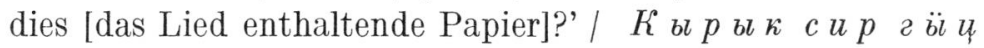
тӥъиты Майский, Ваштаров, Веселицкий, Карманов дӓ молат ылыныт. (Iljakov, 184 WS) 'Vom Bergufer [d.h. von den Bergtscheremissen] waren hier [bei der Versammlung] M., V., V., K. und andere.' In den beiden eingebetteten Sätzen der angeführten Zitate treten die Trennungskasusformen wie üblich an die infiniten Verbformen. Dieser sog. Trennungskasus des Ursprungs kann aber wenigstens in der Schriftsprache auch ohne Verb an das Nomen treten, z.B. Тендан ончылно - - весыже У рал з а в од г и ч мастер Ондрей Онтоныч Носков. (Čavajn, 313 OS) 'Der vor Ihnen stehende - zweite [Mann] ist O.O.N., Meister von der Fabrik Ural.' / 1908 ийьите "Йыллина» лйман и с т о р и й з ы и ойльмаием печатлалт лекте. (С̆avajn, 5 OS) 'I.J. 1908 erschien meine aus der Geschichte stammende Erzählung Jâlanda im Druck.'

Der in den angeführten Belegen stehende Trennungskasus ist lokal u.a. in dem Sinne, dass er in deutlicher Opposition steht z.B. zu den habitiven Bestimmungen der entsprechenden Ausdrücke (s. S. 69). Mittels eines solchen Ausdruckes wird jedoch nicht ausgesagt, dass $\mathrm{X}$ nach ausserhalb des im Trennungskasus stehenden A gelangt (oder gelangt ist). Der Trennungskasus gibt vielmehr die Lokalität an, zu der die Entität in irgendeiner Hinsicht in charakteristischer Beziehung steht: A. bezeichnet z.B. den Entstehungs- oder den ständigen Aufenthaltsort von X. Somit kann A in einem solchen Ausdruck nicht jede beliebige Lokalität bezeichnen. Der Satz Šeryaš $t u \quad k u r \hat{\partial} k$ ümba ̌ 'Der Ring stammt von jenem Felsen' ist z.B. nur in einem solchen Sonderfall möglich, wenn aus dem Kontext der Felsen als irgendwie charakteristischer Aufenthaltsort für den Ring angegeben ist. An sich kommt die Trennungskasusform der angeführten Ausdrücke einem die Beschaffenheit anzeigenden Prädikativum nahe. 
Zumindest in einigen Fällen kann der sog. Trennungskasus der Herkunft auch durch den Wo-kasus ersetzt werden, s. z.B. das Zitat aus Jt S. 75 .

\section{DIE TRENNUNGSKASUSFORM ALS GLIED EINES HABITIVEN VERHÄLTNISSES}

Das habitive Verhältnis kann durch die folgenden Formeln ausgedrückt werden: »Entität X befindet sich im Gewahrsam von Wesen B", "Entität X geht über in den Gewahrsam von Wesen B», "Entität X wird aus dem Gewahrsam von Wesen B weitergegeben». Das habitive Verhältnis setzt also voraus, dass das eine, besitzende Glied belebt oder eine von belebten Wesen gebildete Einheit ist, wie 'Gruppe', 'Kirche' usw.

Der Besitzer kann in einigen Fällen gleichsam durch lokale Formmittel ausgedrückt werden; so gibt es in den fiu. Sprachen allgemein viele Adverben und Postpositionen, die typische lokale Kasusendungen aufweisen, nunmehr aber Besitzverhältnisse ausdrücken. Die Lokalkasusformen vom Wort kit 'Hand' z.B. können im Tscheremissischen zu diesem Zweck verwendet werden: ен' кидыите лияи 'in fremden Händen sein', кидыи пуртаи 'in Gewahrsam nehmen', кид әыч колтаи 'wegnehmen' (Marijsko-russkij slovar', 195-196).

Zusätzlich zu solchen bildlichen Ausdrücken gibt es im Tscheremissischen jedoch auch viele andere Mittel, um ein habitives Verhältnis zu bezeichnen. Ein statisches habitives Verhältnis wird im Tscheremissischen meist entweder durch das Possessivsuffix oder den Genitiv oder beides gleichzeitig

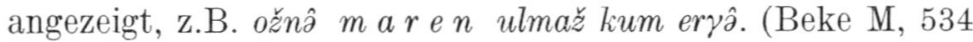
Up) 'Ein Mann hatte einst drei Söhne.' / oks a žâ uke [əิ]lân. (Beke V, $292 \mathrm{~K}$ ) 'Er [der Soldat] hatte kein Geld.' / $i$ k $t$ ə z ə $n$ oksaž-at uke - - (Beke V, $250 \mathrm{~K}$ ) 'Der andere hatte kein Geld - -'.

Der habitive Verwandlungskasus der Tiefenstruktur wird im transitiven Satz oft durch das Subjekt wiedergegeben, manchmal auch durch ein Personenobjekt; im ersten der folgenden Beispiele vertritt das Subjekt ausser dem Agens auch 
den habitiven Trennungskasus; im zweiten Satz drückt wiederum das Personenobjekt den habitiven Wohin-Kasus aus:

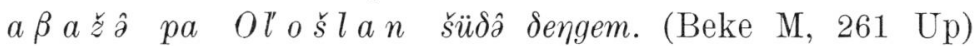
'Die Mutter gibt Aljoscha hundert Rubel.' / Kurâk-patâr, mińâm pukxx̌sen koltâ šüretâm!' (Beke T III, 316 Us) 'Held Berg, gib mir deine Suppe zu essen!' Der Genitiv kann ausser als habitiver Wo-Kasus auch als Wohin- und Tren-

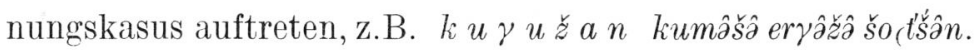
(Beke M, 303 Up) 'Dem König ist ein dritter Sohn geboren.' I te $\delta$ a maren peš šolâštât olmaš müm. (Beke T I, 54 Jo) 'Dem Nachbarn (eigtl. diesem Mann) wurde sehr [oft] Honig gestohlen.' (Über eine derartige Verwendung des Genitivs ausführlicher s. Kangasmaa-Minn, MSFOu 146, 11-46.)

Der üblichste habitive Wohin-Kasus von den obliquen Fällen ist jedoch im gesamten Sprachgebiet der Dativ (s. das Beispiel oben). Als Trennungskasus in habitiver Funktion begegnen die verschiedenen Trennungskasusmorpheme in den einzelnen Dialektgebieten und den verschiedenen Schriftsprachen auf viele Weisen. Insgesamt lassen sich in dieser Hinsicht sogar fünf verschiedene Gebräuche unterscheiden.

1. Der habitive Trennungskasus wird durch den blossen leč-Ablativ ausgedrückt. Im Lichte der zur Verfügung stehenden Dialektliteratur scheint es, als sei diese Vertretung in den Mundarten relativ weit verbreitet. Den Stand dieser Vertretung weisen jene Dialekttexte auf, die die Mundarten von $\mathrm{P}, \mathrm{B}, \mathrm{M}, \mathrm{Up}, \mathrm{Us}, \mathrm{JOk}^{1}$ und $\breve{\mathrm{C}}$ vertreten.

\footnotetext{
${ }^{1}$ Schon Beke erwähnt im Vorwort zu seiner Textveröffentlichung, dass der Dialekt von Kükšnur (JOk) dem von Č sehr nah verwandt ist und dass der Dialekt von Ušütj-tür wiederum dem von M-i nahesteht (Beke T I, XVIII - XIX). Gruzov möchte denn auch den erstgenannten lieber mit $\check{C}$ und den letztgenannten mit M-i als mit dem von JO verbinden (Gruzov, Fonetika, 10). Im Ausdruck des habitiven Trennungskasus entspricht der Stand von Kükšnur dem von Č́, während in den Dialekttexten von Ušüj-tür der für den M-i -Dialekt typische Wechsel lě́ $\sim \delta e \check{c}$ nicht begegnete. Dies kann jedoch auf das knappe Material der Dialektprobe zurückgehen; aus Ušütj-tür liegen nämlich nur knapp 20 Seiten Dialekttext vor. Die Sprachproben aus einigen Mundarten sind so spärlich, dass es unmöglich ist, diese Mundarten auf irgendeine Weise zu gruppieren.
} 
2. Der habitive Trennungskasus wird durch die Morpheme leč und $\delta e c ̌$ in freiem Wechsel ausgedrückt. Diese Vertretung weisen die Dialekttexte von S und M-i auf.

3. Der habitive Trennungskasus wird lediglich durch das Morphem $\delta e c ̌$ ausgedrückt. Diesen Stand vertritt die heutige östliche Schriftsprache (OS) sowie jene Texte, die aus den Dialekten Uj und JOü aufgezeichnet sind. Aus diesen Mundarten liegen sehr wenig Texte vor.

4. Der habitive Trennungskasus wird entweder durch den leč-Ablativ oder den $\gamma \hat{\partial} \check{c}$-Elativ ausgedrückt. Diesen Stand vertreten die Texte, die aus den J-Dialekten aufgezeichnet sind. Es ist offensichtlich, dass die Endungen wenigstens nicht im gesamten, traditionell als J-Dialektgebiet geltenden

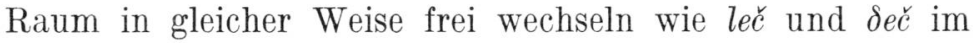
Dialektgebiet von Sernur-Morki. Einige J-Dialekte scheinen eine bestimmte Endung vor allem mit bestimmten Verben zu verwenden; andererseits scheint leč in manchen Dialekten speziell an den Pronominalstamm zu treten, während der $\gamma \hat{\partial} \hat{c}$-Elativ vorwiegend von Substantiven gebildet wird. Das aus den verschiedenen Dialekten vorliegende Material reicht jedoch nicht aus, genaue Grenzen zu ziehen; andererseits ist die genauere Abgrenzung kaum von allgemeinerer Bedeutung. Sicherheitshalber habe ich jedoch die verschiedenen Regionaldialekte von $\mathrm{J}$ mit diversen Abkürzungen versehen ( $\mathrm{Jl}$, Jo, Jt, Ju).

5. Der habitive Trennungskasus wird lediglich durch den $\gamma \hat{\partial} \hat{c}$-Elativ ausgedrückt. Diesen Stand vertritt die westliche Schriftsprache (WS) und der Dialekt von K.

Die Erforschung des habitiven Trennungskasus wird etwas dadurch erschwert, dass sowohl das Morphem $\gamma \partial \hat{c}$ als auch $\delta e c ̌$ im gesamten Sprachgebiet - neben der möglichen habitiven Verwendung - auch lokal benutzt wird. $\gamma \hat{\partial} \check{c}$ begegnes als typisch lokaler Elativ und das Morphem $\delta e c$ wiederum alt lokale Postposition in der Bedeutung 'von weg'. Ferner hat es in der östlichen Schriftsprache und in einigen Dialekten die habitive Bedeutung 'von jemandem' entwickelt. Formal unterscheiden sich die lokale und die habitive Verwendung des Morphems $\delta e \check{c}$ in keiner Weise.

Anders als die $\gamma \hat{a} \hat{c}$ - und $\delta e c ̌-T r e n n u n g s k a s u s$ ist das $l e c ̌-$ 
Morphem gerade eine nichtlokale, habitive Kasusendung, die Trennungskasusentsprechung des dativischen lan-Kasus; in lokaler Bedeutung begegnet sie nur in sehr begrenzten Fällen, wie aus dem vorangehenden Kapitel deutlich wurde. Somit nehmen die auf leč endenden Formen eine wichtige Stellung ein, wenn man die Grenze zwischen lokaler und habitiver Verwendung der Trennungskasus festlegen will.

\subsection{Der Trennungskasus bei einem Verb des habitiven Über- gangs}

Wie oben festgestellt, vertritt das Subjekt eines habitiven Übergangssatzes im transitiven Satz sehr oft auch den habitiven Wohin- oder Trennungskasus der Tiefenstruktur. Hieraus folgt u.a., dass in sehr vielen - allerdings nicht allen - habitiven Transitivausdrücken, wo zur Oberflächenstruktur lediglich ein habitiver Trennungs- und kein Wohin-Kasus gehört, mehr Information erteilt wird als in den ihrer Oberflächenstruktur nach entsprechenden lokalen Übergangssätzen, nämlich die Information: $\mathrm{X}$ geht vom Gewahrsam bei $\mathrm{B}_{1}$ über in den bei $\mathrm{B}_{2}$ (der lokale Übergangsausdruck der entsprechenden Form vermittelt die Kenntnis, dass X von der Lokalität A zur Lokalität -A übergeht, s. S. 20). Die habitiven und lokalen intransitiven Übergangssätze aber entsprechen einander sowohl in der Form als auch in der Bedeutung: sowohl für den Ausdruck "X geht von $B_{1}$ auf $B_{2}$ über» als auch für den Ausdruck »X geht von $\mathrm{A}_{1}$ auf $\mathrm{A}_{2}$ über» ist auch in der Oberflächenstruktur ein Trennungs- und ein WohinKasus notwendig, während der blosse habitive Trennungskasus den Übergang von B zu -B ausdrückt und der blosse lokale Trennungskasus den von A zu -A.

Ich hatte bereits erwähnt, dass man offenbar vor allem von den transitiven, eine lokale Veränderung ausdrückenden Verben mehrere in bestimmten Situationen auch zur Bezeichnung des habitiven Übergangs verwenden kann. Dieser Hinweis auf gerade transitive Verben wurde durch die Wahrnehmung verursacht, dass sich in meinem ziemlich umfangreichen Material nur zwei drei solche Beispiele finden, wo der habitive Trennungskasus bei einem intransitiven Übergangsverb steht 
(diese Feststellung betrifft also nicht alle intransitiven Verben; die späteren Kapitel enthalten eine ganze Reihe von Belegen für habitive Trennungskasusbestimmungen auch bei intransitiven Verben); als Prädikat begegnen in den intransitiven Kontexten dieses Kapitels purem '(herein)kommen' und tolam 'kommen'. So gibt es in meinem Material keinen einzigen Fall, wo mit dem intransitiven Verb gleichzeitig sowohl der habitive Trennungskasus als auch der habitive Wohin-Kasus, der Dativ, verbunden wäre. Wenigstens vom Standpunkt der heutigen Schriftsprachen beruht das Fehlen derartiger Konstruktionen offenbar auf dem Zufall; im folgenden Kontext z.B., wo ein habitiver Trennungskasus steht, könnte man offenbar anstelle des lokalen Wohin-Kasus auch den habitiven Wohin-Kasus, den Dativ, verwenden: Koызыт журнал редакиийыи тудын деч икмыняр почеламут ден "Сальман» лйман поэма пурен. (Ončуko 6/1963, 104 OS) 'Jetzt kamen in die Redaktion der Zeitung' einige Gedichte von ihm und eine Dichtung namens Sal'man.'

Doch auch die transitiven Verben, die in meinem Material als Bezugswort des habitiven Trennungskasus stehen, sind nicht in der gleichen Anzahl vorhanden wie jene, die lokale Trennungskasusbestimmungen erhalten. Die Verben und Verbgefüge, die ich als Bezugswörter der habitiven Trennungskasus gefunden habe, lassen sich in mehrere Gruppen teilen. Die grösste Gesamtheit machen verschiedene Verben und Verbgefüge des Nehmens aus; zu beachten ist allerdings, dass das üblichste Verb des Nehmens im Tscheremissischen, nalam, auch die Bedeutung 'erhalten' haben kann. U.a. haben folgende Verben des Nehmens habitive Trennungskasusbestimmungen erhalten: nalam 'nehmen', nalân kondem 'nehmend bringen', nalân nałgajem 'nehmend wegbringen', nalân tolam 'nehmend kommen', joðân nalam 'fragend nehmen', kuঠaš nalam 'ausziehend nehmen', lüšten nalam 'melkend nehmen', ontalen nalam 'betrügend nehmen', šupšŝn nalam 'ziehend nehmen', numal tolam 'bringend kommen', luktam 'nehmen, herausziehen', šolâštam 'stehlen'; zu diesen Verben gehören einerseits jüarn 'trinken', kočkam 'essen', ontalen kočkân kajem 'heimlich essend gehen', andererseits poyem 'sammeln'; wenigstens in den Westdialekten ist ein besonderes spätes 
Lehnverb mit der Bedeutung 'bekommen' in Gebrauch: polučajem.

Das Subjekt aller dieser Verben vertritt in der Tiefenstruktur gewöhnlich - wenn auch nicht jedesmal - den habitiven Wohin-Kasus, d.h. es drückt aus, in wessen Gewahrsam der Übergang von dem mit dem Trennungskasus bezeichneten Wesen geschieht. Lediglich in den Konstruktionen meines Materials, wo als Verb kondem 'bringen' oder kudašam 'ausziehen, wegnehmen' steht, vertritt das Subjekt stets den blossen Vollstrecker des habitiven Übergangs. Da es solche Kontexte insgesamt sehr wenig gibt, nimmt es nicht wunder, dass ich in meinem Beispielmaterial auch nur zwei transitive Kontexte habe, die gleichzeitig einen habitiven Trennungskasus und einen habitiven Wohin-Kasus, den Dativ, aufweisen.

Die zweite grosse Gruppe von Verben, die als Bezugswörter bei habitiven Trennungskasusbestimmungen stehen, besteht aus verschiedenen Verben des Fragens und Bittens, z.B.

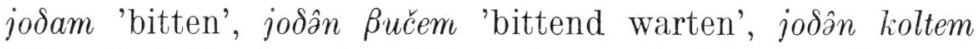
'bitten', jođân kumalam 'bittend beten', joð̧šstam 'fragen',

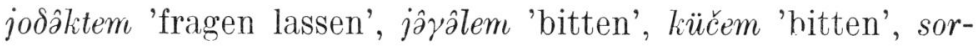
Balem 'beten', tâlanem 'bitten'; zu diesen Verben kann auch noch ßučem 'warten' hinzugefügt werden, semantisch eine Art potentiales Verb des Erhaltens. Auch das Subjekt aller dieser Verben vertritt meist den habitiven Wohin-Kasus der Tiefenstruktur.

Im folgenden bringe ich nach Vertretungstypen geordnete Belege für die habitiven Trennungskasusbestimmungen bei Verben des Übergangs. Obwohl die isolierten Sätze, die Wichmann aus fünf verschiedenen Dialekten aufzeichnete, sehr knapp sind, zeigen sie doch recht beweiskräftig die in den einzelnen Dialekten herrschende unterschiedliche Verwendung; diese Belege stehen hier bei jedem Vertretungstyp am Anfang.

\section{Der leč-Vertretungstyp}

Der leč-Trennungskasus tritt in Hunderten von Kontexten auf, ob nun das Denotat des Subjekts von dem habitiven U̇bergang profitiert oder lediglich als Vollzieher dieses Über- 
gangs angegeben wird: $k$ öl e $t^{\prime} s$ nalt?? (Wichmann R, $418 \mathrm{M}$ )

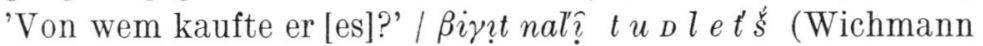
R, $269 \mathrm{M}$ ) 'Mit Gewalt nahm er [es] von ihm.' / a t'a mlet's

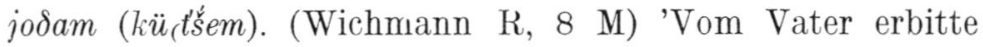
ich [es].' (Beim letzten Beispiel steht bei Wichmann ausdrücklich die Bemerkung: "det's kann nicht verwendet wer-

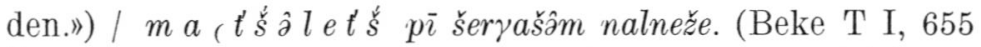
C) 'Der Hund will der Katze den Ring wegnehmen.' / ßatâẑิ naleš, luktân šeryašâm mare žlet'ś. (Beke M, 202 Up) 'Seine Frau macht sich daran, zieht den Ring vom [Finger ihres] Mannes.' / iźaštplak Pikej žßatam Marja le ć kuðaš nalât - - (Genetz, 34 P) 'Die Brüder ziehen Pikej's Kleider der Marja ab, nehmen sie weg - - / na, üktô tiń! ala t e le ( $t^{\prime} \dot{s}$ e t jües. (Beke M, $158 \mathrm{Up}$ ) 'Da hast du, gib du ihm zu trinken. Vielleicht trinkt er von dir.' Das letztgenannte Beispiel gehört also zu jenen, wo das Verb jüam 'trinken' so verwendet wird, dass es gleichsam ein Objekt enthält (vgl. S. 41-42).

Es existiert jedoch ein Text, der nach seinen Herausgebern den B-Dialekt vertritt, der aber u.a. hinsichtlich der habitiven Trennungskasus regelmässig vom Stand der anderen B-Texte abweicht, und zwar die Quelle Sebeok-Ingemann, aufgezeichnet bei einem nach Amerika ausgewanderten Tscheremissen namens Mr. Jewsky. Hier begegnet in den diesbezüglichen Kontexten regelmässig der $\delta e c ̌$-Kasus; dafür ein paar Beispiele: ta p o jande ě šüdö metar artanam naleš. (Sebeok-Ingemann, 72 B) 'Von diesem Reichen kauft er 100 m Brennholz.' / kug a ž a d e č adak jodeš oksam. (Sebeok - Ingemann, 72 B) 'Er bittet den Kaiser wieder um Geld.' Ausser diesem Text habe ich nur zwei Kontexte aus Up aufgezeichnet, in denen ein vermutlich für den habitiven Trennungskasus stehender $\delta e \check{c}$-Kasus vorkommt; im einen Beleg steht $\delta e \check{c}$ in unmittelbarer Nähe des "normalen» leč-

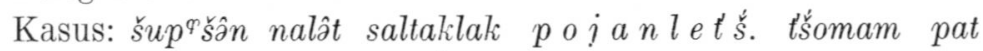

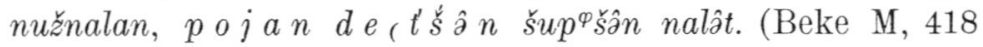
Up) 'Die Soldaten nehmen [das Fohlen] dem Reichen weg. Sie geben das Fohlen dem Armen, dem Reichen nehmen sie

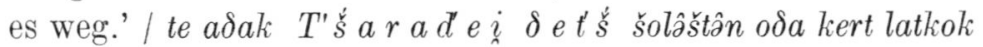


jolan imńâžâm? (Beke M, 448 Up) 'Könnt ihr [== die Vögel] noch nicht von $T$ 'šarad'ei sein zwölffüssiges Pferd stehlen?'

In einigen Liedern aus $\mathrm{P}$ und $\mathrm{B}$ scheint jedoch als habitiver Trennungskasus vom Wort kuyâża 'Kaiser' beim transitiven Verb kondem 'bringen' und beim intransitiven tolam 'kom-

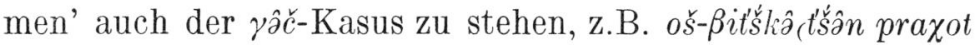

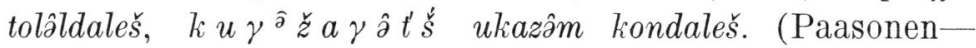
Siro T, 159 B) 'Von der Belaja kommt ein Dampfschiff, es bringt vom Kaiser einen Befehl.' I _ - Ozangâć toleš toj pot

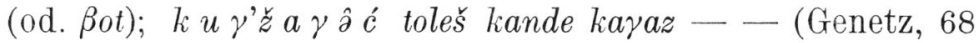
P) '- - von Kasan kommt ein Kessel aus Messing; vom Kaiser, da kommt das blaue Briefchen -- ' I - o $k u \gamma^{\prime} \check{z} a \gamma \hat{a} \dot{c}$ tolšo salam. (Genetz, $68 \mathrm{P}$ ) '- - ein Brief ist es vom hehren Kaiser.'

In einigen Gebeten aus B wird anstelle des 'normalen' pronominalstämmigen leč-Kasus eine Art Umschreibung verwendet, pelečet 'von deiner Seite', also ein č-Trennungskasus vom Wort pel 'Seite, Hälfte' mit dem Possessivsuffix, z.B.

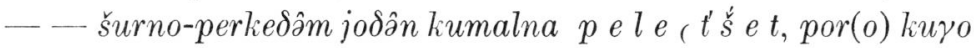
jumo. (Paasonen-Siro T, 38 B) '- - um Getreide-Überfluss bittend beten wir zu dir, guter, grosser Gott.'

\section{Der Vertretungstyp leč $\sim \delta e \check{c}$}

Beispiele, die das Aufrteten der Endung leč und $\delta e \check{c}$ in ähnlichen Kontexten zeigen: kölet'śs nal'â? S / kele t'śs $\left(k e-\delta e t^{\prime} s \grave{s}\right)$ nalâ? M-i (Wichmann R, 418) 'Von wem kaufte

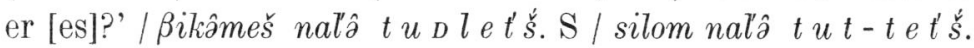
M-i (Wichmann R, 269) 'Mit Gewalt nahm er [es] von ihm.'

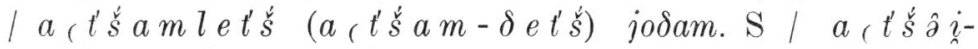
le t's $\left(a, t^{\prime} \dot{s} \hat{\partial} i-\delta e t^{\prime} s\right)$ jodam. M-i (Wichmann R, 8) 'Von meinem Vater erbitte ich [es].' / pörtâs purmöngö ü $\delta \hat{\partial} r$ -

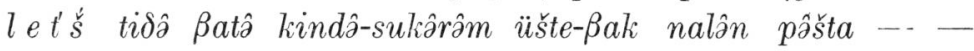
(Wichmann V, 32-33 S) 'In das Haus gekommen, nimmt jene Frau das Brot dem Mädchen ab und legt es auf den Tisch

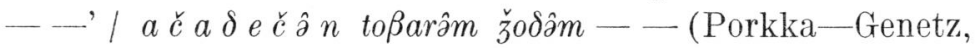
35 M-i) 'Eine Axt ich bat von meinem Vater _- - '.

In einem von Porkka aufgezeichneten Gebet erscheint jedoch zweimal die für dieses Dialektgebiet exzeptionelle 


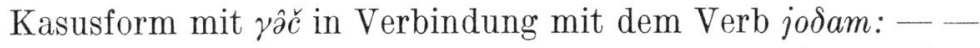

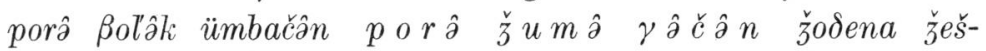

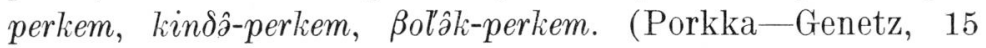
M-i) ' - _ bei dem dir gefälligen Tiere flehen wir vom guten Gotte Gedeihen der Familie, Reichtum an Brot, Reichtum

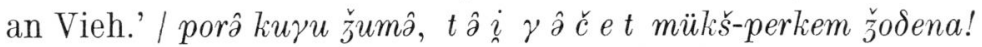
(Porkka-Genetz, 16 M-i) 'Guter, grosser Gott! Von dir erbitten wir Reichtum an Bienen.'

\section{Der $\delta e c$-Vertretungstyp}

Ich habe kein einziges, vom $\delta e c$-Stand abweichendes Beispiel aufgezeichnet: —— $k a t^{\prime} \dot{s} \hat{\partial}-m a r i \quad \delta e$ (t'š ik kumârâm-at om nal, maneš. (Beke T III, $172 \mathrm{Uj}$ ) '-- - ich nehme vom Bräutigam keine Kopeke an, sagt man.' / o $\beta \delta a-k_{a} a \beta a$ k tor o $_{\beta}$ oi $\delta$ e t'šs jodeš arakam. (Beke T III, $146 \mathrm{Uj}$ ) 'Ein о $\beta \delta a$ - - bittet den Wirt (eigtl. den Händler der Schenke) um Schnaps.' / Ваню, мемнан долркына-влак тений кажнне ушкал деч ныл тӥюем литр дене шӧрым лӥитен налаи лийыныт. (Ončyko 6/1963, 82 OS) 'V., dieses Jahr werden unsere Melker von jeder Kuh viertausend Liter Milch melken.' / - - по икудо - влак де ч ондален погылм окса —— (Ončyko 6/1963, 97 OS) '- - bei (von) den Nachbarn betrügerisch gesammeltes Geld —- / Mый тыланда, эрыкан марий-влаклан, У рал завод пашазе- влак де ч пӧлекым конденам - - (Čavajn, 314 OS) 'Ich habe euch, freie Tscheremissen, Geschenke von den Fabrikarbeitern des Ural gebracht _- - .'. Im letztzitierten Beleg steht also gleichzeitig sowohl der habitive Trennungs- als auch Wohin-Kasus.

\section{Der Vertretungstyp $l e \breve{c} \sim \gamma \hat{\partial} \breve{c}$}

Wichmanns Sätze aus dem Dialekt Jl zeigen deutlich die Schwankung im Gebrauch des Morphems leč und $\gamma \hat{a} c ̌ c: ~ k \ddot{u} n^{-}$ $\gamma$ ṇ ts näl’. (Wichmann R, $418 \mathrm{Jl}$ ) 'Von wem kaufte er [es]?' / silom näl'a tṇ $\delta n n \gamma n$ ts (tṇ $\delta n n$ lets). (Wichmann R, $269 \mathrm{Jl}$ ) 'Mit Gewalt nahm er [es] von ihm.' / ä $t^{\prime a} m \gamma$ əts (selten: ä $t^{\prime} \ddot{a} m l e t s$ ) kṇ.(tsem. (Wichmann R, $8 \mathrm{Jl}$ ) 'Ich erbitte [es] von meinem Vater.' In den anderen Belegen aus 
dem Dialekt $J$ tritt leč vor allem an den Pronominal-, $\gamma \partial \hat{a} \breve{c}$ wiederum bevorzugt an den Substantivstamm. Beispiele: nnnnn ñi-mam ayât kacts ayât jü male ctsem. (Beke T I, 38-39 Jo) '[Diese Burschen] essen [und] trinken nichts bei

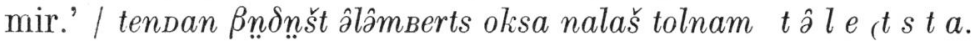
(Beke T I, 251 Jt) 'Ich bin gekommen, um von euch Geld [dafür] zu verlangen, dass (eigtl. weil) ihr im Wasser haust.' I atâm nalât $k \circ \beta$ a $\gamma \hat{\partial} t s, k \circ \delta a l a ̂ t$. (Beke T I, $333 \mathrm{Jt}$ ) 'Sie nehmen die Töpfe (Sing.) von der alten Frau entgegen [und]

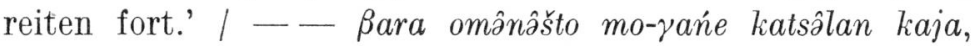

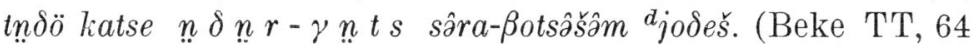
Jt) ' - - so heiratet sie den, der von ihr im Schlafe den Schlüssel verlangt.'

\section{Der $\gamma \hat{\partial} c ̌-V e r t r e t u n g s t y p$}

Die allgemeinste $\gamma \hat{a} c ̌-V e r t r e t u n g$ zeigen z.B. die folgenden Kontexte: k $\ddot{u} \gamma$ ats nül ? (Wichmann R, $418 \mathrm{~K}$ ) 'Von wem

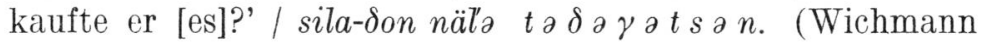
$\mathrm{R}, 269 \mathrm{~K}$ ) 'Mit Gewalt nahm er [es] von ihm.' / ä t'ä $m \gamma$ ə $t s$ kətšsem. (Wichmann R, $8 \mathrm{~K}$ ) 'Ich erbitte [es] von meinem

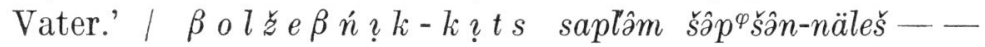
(Ramstedt, $194 \mathrm{~K}$ ) '[Der Bruder] entreisst dem Kobold den Säbel - - I lapa-pândašet layaštä yən, oksam ik tä̋za$\gamma$ ats nälät. (Beke V, $28 \mathrm{~K}$ ) 'Juckt dich deine Handfläche, bekommst du von jemandem Geld.' / Тӥ̈ндон шукыхиь

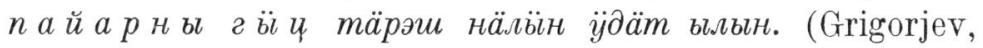
$43 \mathrm{WS})$ 'Deshalb nahmen viele von den Bojaren [Land] in Pacht und bebauten es.' / Ик лу ииты $m \ddot{a}$ г в̈ц цेда музыкальный кого произведенийым вычем - - (Iljakov, 124 WS) 'Nach zehn Jahren erwarte ich von Ihnen ein grosses Musikwerk - - '.

In drei-vier Belegen aus dem Dialekt $\mathrm{K}$ sowie in ungefähr ebenso viel aus WS scheint jedoch der deč-Kasus habitiv verwendet zu sein, z.B. - - katšķăşàm namaleš $\beta$ es $i m \dot{n} i$ $\delta o(t s \hat{z} n$. (Beke V, $50 \mathrm{~K})$ '- - [der Teufel] nimmt vom andern Pferd das Futter weg.' I ä $\beta$ äzə $\delta o$ ( $t s \hat{\jmath} n$ šüdə dängäm oksam namal doleš — - (Beke V, $312 \mathrm{~K})$ '[Puella] a matre centum rublos affert _-, _ - ti $\beta$ äta poluctšaja 


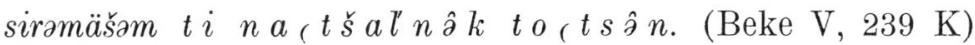
'- - diese Frau bekommt einen Brief von diesem Befehlshaber.' / ІІйіртемат шукы улы, тагачь веле кооператив гйи, Ваштаров П етр дориын, нӓлын канденам. (Iljakov, 55 WS) 'Ich habe auch viel Garn (Wolle), gerade heute habe ich es im Konsum gekauft, bei P.V.' / T̈̈ъды әче ирокок

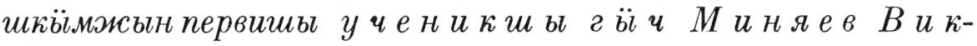

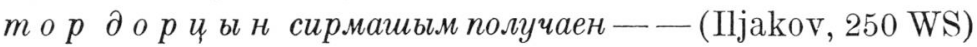
'Er hatte schon früh von seinem ersten Schüler V.M. einen Brief erhalten - - '. Das letzte Beispiel weist sich also da-

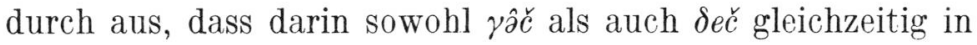
habitiver Verwendung zu stehen scheinen.

Die $\delta e c ̌$-Belege verlangen nach Kommentaren. In den beiden ersten Beispielen fungiert das Denotat des Subjekts lediglich als Übertrager, übernimmt nicht in den eigenen Gewahrsam. Im ersten Beleg aus der Schriftsprache dagegen scheint es sich um habitiven Übergang zugunsten des Denotats des Subjekts zu handeln; dennoch ist zu beachten, dass als Prädikat das Verb kondem 'bringen' steht, das normalerweise in Sätzen auftritt, in denen eine habitive Vermittlungsaufgabe ausgedrückt wird. In den beiden anderen Beispielen ist das Prädikat wiederum das späte Lehnverb polučajem 'bekommen', das im Russischen die Präpositionsbestimmung ot 'von weg, von jemandem' erhält. Da die tscheremissische Postposition $\delta e c ̌$ die Bedeutung 'von weg' hat, könnte sich die Entsprechung der russ. Präposition ot und der tscher. Postposition $\delta e c ̌$ in solchen Fällen auch auf das Gebiet der habitiven Verwendung ausdehnen.

\subsection{Der Trennungskasus bei einem Verb des Entstehens}

Die Grenze zwischen den habitiv und lokal zu verstehenden Fällen lässt sich an manchen Stellen sehr schwer ziehen. Eine Pflanze z.B. ist eine belebte Entität, unterscheidet sich aber von der übrigen belebten Natur u.a. darin, dass sie kaum als Besitzer fungieren kann, weshalb auch das sie bezeichnende Wort allgemein wohl nicht als besitzendes Glied eines habitiven Verhältnisses auftreten kann. Charakteristisch 
für Pflanzen ist jedoch ihre Vermehrung wie in den Hauptzügen auch für die Tiere, weshalb man in den Kontexten, wo es um die Entstehung aus etwas geht, die Beispiele aus der Tier- und Pflanzenwelt offenbar zusammen zu behandeln hat.

Anders als z.B. im Finnischen, wo im Ausdruck 'entstehen aus etwas' stets lokale Kasus verwendet werden, sind im Tscheremissischen logischerweise die habitiven Kasus in den Fällen in Gebrauch, wo die Trennungskasusbestimmung eines +Anim-Wortes bei einem Verb des Entstehens bzw. Geborenwerdens oder Hervorbringens bzw. Gebärens steht. Bei einem jeden Vertretungstyp werden nur die gerade für ihn eigenen habitiven Trennungskasusformen verwendet; Belege für den 5. bzw. den $\gamma \partial \hat{a} c$-Vertretungstyp liegen jedoch nicht vor.

\section{Der leč-Vertretungstyp}

- - tâjân, maneš, müšküret ulo, tĥl $l e$ c $t^{\prime} \dot{s}$ e $t$, maneš, ik-

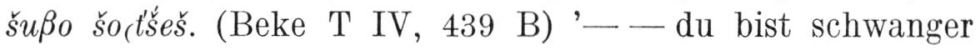
(eigtl. du hast einen Bauch). Du wirst ein Kind gebären (eigtl. von dir wird ein Kind geboren werden).' / ko $o z l e t^{\prime} s$

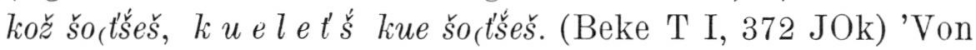
einer Fichte stammt [wieder nur] eine Fichte, von einer Birke (stammt) [wieder nur] eine Birke.' / - - $t^{\prime} \dot{s} u \beta$ arle $t^{\prime} \dot{s}$

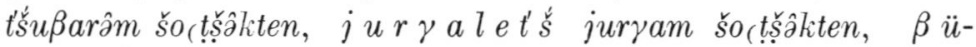

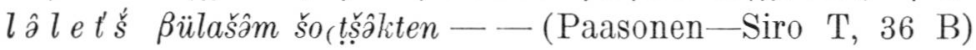
'_- lasse die Schecke eine Schecke werfen, lasse den Passgänger einen Passgänger werfen, die Stute ein Stutenfohlen $-\ldots$.'.

\section{Der Vertretungstyp leč $\sim \delta e \check{c}$}

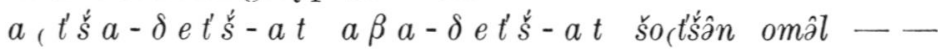
(Wichmann V, $263 \mathrm{~S}$ ) 'Von einem Vater und einer Mutter bin ich nicht geboren —-' / — - Bolâkâmat t ü $s$ le ě tüsâm šočâkten šo auch die Herde lieblich anzuschauen [eigtl. lass Vieh entstehen, vom gleichaussehenden gleichaussehend] - - '.

\section{Der $\delta e c$-Vertretungstyp}

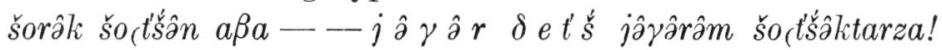


(Beke T' III, 123 Uj) 'Schafe (Sing.) entbindende Mutter ——von Zwillingen bring (Plur.) Zwillinge zur Welt!' । Шочын от ул ав а дечын, волыио улат кава гычын. (Cavajn, 248 OS) 'Du bist nicht von einer Mutter geboren, du bist aus dem Himmel herabgekommen.'

4. Der Vertretungstyp lě̌ $\sim \gamma \hat{\partial} \check{c}$

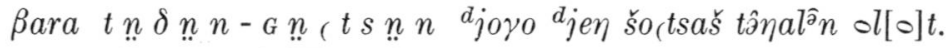
(Beke T I, 193 Jt) 'Von diesem [Menschen] stammen (Sing.) (dann) die faulen Menschen ab (eigtl. begannen [Sing.] ge-

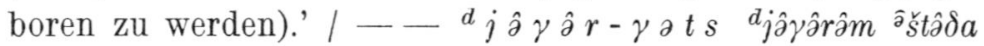
- maneš - patam! (Beke TT, $20 \mathrm{Jt}$ ) '- - werfet von den Zwillingen Zwillings-Schafe! sagen sie.' / u $\delta a$ š $u \delta \circ \gamma$ âts sai nösmo og li. (Wichmann V, $123 \mathrm{Ju}$ ) 'Von schlechtem Gras bekommt man [eigtl. entstehen] keine guten Samen.'

\subsection{Der Trennungskasus bei einem Verb der Trennung oder der Loslösung}

Die Kontexte, die die Loslösung oder Lostrennung aus dem Gewahrsam eines Wesens, das Errettetwerden oder Retten, das Befreitwerden oder Befreien ausdrücken, bilden gewissermassen eine Gruppe habitiver Kontaktausdrücke. Anders als in den Ausdrücken habitiven Übergangs, in denen i.a. zum Ausdruck gebraucht wird, wie eine Entität aus dem Gewahrsam von jemandem in den eines anderen übergeht, teilen diese Kontexte allgemein mit, dass eine Entität aus dem Gewahrsam von jemandem in einen besitzlosen Zustand gerät. Ein Grossteil meiner Beispiele enthält Kontexte mit einem Verb des Rettens oder Gerettetwerdens als Prädikat; die Zahl der hierher gehörenden intransitiven Satzzusammenhänge ist beachtlich gross. In den Belegen stehen nach den verschiedenen Vertretungstypen — regelmässig die habitiven Trennungskasus.

1. Der leč-Vertretungstyp

o $\beta \delta a$ noinmöngö o $\beta \delta$ a le t'šs muț̣̌ušten imńažm kuškuz kuSalân. (Beke R, 43 B) 'Nachdem die o $\beta \delta a$ müde geworden 
war, entkam er den Händen der $o \beta \delta a$ und ritt, auf sein Pferd steigend, fort.' I — $\beta u \beta$ er $-k u \beta$ a le t'śs utlušna - (Beke T IV, $88 \mathrm{M}$ ) ' - - wir sind die $\beta$ u $\beta$ er-Alte los geworden - - .

2. Der Vertretungstyp leč $\sim \delta e \check{~}$

ruš pirâ-pot t'śâm ku(t'śa- - a pirâ r u š-te t'śs uDlen kuSalě̌. (Wichmann V, $167 \mathrm{M}-\mathrm{i}$ ) 'Der Russe fasst den Wolf beim Schwanz — - aber der Wolf befreit sich und läuft dem Russen davon [vielleicht genauer: - - der Wolf wird frei vom Russen und läuft (weg)].' / Bot tỉô mariem mâjâm i a $\delta$ e č utaren - - (Porkka-Genetz, 2 M-i) 'Sieh, dieser, mein Mann, mich vom Bösen befreiend _- -

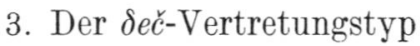

Ты а ай тӧра деч ӥдырым тале ӥзар гына утарен кертын. (Cavajn, 79 OS) 'Vor einem solchen Fürsten konnte nur eine starke Waffe das Mädchen retten'.

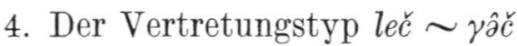

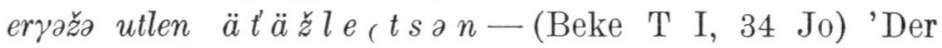
Junge entwand sich [endlich] [den Händen] seines Vaters ——' I — - maska — — tsâla pop üpâm kṇrṇn pâtaren. pop

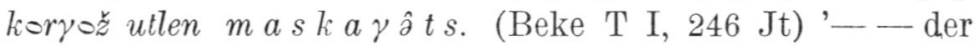
Bär - - riss [die Haare des Priesters] (alle) aus. Der Priester entfloh im Laufschritt (eigtl. laufend) vor dem Bären'.

5. Der $\gamma \hat{\partial} \hat{c}$-Vertretungstyp

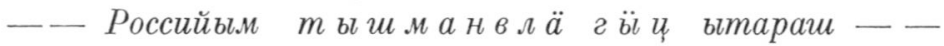
(Iljakov, 245 WS) '- - Russland vor den Feinden retten

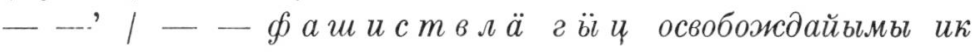
белорусский солаптылы - - (Iljakov, 255 WS) '- - in einem aus der Hand der Faschisten befreiten weissrussischen Dorf - -'.

\subsection{Der Trennungskasus bei einem Verb des Bleibens}

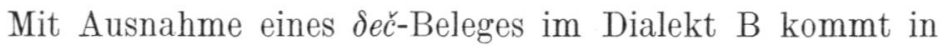


allen Beispielen stets der dem Vertretungstyp entsprechende habitive Kasus zur Anwendung; Belege liegen jedoch nicht für alle Vertretungstypen vor.

\section{Der leč-Vertretungstyp}

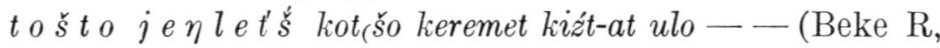
379 B) 'Der vom einstigen Mann gebliebene keremet ist noch da - - '. Im folgenden, im selben Märchen oft wiederkehrenden Kontext steht i.a. der leč-Kasus: - - tâde o s s o a $\beta$ a m a ( $t \check{s}$ a m l et $\breve{s}$ kotšo nästä - - (Paasonen-Siro T, 221 B) '- - dies ist von meinen abgeschiedenen Eltern [eigtl. von meinem Vater, von meiner Mutter] hinterlassene

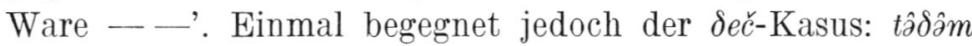

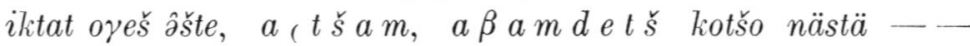
(Paasonen-Siro T, 223 B) 'Das hat niemand gemacht, es ist von meinem Vater und meiner Mutter hinterlassene Ware - - '

\section{Der $\delta e \check{c}$-Vertretungstyp}

Тиде удмурт-влак деи кодио лӥм. (Ončyko 6/ 1963, 93 OS) 'Dieser [Ortsname] ist ein von den Wotjaken gebliebener Name.'

\section{Der Vertretungstyp leč $\sim \gamma \hat{\partial} \check{c}$}

Borlets pârdâš tsâla kodešs, to [l] le ts ńi-mo o[k] kot. (Beke TT, $72 \mathrm{Jt}$ ) 'Von dem Diebe bleiben alle Mauern übrig, von dem Feuer bleibt nichts übrig.'

Dieses Sprichwort ist in etwas unterschiedlicher Gestalt aus mehreren Dialekten des 1. Vertretungstyps aufgezeichnet worden, und es enthält regelmässig zwei leč-Kasusformen; in diesem Fall ist das Wort tul 'Feuer' einem +Anim-Wort vergleichbar.

\subsection{Der Trennungskasus bei einem Verb des Verzichtens}

Die Verben des Nehmens und Erhaltens drücken meist je einen habitiven Übergang zugunsten des Denotats des Subjekts aus, wie in dieser Arbeit schon des öfteren festgestellt wurde. Der Unterschied der Verben besteht darin, dass bei 
der Verwendung eines Verbs des Nehmens gleichzeitig die aktive Tätigkeit des Denotats des Subjekts zwecks Verursachung des Übergangs ausgedrückt wird, während das Denotat des Subjekts bei einem Verb des Erhaltens allgemein als passiv hinsichtlich der Tätigkeit gilt.

Die Verben des Gebens können den Verben des Nehmens deutlich zur Seite gestellt werden: ihre Anwendung verrät, dass das Denotat des Subjekts aktiv tätig ist zwecks Verursachung eines habitiven Übergangs weg vom Besitz des Denotats des Subjekts. In vielen Sprachen kann jedoch auch der dem Erhalten entsprechende Prozess ausgedrückt werden, wo die Richtung vom Gewahrsam des Denotats des Subjekts weg verläuft; zu diesem Zweck werden Verben des Verzichtens verwendet. Das Besondere zumindest in vielen europäischen Sprachen ist, dass solche Konstruktionen, in denen ein Verb des Verzichtens vorherrscht, wesentlich von der mit den anderen genannten Verben benutzten normalen Subjekt + Objekt-Konstruktion abweichen; in der letztgenannten Konstruktion drückt also das Subjekt den habitiven Wohin- oder Trennungskasus aus und das Objekt die Entität, deren Besitzverhältnis sich ändert. Auch das Subjekt vom Verb 'verzichten' drückt einen habitiven Trennungskasus der Tiefenstruktur aus, die Entität aber, die aus dem Besitz oder aus der Benutzung des Denotats des Subjekts verschwindet, wird dagegen durch den Trennungskasus oder eine ihm entsprechende Konstruktion angezeigt. So verhält es sich auch im Tscheremissischen.

Es gibt im Tscheremissischen offenbar mehrere Verben, die in Konstruktionen, die einen Verzicht beschreiben, auftreten; hier kommen wenigstens folgende Verben in Frage: Bolem 'eigtl. sich herablassen', kodem 'eigtl. verlassen', śörlem 'eigtl. sich auflösen, zurückkehren', čaknem 'eigtl. sich zurückziehen' sowie das späte Lehnverb otkazatlaltam, WS otkazem. Da die im Tscheremissischen in einer solchen Konstruktion stehenden autochthonen Verben meist eigentlich intransitive lokale Übergangsverben sind, kann man auch leicht verstehen, warum sie in diesen Konstruktionen des Verzichtens eine Trennungskasusbestimmung erhalten. Zu bemerken ist allerdings, dass die Trennungskasusbestimmung in habitiven 
Kontexten nicht identisch ist mit jener in lokalen Kontexten; im Gegenteil -- sie ist in all jenen Vertretungstypen, für die Belege vorliegen, regelmässig der Form nach habitiv. Beispiele für die Konstruktion 'auf etwas verzichten' nach Vertretungstypen; für Typ 2 liegen keine Belege vor:

\section{Der $l e \check{c}$-Vertretungstyp}

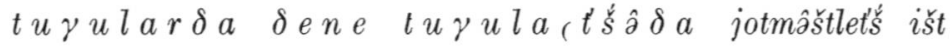
Bolo - - (Beke T IV, 199 B) 'Euer Schwippschwager und eure Schwippschwägerin liessen von dem, was sie verlangten, nicht nach - - / šk e o je t le e t’śs it śörlâ! (Beke T III, 416 Up) 'Von deinem eigenen Wort lass nicht ab!'

3. Der $\delta e c ̌-V e r t r e t u n g s t y p$

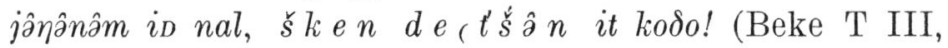
$38 \mathrm{Uj}$ ) 'Nimm nicht weg, was dem anderen gehört, lasse nicht ab [von dem], was dir gehört!' / $s k e$ o jet te t's it t'šagne! (Beke T III, $54 \mathrm{Uj}$ ) 'Lasse nicht ab von deinem eigenen Wort!' / Революций лиймек, М. Ф. Токмурзин nоп лӥм деч отказатлалтын - - (Ončyko 6/1963, 92 OS) 'Nach der Revolution verzichtete M.F.T. auf den Namen des Priesters _- - '.

4. Der Vertretungstyp leč $\sim \gamma \hat{\partial} \check{c}$

$\breve{s} k$ e o jetlets it tsäkna! (Beke T I, 21 Jo) 'Lass von deinem Wort nicht ab!' I ške kal as âmet-kâts it tsakne - - (Beke TT, $82 \mathrm{Jt}$ ) '[Hast du etwas ausgesprochen], so sollst du nicht mehr zurücktanzen - - '.

5. Der $\gamma \hat{\partial} \check{c}-$ Vertretungstyp

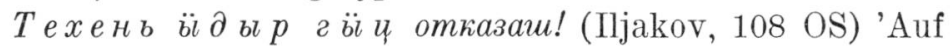
ein solches Mädchen verzichten!'

4.6. Der Trennungskasus in Nominalsätzen sowie in Sätzen mit 'sein'

Genau wie in lokalen (s. S. 50-52) kann mitunter auch in habitiven U̇bergangsausdrücken das Prädikat unausge- 
drückt bleiben. Auch dann werden natürlich allgemein die üblichen habitiven Kasus verwendet, z.B. im folgenden intransitiven Ausdruck der leč-Kasus: sojakâm lištet, man, ke

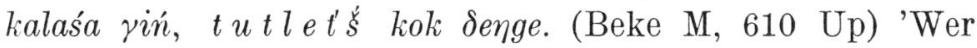
da sagt: "Du lügst», der [zahlt] 200 Rubel.' Dennoch begegnen wenigstens in einem Kontext, der aus dem Gebiet des habitiven leč-Vertretungstyps stammt, elliptisch im intransitiven Ausdruck habitiv verwendete $\gamma \hat{\partial} c ̌$-Elativformen; zu beachten ist, dass zu Anfang des Liedes als habitive Bestimmung des Verbs kondalam 'bringen' oleichsam als Ausnahme

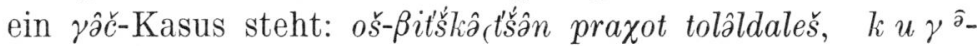
$\check{z} a \gamma \hat{\partial} t^{\prime} \check{s}$ ukazâm kondaleš. $k u \gamma^{\hat{\partial}} \breve{z} a \gamma \hat{\partial} t^{\prime} \dot{s}$ ukaz, $j u m \hat{\partial}-$

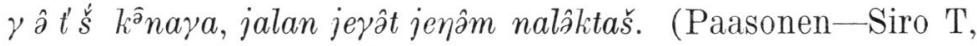
159 B) 'Von der Belaja kommt ein Dampfschiff, es bringt vom Kaiser einen Befehl. Vom Kaiser einen Befehl, von Gott ein Buch, immer mehr junge Männer zu fordern [?, zu nehmen].'

Wie die lokalen Trennungskasus können auch die mit habitiver Funktion in statischen Sätzen zum Ausdruck der Herkunft verwendet werden, in diesem Fall zum Ausdruck dessen, von wem etwas stammt oder ausgeht. Meine hierher gehörenden Belege kommen speziell aus WS. In den folgenden Zitaten aus WS steht der 'normale' $\gamma \partial \hat{\partial} c$-Kasus: $K \ddot{y}$

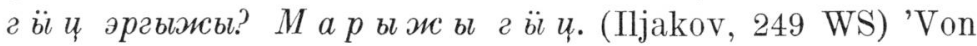
wem ist ihr Sohn [d.h. wer ist der Vater ihres Sohnes]? Von ihrem Mann.' / Лaч ӓважок! М икола й г в̈и и нимат уке. (Iljakov, $330 \mathrm{WS}$ ) 'Wie seine Mutter! Von M. ist nichts (d.h. hat das Kind nichts geerbt).' In all den vielen Beispielen aber, in denen es darum geht, von wem ein Brief oder eine entsprechende konkrete Mitteilung stammt, steht regelmässig

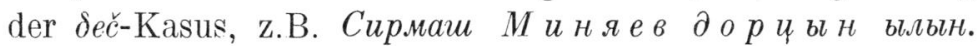
(Iljakov, $264 \mathrm{WS}$ ) 'Der Brief war von M.' / $M$ икола й д о р ц сирмаи уке? (Iljakov, 361 WS) 'Von M. ist kein Brief [da]?'

Solche statischen Belege, in denen der eigentliche habitive Trennungskasus, der leč-Kasus, die 'besitzmässige Herkunft' bezeichnen würde, habe ich dagegen nicht aufgezeichnet. An sich sind Kontexte mit dem leč-Kasus in habitiver Funktion 
im statischen Satz in den Texten des 1. habitiven Vertretungstyps nicht einmal selten; das Besondere ist nur, dass die Bedeutung des leč-Kasus in diesen Belegen ganz exzeptionell wirkt: der Kasus steht in der Funktion des habitiven WoKasus. Beispiele: üßâr maneš: me mišna aťśam denâ olaškâ,

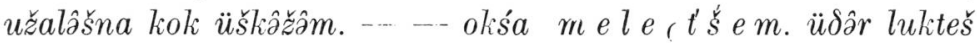
okśam, pa ti ßatâlan. (Beke M, 191 Up) 'Das Mädchen sagt: Ich war mit meinem Vater in der Stadt, [wir] verkauften zwei Ochsen. - - Das Geld [ist] bei mir. Das Mädchen nimmt das Geld heraus, [über]gibt es dieser Frau.' / iktâže šöryäšam šâl-

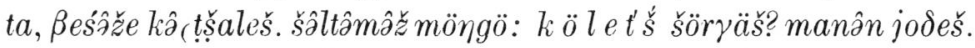
(Beke T IV, 189 B) 'Der eine versteckt den Ring, der andere sucht ihn. Nachdem sie ihn versteckt haben, fragt [der eine]: Bei wem ist der Ring?' / kuštâ tu tußâret? kußan šeškâž̆ maneš: tu tußâr a $\beta$ a m l e t'ś. (Beke M, $404 \mathrm{Up}$ ) 'Wo ist jenes Hemd? Die Schwiegertochter der Alten antwortet: Jenes Hemd [ist] bei meiner [Schwieger]mutter.' / olma yâna t'śußar imńnle $t^{\prime} \dot{s}$ oksa yânaj šikar pojanlet's. (Paasonen-Siro T, 150 B) 'Eine scheckige Farbe hat das Pferd, Geld und Zucker hat der Reiche.' / miñân t'śonem telect'ś et, tiñân t'śonet me le c $t$ 's e m, oka(n) mundâraž te le (t'śset, porśân mundâražs me le (t'śs em. (Beke T' III, 275 Uś) 'Mein Herz [ist] dein (eigtl. bei dir), Dein Herz ist mein (eigtl. bei mir), Das Posamentknäuel [ist] dein (eigtl. bei dir), Das seidene Knäuel [ist] mein (eigtl. bei mir).' / kutkâ šuldâr kue-par ( $t^{\prime} \dot{s} a-$ let'ś, kue part'śsa jum âle t'śs. Beś-kana-lai užmeškâ nemnan $\beta u i z ̌ z-a t ~ j u m \hat{\partial} l e t^{\prime} \dot{s}$. (Beke T III, $357 \mathrm{Us)}$ 'Die Flügel (Sing.) der Ameise [sind] im Wipfel der Birke, der Wipfel der Birke [ist] bei Gott. Bis ich dich noch ein zweites Mal sehen werde, [wird] auch unser Kopf bei Gott sein.'

In den ersten Belegen des obigen Verzeichnisses, die aus Prosatext stammen, besteht zwischen dem Subjekt und der leč-Trennungskasusform ein deutliches habitives statisches Verhältnis. In einigen Kontexten der Lieder - die drei zuletzt angeführten Zitate stammen aus Liedern - ist die Bedeutung des Ausdruckes etwas unklar; im folgenden Zitat z.B., das gegen Ende stark an den letzten Beleg erinnert, hat Paasonen im Zusammenhang mit dem Trennungskasus einen 
Hinweis auf die Bedeutung 'von jemandem abhängig sein' gesehen: por(o) imńe košteš poro jẹ kiðâšte, por(o) ul'mân ßujžo ju $m$ âle $t^{\prime} \dot{s}$. (Paasonen-Siro T, 103 B) 'Das gute Pferd geht an der Hand des guten Mannes, der Kopf des guten Mannes ist in Gottes Hand. [In der Fussnote: завидить (э: зависитъ) отъ.]'

Offenbar ist Paasonens Anmerkung begründet, denn z.B. der leč-Kasus im folgenden Lied kann eigentlich überhaupt nicht mehr als habitiv gedeutet werden, sondern darin drückt die leč-Kasusform die belebte Entität aus, von der etwas abhängig ist, von der eine Erlaubnis oder Fügung kommt; semantisch nähert sich der Kontext somit den kognitiven

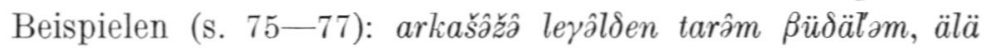

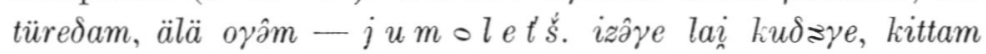

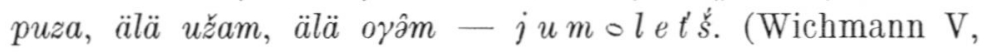
448 B) 'Ich ging hinaus auf die Anhöhe und säte Hirse, vielleicht werde ich [sie] ernten, vielleicht nicht - [das hängt] von Gott [ab]. [Ihr] kleinen und [ihr] grossen, gebet [mir] alle eure Hände, vielleicht werde ich [euch wieder] sehen, vielleicht nicht - [das hängt] von Gott [ab].'

\section{DIE TRENNUNGSKASUSFORM ALS GLIED EINES KOGNITIVEN VERHÄLTNISSES}

Entsprechend der habitiven Relation kann auch die kognitive mittels folgender Formeln wiedergegeben werden: »Wesen C kennt Entität X», "Wesen C erfährt Entität X», »Wesen C gibt die Kenntnis von Entität X weiter». Wie bei dem habitiven setzt also auch das kognitive Verhältnis voraus, dass das eine Glied der Relation, das wissende oder erkennende belebt ist bzw. - in periphrastischen Ausdrücken eine Einheit belebter Inhalte darstellt. Überhaupt stehen sich das habitive und das kognitive Verhältnis sehr nahe, obwohl es zwischen ihnen auch in dem Masse Unterschiede gibt, dass sie zweckmässigerweise getrennt behandelt werden.

Die Unterschiede zwischen dem habitiven und kognitiven Verhältnis werden sichtbar, wenn man z.B. an die in ihrem 
Bereich vor sich gehenden Veränderungen denkt. Die habitive Veränderung bedeutet meistens, dass die Entität, nachdem sie in ein Besitzverhältnis geraten ist, nunmehr nicht mehr im früheren Besitzverhältnis oder im besitzlosen Zustand verbleibt. Die kognitive Veränderung ist i.a. ganz anders geartet. Dies beruht darauf, dass ins Bewusstsein eines lebendigen Wesens keine Kenntnis in der gleichen Weise übergehen kann wie z.B. eine Entität von einem Ort oder Besitz an bzw. in einen anderen übergeht; neue Kenntnisse und Wahrnehmungen sind vielmehr stets das Ergebnis eines Prozesses, der durch Impulse von irgendwoher verursacht wird. Wenn eine Kenntnis in das Wissen von jemandem übergeht, bedeutet dies i.a. nicht, dass diese Kenntnis nun nicht mehr an ihrer früheren Lokalität oder in ihrem früheren Wissen existiert. Wenn ein Wissenselement aus dem Wissenskreis eines Wesens anderswohin gelangt - an eine Lokalität oder zu einem anderen Wesen -, so bedeutet dies entsprechend i.a. nicht, dass seine Existenz im bisherigen Wissenskreis damit aufhört. Somit ist sogar der Terminus 'kognitiver Übergang' in gewisser Hinsicht übertragen; eher hat die kognitive Veränderung normalerweise den Charakter einer Verbreitung oder Expansion, vergleichbar z.B. jenem lokalen Ereignis, das z.B. die Verbreitung von Feuer oder Schimmel von einem Ort zum anderen bedeutet. Nehmen wir z.B. den Ausdruck Л удшо - влаклан Чачавийын икмурыюым каласен пуэм әын - - (Čavajn, 88 OS) 'Wenn ich den Lesern ein Lied von Č. vorführe - - '. Der kognitive Übergang besteht darin: das Lied gelangt in die Kenntnis des Lesers; es verschwindet wegen dieses Vorgangs nicht aus dem Bewusstsein des Ich im Zitat, des Autors.

Es gibt jedoch auch Kontexte, in denen der kognitive Prozess in erster Linie einem lokalen oder habitiven Entstehungsprozess vergleichbar ist; das sind solche Satzzusammenhänge, in denen ausgedrückt wird, wie ein neuer Gedanke gefunden oder eine Wahrnehmung gemacht wird, z.B.

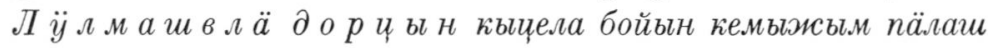
ұұаца. (Iljakov, 277 WS) 'Er versucht aus den Schüssen herauszubekommen, wie der Kampf verläuft.' 
Andererseits liegen auch Kontexte vor, in denen der kognitive Prozess ein Verschwinden ausdrückt; hierher gehören u.a. jene, in denen jemand etwas vergisst.

Wie das habitive Verhältnis kann auch das kognitive in bestimmten Fällen gleichsam durch lokale Formenmittel wiedergegeben werden, z.B. уиышто кучаи 'im Sinn halten', уи гыч луктаи 'aus dem Sinn lassen', уиыши кондаи 'sich erinnern, ins Gedächtnis zurückrufen' (Marijsko-russkij slovar, $637)$.

Anders als das habitive Verhältnis wird die statische kognitive Relation im transitiven Satz meist mittels Subjekt und Objekt wiedergegeben; als Prädikat steht in einem solchen Ausdruck ein Verb des Wissens oder Verstehens, z.B. kit kiðâm šiń,ď̌a . (Paasonen-Siro T, 84 B) 'Hand kennt Hand.'

\subsection{Der Trennungskasus bei einem Verb der Veränderung}

Auch der kognitive Veränderungskasus der Tiefenstruktur wird sehr oft durch das Subjekt vertreten; z.B. im ersten Beleg dieses Kapitels, im Beispiel aus OS, vertritt das Subjekt den kognitiven Trennungskasus, im darauffolgenden Beispiel aus WS wiederum den kognitiven Wohin-Kasus. In einigen Fällen kann der kognitive Veränderungskasus der Tiefenstruktur auch durch das Personenobjekt wiedergegeben werden, wie der Wohin-Kasus der Tiefenstruktur im folgenden

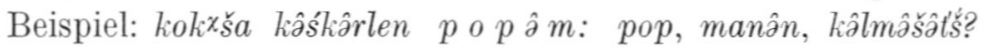
manân. (Beke T IV, 105 M) 'Der Kahle rief dem Popen zu: Pope, (sagte er), ist dir kalt geworden? (sagte er).'

Der kognitive Wohin-Kasus kann in der Oberflächenstruktur jedoch auch durch den Wohin-Kasus der Oberflächenstruktur, den Dativ, ausgedrückt werden; das ist z.B. in jenem OS-Beleg der Fall, auf den gerade verwiesen wurde. Als kognitive Trennungskasus der Oberflächenstruktur begegnen in den einzelnen Dialektgebieten und Schriftsprachen genau dieselben Trennungskasus wie als habitive Trennungskasus. Die Kontexte, in denen durch Verwendung des Trennungskasus ein Wesen angegeben wird, aus dessen Kenntnis- 
bereich ein Wissen anderswohin gelangt, bilden in meinem Material eine sehr homogene Gesamtheit mit weitaus übereinstimmenden Beispielen, so dass sich eine Unterteilung erübrigt.

In allen Trennungskasusbeispielen wird ein zugunsten des Denotats des Subjekts geschehender kognitiver Übergang ausgedrückt; alle diesbezüglichen Beispiele vertreten den Typ "X geht von $\mathrm{C}_{\mathbf{1}}$ auf $\mathrm{C}_{\mathbf{2}}$ über». Alle Sätze lassen sich also zusammenstellen mit jenen habitiven Beispielen, in denen das Verb 'nehmen' oder 'erhalten' bedeutet und wo sich der Übergang des Besitzes zugunsten des Denotats des Subjekts vollzieht. Als Prädikat stehen in den zu behandelnden kognitiven Kontexten Verben des Hörens, Fragens, Lernens, Wartens. Bei den einzelnen Vertretungstypen gibt es noch weniger Ausnahmen als bei den habitiven Belegen. Beispiele nach Vertretungstypen:

\section{Der leč-Vertretungstyp}

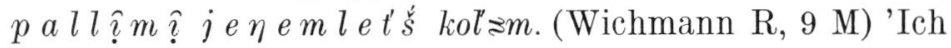
hörte [es] von meinem Bekannten.' / $i_{n}^{i} a$ nndṇr, $k u \gamma \hat{\partial} z a n$

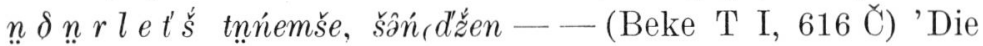
(von der Kaisertochter lernende) Teufelstochter wusste - -'।

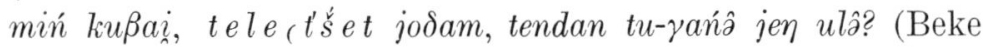
M, $288 \mathrm{Up}$ ) 'Ich, Alte, frage dich, ob so ein Mensch bei euch ist.'

Neben den vielen leč-Beispielen mit dem Verb jodam 'fragen' habe ich einen $\delta e c ̌$-Kontext aufgezeichnet: jodeš š or $\hat{z} k$

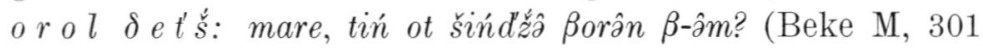
Up) 'Er fragt den Schäfer: Mensch, kennst du ßorân ßorânit's nicht?' Ausserdem steht in den auch in diesen Zusammenhang gehörenden Beispielen der Texte von Sebeok-Ingemann regelmässig der $\delta e c ̌$-Kasus, z.B. tə čort jodan u $r$ g ә z a de ě: mom aštet taj. (Sebeok-Ingemann, 69 B)' Dieser Teufel fragte den Schneider: Was tust du?'

\section{Der Vertretungstyp leč $\sim \delta e \check{c}$}

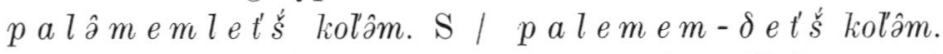
II-i (Wichmann R, 9) 'Ich hörte [es] von meinem Bekannten.' 


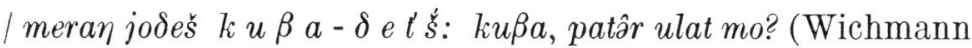
V, 158 S) 'Die Hase fragt die alte Frau: Alte, bist du

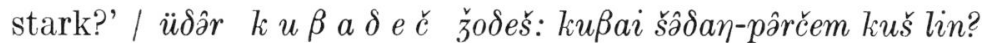
(Porkka-Genetz, 4 M-i) 'Das Mädchen fragt das Weib: Mütterchen, wo ist mein Weizenkörnlein hingekommen?'

\section{Der $\delta e \breve{c}$-Vertretungstyp}

a $p^{\varphi} \breve{s}$ a $t$ te $t^{\prime} \dot{s}$ jodeš: iruñâm tayanled mo? (Beke T III, $152 \mathrm{Uj}$ ) 'Er fragt den Schmied: Beschläger du wohl das Pferd?'/ Ну н ви н деч "йӱдым каена» манме шомакымат колын. (Ončyko 6/1963, 57 OS) 'Er hörte von ihnen die Worte "In der Nacht gehen wir».' / Тудо, й̈̈дымсӧ памада нерген, тен на ан де ч чыла пален налаи ийдыи. (Ončykn 6/1963, 60 OS) 'Er befahl, alles übor eure nächtlichคn Unternehmungen in Erfahrung zu bringen.'

\section{Der Vertretungstyp leč $\sim \gamma \partial \hat{c}$}

ja $l$ t a š e $m \gamma$ ə $t s$ kolə̂m. (Wichmann R, $9 \mathrm{Jl}$ ) 'Ich hörte [es] von meinem Bekannten.' / djalmanlets ot tnnem

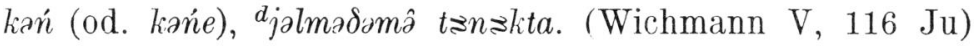
'Wenn du von dem Sprechenden nicht lernst, wird [dich] der

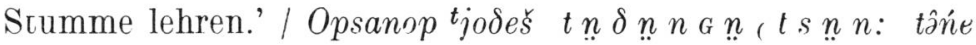
k š́t olš $[0]$ olat? (Beke T I, $308 \mathrm{Jt}$ ) 'Opsanow fragt ihn: Von wo bisc du?'

\section{Der $\gamma \hat{\partial} \hat{c}$-Vertretungstyp}

$p \ddot{a} l^{2} m$ e m $\gamma$ əts kol’am. (Wichmann R, $9 \mathrm{~K}$ ) 'Ich hörte [es] von meinem Bekannten.' / Стихвлӓм сираи техникым

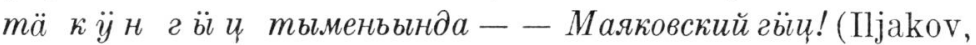
182 WS) 'Von wem habt ihr die Technik des Gedichteschreibens gelernt? - - Von M.!' / Мольжкы лешангышылаок тамам смелам келесымым Миколай а й ц выченыт- (Iljakov, 139 WS) 'Die anderen erwarteten bald eine mutige Rede von M. - - ' ${ }^{1}$

${ }^{1}$ Alle Verben, die in den zitierten kognitiven Beispielen vorkommen, setzen durch den Sprechakt bei dem Denotat der Trennungskasusform eine Handlung voraus, damit der kognitive Übergang statt- 


\subsection{Der Trennungskasus in Nominalsätzen sowne in Sätzen mit 'sein'}

Die Trennungskasus mit kognitiver Bedeutung waren in den von mir exzerpierten Beispielen normalerweise Bestimmungen transitiver Verben. In den Texten kamen aber auch einige intransitive Kontexte völlig ohne verbales Prädikat vor - in ihnen drückt die Nominariv- und nicht die Akkusativform das die Veränderung bzw. den Übergang erfahrende Argument aus -, z.B. Туге гын, мемнан деч тыланда чап дене пагалымаш. (Ončyko 6/1963, 20 OS) 'Wenn es so ist, [kommt] von uns zu euch Ehre und Respekt.' I Счастливцев-Ваштаровлан несчастливцев-Карман о в г в̈̈ и шӓла! (Iljakov, 151-152 WS) 'Dem Glückspilz V. Grüsse vom Pechvogel K.!'

Derartige Kontexte drücken jedoch einen typischen kognitiven Übergang aus. Und doch liegen auch einige Beispiele - vor allem aus Liedern - für solche Satzzusammenhänge vor, die ihrem Charakter nach den kognitiven statischen Kontexten am nächsten stehen und den Ursprung einer kognitiven Entität ausdrücken. Alle von mir verzeichneten Belege stammen aus Texten des habitiv-kognitiven leč-Vertretung'styps und in einigen Belegen steht auch erwartungsgemäss ein leč-Kasus: $m$ âi le ( $t^{\prime} \dot{s}$ e $m$ uruksat ulo. (Beke T IV, 216 B) 'Ich gebe [euch] die Erlaubnis [eigtl. (ihr habt) von mir

findet. In einigen Sätzen, in denen ein Verb des Bittens als Prädikat steht, wird das mit der Trennungskasusform bezeichnete Wesen entweder um Erlaubnis für eine Handlung gebeten, die der Bittende durchführen will, oder es wird um eine andersartige Handlung zugunsten des Bittenden gebeten. Auch in diesen Sätzen, die sich von den eigentlichen kognitiven unterscheiden, steht immer ein habitiv-kognitiver Trennungskasus. Meine Beispiele sind jedoch so spärlich und stereotyp, dass ich sie nicht in einem eigenen Kapitel behandelt habe. Z.B. oźzalets malaš jodeš. (Beke M, $622 \mathrm{Up}$ ) 'Einen Wirt bittet sie um ein Nachtlager

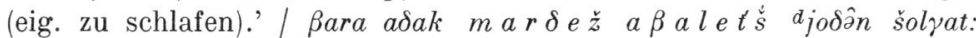

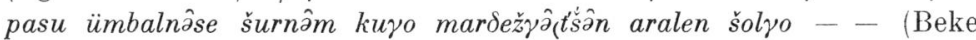
T I, $460 \mathrm{JOk}$ ) 'Dann fleht man noch zur Wind-Mutter: Behüte das Getreide auf dem Feld vor grossem Wind - -'. I keltamäš kattša $\ddot{a} p^{\varphi} \check{s} \ddot{a} t-k$ a ( $t s$ a $n$ : mańam koltâ! (Beke V, $119 \mathrm{~K}$ ) 'Der Teufel bittet den Schmied: Lass mich los!' 
die Erlaubnis (zu spielen und zu tanzen)].' / nemnan deke

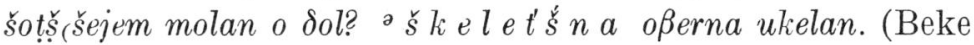
T IV, 313 B) 'Warum kommt mein Verwandter nicht zu uns? Weil er keine Kunde von uns hat.' (S. auch letztes Beispiel S. 71.)

Es ist etwas überraschend, dass in einer anderen Variante aus dem B-Dialekt in dem letztzitierten Lied ein $\delta e c ̌$-Kasus steht, in wieder einer anderen aus demselben Dialekt wie-

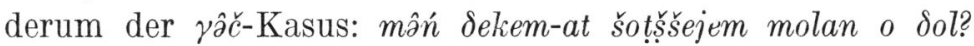
马 ške $\delta$ e ( $t$ 's e em salamem ukelan. (Wichmann V, $428 \mathrm{~B}$ ) 'Warum kommt mein Verwandter nicht zu mir? Darum, weil [er] von mir keine Grüsse [bekommen hat].' I mâj šoț̌šsem-

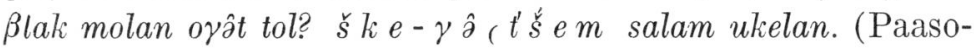
nen-Siro, 127 B) 'Warum kommen meine Verwandten nicht? Weil von mir kein Gruss zu ihnen [gekommen] ist.'

\section{DIE TRENNUNGSKASUSFORM DRÜCKT DAS AGENS AUS}

Im Tscheremissischen wird das Agens sehr selten mittels Trennungskasus wiedergegeben. ${ }^{1}$ Ich habe in den Texten

${ }^{1}$ In der Arbeit von Kangasmaa-Minn, MSFOu 139 (S. 215), sind drei Belege für die agentive Verwendung des Trennungskasus angegeben. In zwei Fällen davon ist der Trennungskasus jedoch anders zu

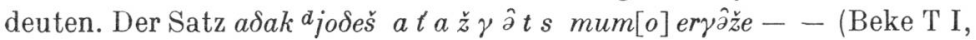
$315 \mathrm{Jt}$ ) wird in dem genannten Werk wie folgt übersetzt: 'The boy whom father had found asks another question'. Die Trennungskasusform gehört jedoch nicht zum Verb muam 'finden', sondern ist eine normale Bestimmung des Verbs joঠam; Bekes Übersetzung lautet denn auch folgendermassen: 'Der Sohn, das Findelkind, bittet wieder seinen Vater - -'. Das zweite Beispiel stammt aus dem Manuskript von Jevsevjev: $\beta$ or-Detš kotšo alašažc $\beta$ üta opsa potš šintšaleś 'The gelding left by the thief remains at the door of the stable.' Das Bezugswort des Trennungskasus lautet in diesem Beleg jedoch nicht kodem 'verlassen', sondern koঠam 'bleiben'; das Beispiel ist ähnlich wie die Belege für das Verb koঠam, die S. 35-38 behandelt wurden. Der Satz müsste so übersetzt werden: 'Der vom Dieb gebliebene Wallach (d.h. vom Dieb nicht genommene) wiehert durch die Stalltür.' Das dritte Beispiel in der genannten Arbeit enthält allerdings einen Agenselativ, 
jedoch zwei sporadische Belege gefunden - auch sie untereinander noch verschieden - , wo der Trennungskasus offenbar den Täter ausdrückt. Sowohl im Beleg aus JT als auch in dem aus $\mathrm{K}$ steht als Trennungskasus der Elativ: pu-on,

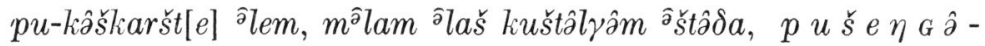

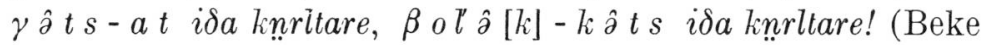
TT, 23 Jt) 'Baum-Fürst[en], ich wohne in einem Holz-Gebäude, machet mir das Leben (eigtl. zu leben) leicht, gestattet nicht einem Baume mich zu erschlagen, gestattet nicht dem Vieh mich zu zerreissen.' / taðəm ikt-ät pâdârten a [k] kertep,

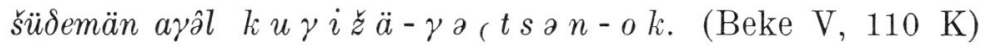
'Die [Kirche] kann niemand niederreissen, auch vom König ist es nicht erlaubt.'

\section{DIE TRENNUNGSKASUSFORM DRÜCKT DEN URHEBER EINER EMPFINDUNG AUS}

Der Trennungskasus begegnet auch als Rektionskasus einiger Verben, die vor allem ein negatives Gefühl ausdrücken; er zeigt an, wer oder was das Gefühl beim Denotat des Subjekts verursacht hat. Ein solcher Trennungskasus steht u.a. bei Verben mit folgender Bedeutung und teils statischem, teils dynamischem Charakter: 'fürchten', 'erschrecken', 'sich genieren', 'bezweifeln', 'sich ekeln', 'etwas satt haben, einer Sache überdrüssig sein'; je ein Beleg enthält eine 'Trennungskasusbestimmung auch bei einem Verb des Sich-Wunderns und des Genug-Kriegens.

An sich ist das Auftreten des Trennungskasus in einem derartigen Zusammenhang logisch gar nicht schwer zu verstehen und unterscheidet sich nicht sonderlich vom sonstigen Gebrauch dieses Kasus. Oben wurde bereits der Kontext 'X entziffert (versteht) das Tatarische' (s. S. 47) behandelt. In diesem Zitat drückt der Trennungskasus aus, worin der

doch stammt die Stelle aus den Evangeliumübersetzungen von Wiedemann und ist eindeutig eine Lehnübersetzung: tolemada, minin $\ddot{a} t \ddot{a}$ g i t s e m jaratemaslä 'Come you who have my father's blessing'. 
kognitive Reiz besteht, der das Denotat des Subjekts erreicht. In dem in diesen Zusammenhang gehörenden Ausdruckstyp имни ар а в а г ӥъ ұ ак ойо (Marijsko-russkij slovar, 398 WS) 'Das Pferd fürchtet keine Wagen' drückt der Trennungskasus арава entsprechend aus, welches der Reiz ist oder von wo er ausgeht, der im Denotat des Subjekts das durch das Prädikat ausgedrückte Gefühl verursacht.

Als Trennungskasusbestimmungen stehen bei den Gefühlsverben regelmässig die habitiv-kognitiven Trennungskasus; Beispiele nach Vertretungstypen:

\section{Der leč-Vertretungstyp}

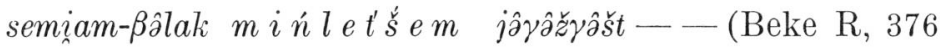
B) 'Die Mitglieder meiner Familie haben vor mir einen Ekel bekommen - - / imniem ojâš pijlet'š (Paasonen-Siro W, 80 B) 'mein Pferd scheute vor einem Hund' / öräm $t u t l e t^{\prime} \dot{s}$ od. $t u \delta \hat{\partial} m$ (Paasonen-Siro W, 87 B) '[ich wundere mich über ihn]' ! pare $\eta \gamma \hat{\partial} l e t$ ' $\dot{s}$ kul'âmâm (Paasonen--Siro W, 51 B) 'die Kartoffeln wurden mir zuwider' / aza-šorle ( $t$ 's $\hat{\jmath} n$ djârnen. (Beke T I, $444 \mathrm{JOk}$ ) '[Die Wolke] bekam Ekel vor dem Säuglingsd[rec]k.' । šoțşmo, kušmo maländalet'ś kö temân. (Beke T' IV, 304 B) 'Wer wird (eigtl. wurde) seiner Heimat satt.'

In einem einzigen hierher gehörenden Beispiel steht der

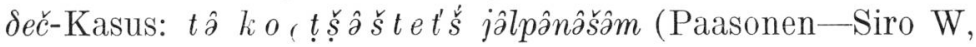
31 B) '[ich wurde dieser Speise überdrüssig].'

\section{Der Vertretungstyp leč $\sim \delta e c$}

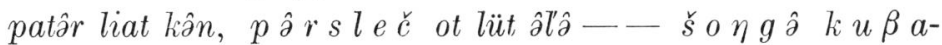
$\delta e \check{c}$ ot lüt âl's. (Porkka-Genetz, $1 \mathrm{M}-\mathrm{i}$ ) 'Wenn du wirklich stark wärest, würdest du die Katze nicht fürchten - - würdest du das alte Weib nicht fürchten.' / mo le t's lü $\delta \hat{a} ? \mathrm{~S}$ / mole $t^{\prime} \dot{s}\left(m o-\delta e t^{\prime} \dot{s}\right)$ lïß $\hat{s}$ ? M-i (Wichmann R, 418) 'Wovor bekam er Angst?'

3. Der $\delta e c$-Vertretungstyp

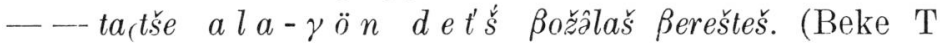
III, $95 \mathrm{Uj}$ ) ' - - man wird sich am selben Tag (eigtl. heute) 
vor jemandem zu schämen haben.' / $K \ddot{o}$ де ч апmранет?

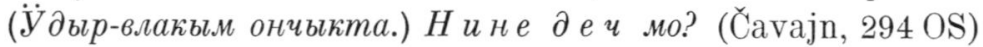
'Vor wem genierst du dich?' (Zeigt auf die Mädchen.) Vor ihnen?' / Шукымко тымарте м арийулм иит деч вожыл коштыныт гын - - (Čavajn, 5 OS) 'Wenn sich auch viele bisher dessen geschämt hatten, dass sie Mari waren - - '.

\section{Der Vertretungstyp lě $\sim \gamma \hat{\partial} \tilde{c}$}

ma $\gamma \hat{\jmath} t s$ (mal ets) lüßa? (Wichmann R, $418 \mathrm{Jl}$ ) 'Wovor

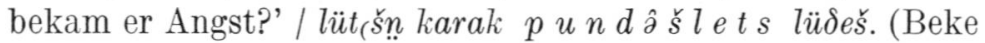
T I, $19 \mathrm{Jo}$ ) 'Die ängstliche Krähe fürchtet sich [auch] vor dem Baumstumpf.' / izir $a[k]-k \hat{\partial} t s$ lüt $[t] a, k u \gamma u r a[k]-$ $k \hat{a} t s \beta$ o zâl $\delta a$ ! (Beke TT, $41 \mathrm{Jt}$ ) 'Fürchtet die Kleineren, schämet euch vor den Grösseren!'

\section{Der $\gamma \hat{\partial} \hat{c}$-Vertretungstyp}

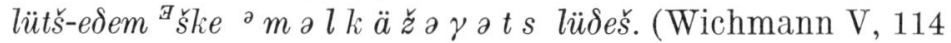
K) 'Der Feigling fürchtet sich vor seinem eigenen Schatten.' / Фашиствлӓ гйц веле агыл, мири й әдемвлӓ г в̈̈ и а $m$ шекланаи вӓрештеш. (Iljakov, 311 WS) 'Es ist nicht nötig, nur die Faschisten zu fürchten, sondern auch die ruhigen Menschen.'

Wie das dritte Beispiel beim 1. Vertretungstyp zeigt, ist es wenigstens in einigen Fällen möglich, statt des Trennungskasus auch das Objekt zur Bezeichnung der Ursache des Gefühls zu verwenden. Offenbar können die einen Trennungskasus enthaltenden Ausdrücke jedoch durchgehend mittels normaler transitiver Sätze ersetzt werden, dann muss aber das Verhältnis zwischen Experiencer und Urheber ganz anders ausgedrückt werden: Prädikat des Kontexts wird dann das Kausativverb, das die Verursachung des Gefühls bezeichnet, der Experiencer wird durch das Objekt wiedergegeben und der Urheber des Gefühls durch das Subjekt. Z.B. je š $e$ -

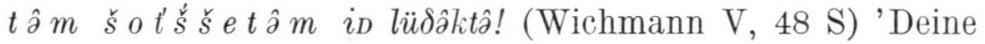
Angehörigen [und] deine Kinder erschrecke nicht!'

In einigen Fällen scheint es, als könne bei den genannten Verben der Dativ den Trennungskasus ersetzen. In der Quelle Paasonen-Siro W beispielsweise stehen hintereinander die 


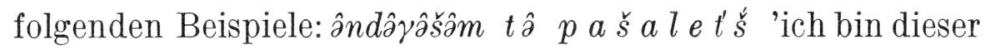
Arbeit überdrüssig' und ândâyâŝâm $t u \delta \hat{\partial} n$ al $a k \hat{s} \hat{\partial} l a n$ 'seine Verleumdungen sind mir zuwider geworden' (S. 170). Offensichtlich ist jedoch, dass die verschiedenen Kasusformen genau genommen nicht völlig synonym sind; der Trennungskasus drückt nämlich in erster Linie die Entität aus, die das Gefühl verursacht, der Dativ wiederum den Grund, warum jene Entität das Gefühl bewirkt. Der Bedeutungsunterschied dieser Formen wird u.a. dann deutlich sichtbar, wenn sie beide im selben Kontext stehen, z.B. Bara kuyâzo peš lüßân $\beta i \eta \hat{\partial} z \hat{\gamma} \hat{t} s$ ti o illan-—(Beke T I, $140 \mathrm{Jt}$ ) 'Ob dieser Rede erschrickt (Prät.) (dann) die Schwiegermutter sehr vor ihrem Schwiegersohn - - I t'šerle $\beta$ at âlet's $u z a k$

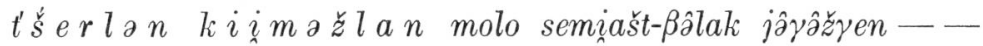
(Beke R, 375 B) 'Da sie schon lange krank lag, ekelten sich die anderen Angehörigen vor jener alten Frau _ — '.

\section{DIE TRENNUNGSKASUSFORM IN FINALER VER- WENDUNG}

\subsection{Der Trennungskasus bei einem Verb des Beschützens}

In Kapitel 2 sind Kontexte behandelt, wo das Denotat von Subjekt oder Objekt mit Hilfe des Trennungskasus mit einer Lokalität in Beziehung gebracht wird. Auch in den Beispielen folgender Art scheint es sich um die Relativierung des Denotats eines im Kontext zwar nicht ausgedrückten

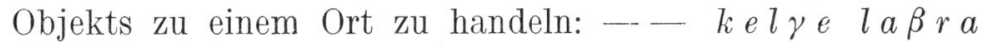
pama šs šnd $d^{\prime} a-\gamma \hat{\partial} t^{\prime} \dot{s}-a t$ saklen-—(Beke R, $715 \mathrm{~B}$ ) '_- bewahrend [das Vieh] von tiefen Pfützen, Quellen - - '. Im folgenden Kontext aber, wo das Prädikat ebenfalls ein 'Schützen' ausdrückt, werden durch den Trennungskasus deutlich keine lokalen Relationen bezeichnet: - - $k u k s \hat{s}$

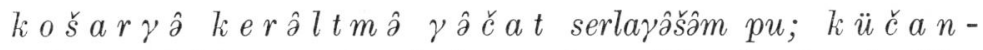

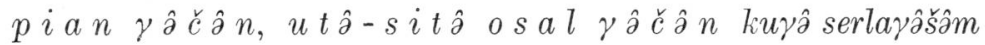
pu —— (Porkka-Genetz, 21 M-i) '- — bewahre [das Vieh] vor dem Stiche von dürren und spitzigen [Zweigen], vor 
Klauen, vor Zähnen [eigtl. vor solchen mit Klauen, mit Zähnen], vor dem Bösen und U̇bel bewahre insbesondere

Meiner Meinung nach bezeichnet der Trennungskasus bei einem Verb oder Verbalnomen des Schützens weder ein lokales noch habitives oder kognitives Verhältnis, sondern hat finale Bedeutung. Unabhängig davon, ob die Trennungskasusform von einem verbalen oder andersartigen Nomen gebildet ist, enthält sie in der Tiefenstruktur einen Hinweis auf die Tätigkeit oder den Vorgang und ist somit eine Art eingebetteter Satz. In dem zuletzt von mir zitierten Biespiel ist die Trennungskasusform von der Nominalform des Verbs gebildet und vertritt somit auch in der Oberflächenstruktur deutlich einen eingebetteten Satz: - - kukšâ košaryâ kerâltmâ

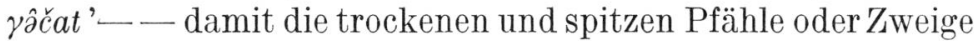
nicht stechen'. Im folgenden Beleg dagegen, der aus demselben Gebet stammt wie das erste Zitat dieses Kapitels, ist die Trennungskasusform kein Verbalnomen, aber trotzdem hat der Ausdruck genau dieselbe Bedeutung: - - k $u k s$ o

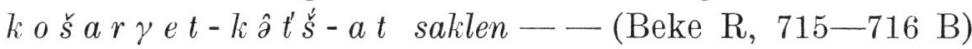
'- - schützend [das Vieh] vor trockenen [und] spitzen [̈̈sten] _ - '.

Jenes Satzäquivalent finalen Charakters, das durch die Trennungskasusform vertreten wird, ist seiner Bedeutung nach immer negativ. Dies hängt zusammen mit dem allgemein im Trennungskasus enthaltenen negativen Bedeutungsmerkmal. McCawley z.B. stellt fest, das allgemeine Bedeutungsmerkmal des Wohin-Kasus sei die Position BEcome IN, das des Trennungskasus die Negation BEcome not IN (McCawley, Prelexical Syntax, 40). ${ }^{1}$

In den Fällen, wo die mit dem Verb des Schützens ver-

${ }^{1}$ Mit dem allgemeinen negativen Merkmal des Trennungskasus hängt offenbar zusammen, dass das Element $\gamma e c ̌ e, ~ \gamma \hat{\partial} \breve{c}(e)$, das vermutlich gleicher Herkunft ist wie das elativische Morphem $\gamma$ ã Ostdialekten an das auf - $\delta e$ endende karitive Verbalnomen treten kann, wodurch gleichsam die karitive Bedeutungskomponente verstärkt wird (s. z.B. Galkin, Istor. grammatika I, 170-171; Alhoniemi, FUF 38, $106-107)$. 
bundene Trennungskasusform ${ }^{1}$ ein Verbalnomen ist, geht die Bedeutung des Prädikats des eingebetteten Satzes hieraus hervor: 'schütze das Getreide vor dem Fressen der Würmer' = 'schütze, damit die Würmer das Getreide nicht fressen'; 'schütze das Vieh vor den Verzaubernden' = 'schütze, dass die Verzaubernden das Vieh nicht verzaubern'. Auch in vielen solchen Fällen, wo ein nichtverbales Nomen als Trennungskasusform steht, ist die für den eingebetteten Satz vorgestellte Tätigkeit völlig klar. Da z.B. das Feuer nur verbrennen kann, ist die Bedeutung des Satzes 'behüte das Haus vor Feuer' zweifellos 'behüte, dass das Feuer das Haus nicht verbrennt'. Es gibt allerdings auch solche Kontexte, in denen die Art der Tätigkeit oder des Geschehens, die man aufgrund der Bedeutungen des Objekts und des Trennungskasus-Adverbials für den eingebetteten Satz erschliessen kann, nicht eindeutig klar ist, z.B. 'behüte das Vieh vor dem Bären' = 'behüte, dass der Bär das Vieh nicht anfällt oder z.B. frisst'; 'behüte uns vor dem Krieg' = 'behüte uns, dass wir nicht in Krieg geraten' oder 'behüte uns, dass wir keinen Krieg bekommen'; 'behüte uns vor dem Bösen' = 'behüte uns, dass uns nichts Böses geschieht' oder 'behüte uns, dass wir nicht in die Gewalt des Bösen geraten' usw.

Die Satzäquivalente, die durch die Trennungskasusform vertreten sind, können grob gesagt in zwei Gruppen geteilt werden. In den einen Kontexten wird das Subjekt des eingebetteten Satzes ausgedrückt durch das Objekt des Rahmensatzes: 'behüte das Vieh vor einer schlechten Brücke' = 'behüte, dass das Vieh nicht auf eine schlechte Brücke gerät'. In den anderen Kontexten wird das Subjekt des eingebetteten Satzes wiederum ausgedrückt durch die Trennungskasusform oder durch den Subjektteil der verbalen Trennungskasusform, z.B. 'behüte das Vieh vor dem Bären oder vor dem Gefressenwerden durch den Bären' = 'behüte, dass der Bär das Vieh nicht frisst'; 'behüte uns vor allem Bösen' = 'behüte uns, dass uns nichts Böses geschieht'.

${ }^{1}$ In den deutschen Übersetzungen entspricht dem tscher. Trennungskasus die Präposition vor. 
In jenen Kontexten, wo das Objekt des Rahmensatzes das Subjekt des eingebetteten Satzes zum Ausdruck bringt und der Trennungskasus von dem die Lokalität bezeichnenden Wort gebildet ist, ist die Gesamtbedeutung der Trennungskasusform also folgende: 'dass (das zu behütende $\mathrm{X}$ ) nicht nach A gerät'. Im gesamten Sprachgebiet wird in diesen Fällen als Trennungskasus der $\gamma \hat{\partial} c$ - oder $\check{c}$-Elativ verwendet. Z.B.

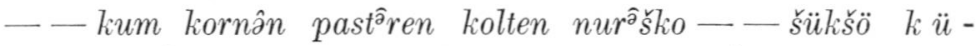

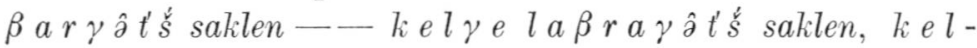

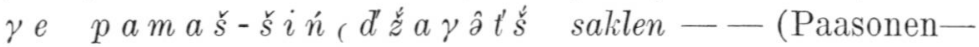
Siro T, 35-36 B) '- - auf drei Wegen zum Acker [das Vieh] fahren - - schütze vor morscher Brücke - - schütze vor tiefem Schlamm, schütze vor tiefen Quellen — _ / _ -

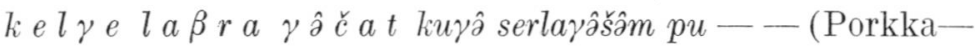
Genetz, 21 M-i) '- - vor tiefem Schmutz bewahre besonders - - I Bolâkâm - - aralen kondâš $[t]$ ta - $k u \gamma o$ $l a \beta r a \gamma \hat{\partial}$ ( $t^{\prime} \dot{s} \hat{\partial} n, \quad k u \gamma o \quad \beta \ddot{u} t k \hat{\partial}$ ( $t^{\prime} \dot{s} \hat{\partial} n, \quad k u \gamma o \quad k o-$ remģ่t's - (Beke T I, 460 JOk) 'Behütet das Vieh — - vor grossem Kot, grossem Wasser, tiefen (eigtl. grossen) Schluchten —- -

In jenen Kontexten, wo als Trennungskasusform ein Verbalnomen in der Bedeutung eines Nomen actionis auftritt,

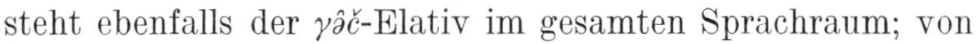
dem auf das Verb verweisende Pronomen begegnet der $\check{c}$-Kasus.

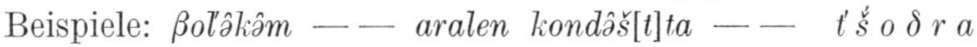

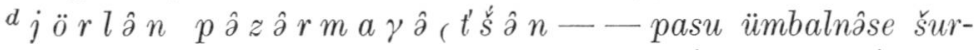

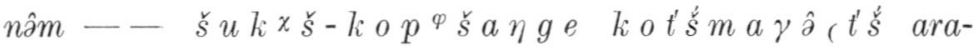
len šolyâ — - (Beke T I, $460 \mathrm{JOk})$ 'Behütet das Vieh —— davor, dass Bäume (Sing.) (eigtl. Wald) auf es stürzen und [es] erdrücken — - behüte das Getreide auf dem Feld - vor dem Benagen des Gewürms, der Käfer - - / - - jân

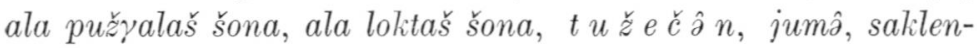

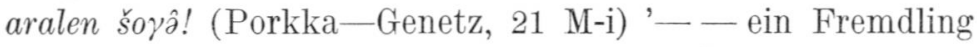
beabsichtigt vielleicht [die Tiere] zu verderben, denkt vielleicht ihr zu schaden; davor schütze sie, o Gott!' / ß

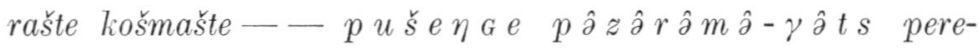
$\gamma \hat{\partial} \delta a !$ (Beke TT, 22 Jt) 'Das Vieh schützet während des Gehens im Walde — - dass der Baum sich nicht auf es stürze 


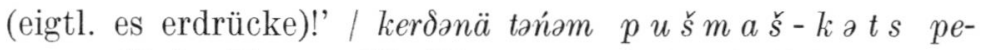
reven. (Beke V, $243 \mathrm{~K}$ ) 'Könnten wir [nur] dich vor der Hinrichtung bewahren.'

In jenen Kontexten, wo die Trennungskasusform auch das Subjekt des eingebetteten Satzes ausdrückt, begegnet dagegen formal eine sehr bunte Vertretung. Die Heterogenität beruht einmal darauf, dass die Praxis in den einzelnen Dialektgebieten offensichtlich in gewissem Umfang schwankt, zum anderen bevorzugen die einzelnen Verben offenbar Trennungskasusbestimmungen verschiedenen Typs.

\section{Der $l e \check{c}$-Vertretungstyp}

Die Bestimmungen des in den verschiedenen Quellen vorkommenden Verbs saklem 'behüten, beschützen', deren es insgesamt über 100 gibt, sind ihrer überwiegenden Mehrheit nach $\gamma \hat{z} \hat{c}$-Elative. In der Quelle Beke $\mathrm{R}$ begegnen allerdings 5 leč-Bestimmungen und in der in mancher Hinsicht exzeptio-

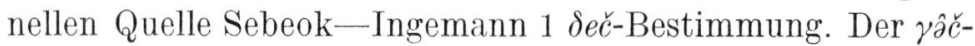
Kasus begegnet in Gebeten allgemein ebenso häufig für ein belebtes wie für ein unbelebtes Denotat, z.B. - - ar $t \ddot{u} r$ $l \hat{\partial} \gamma \hat{\partial} t^{\prime} \dot{s}$ saklen - $-j \ddot{u} t-\beta$ or $\gamma \hat{\partial} t^{\prime} \dot{s}$ saklen, $k e$ c $t \stackrel{s}{s} e-$

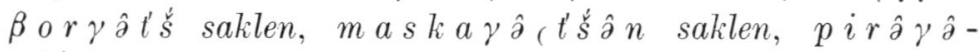
( $t^{\prime} \dot{s} \hat{a} n$ saklen - - (Paasonen-Siro T, 35-36 B) '- schütze [das Vieh] vor allerlei [Bösem] — — schütze vor Dieben in der Nacht, schütze vor Dieben am Tage, schütze vor Bären, schütze vor Wölfen — - '. Wie auch aus diesem Zitat erhellt, kann die Endung $\gamma \hat{\partial} c ̌$ ebenfalls an Wörter treten, die einen Menschen bezeichnen; in den Texten finden sich Dutzende solche Bestimmungen. In zwei Gebeten der Quelle Beke $\mathrm{R}$ wird jedoch eine lange $\gamma \hat{\partial} c$-Kette durch leč-Kasus unterbrochen, die eben von Wörtern für den Menschen gebildet sind; z.B. - n e le a jar šok $k$ e $e t-k \hat{a} t ’ \dot{s}-a t$ saklen, a $\delta$ eme tušmanlet'š́-at, 'kuț̣̌en nalam' man-

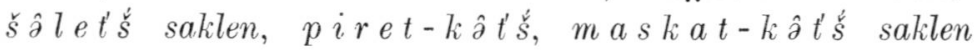
——(Beke R, $716 \mathrm{~B})^{\prime}$ - — schützend sie auch vor schadender Hitze, beschützend sie vor bösen Menschen, Räubern [eigtl. vor 'ich nehme'-Sagenden], beschützend sie vor Wölfen, Bären - - ' 
Ein unbedingter Unterschied zwischen den Trennungskasus verschiedenen Typs besteht jedoch auch in dieser Quelle

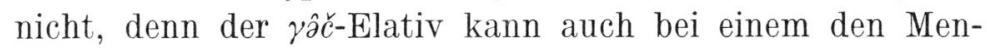
schen bezeichnenden Wort Verwendung finden, und andererseits sind zwei leč-Kasus auch von einem Wort gebildet, das eine Naturerscheinung bezeichnet, z.B. - - a $\delta$ e me $t u \check{s}$ man-gât' š́-at sakle - - (Beke R, 723 B) '- - bewahre [die Bienen] vor bösen Leuten - - ' I - - kok jalnam-at

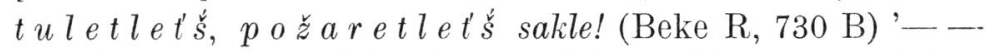
bewahre unsere zwei Dörfer vor deinem Feuer, vor deiner Feuersbrunst!'

Im Text von Sebeok-Ingemann findet sich also der einzige Kontext des Vertretungstyps mit einem $\delta e c$-Kasus: - os a l tǔ́mandě́ sakle. (Sebeok-Ingemann, 78 B) '- - beschütze [uns] vor dem bösen Feind.'

Im Text Beke JOk tritt als Verb des Beschützens aralem auf. Die Bestimmungen dieses Verbs, die eine Naturkraft und ein Tier bezeichnen, stehen ebenfalls im $\gamma \hat{\partial} \hat{c}$-Kasus. Nur einmal tritt der leč-Kasus an das Verb, und zwar in einem Verbalnomen, das 'böser Geist' bedeutet. Z.B. ßol’âkâm - -

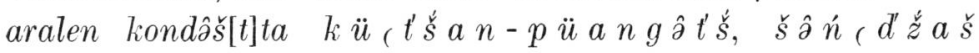
k o i t âmâl let'ś - (Beke T I, $460 \mathrm{JOk}$ ) 'Behütet [das Vieh] — - vor Raubtieren (eigtl. [vor Tieren] mit Krallen [und] Zähnen), bösen Geistern (Sing.) (eigtl. vor nicht in die Augen Fallendem, d.h. dem Unsichtbaren).'

Die Verben des Beschützens šojâštem und pâdalam scheinen vor allem in einigen Dialekten von U aufzutreten. Thre Trennungskasusbestimmungen, die sowohl eine Naturkraft als auch ein belebtes Wesen bezeichnen, sind regelmässig leč-

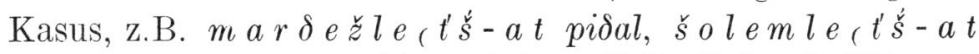

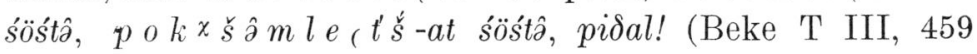
Up) 'Verschone [das Getreide] auch vor dem Wind, bedecke es (auch) vor dem Hagel, bedeck es auch vor dem Frost,

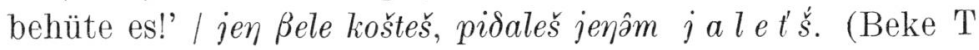
III, 475 Up) '[Der Engel] geht neben dem Menschen und schützt ihn vor dem Teufel.'

2. Der Vertretungstyp lě̌ $\sim \delta e \check{c}$

In den Texten dieses Vertretungstyps haben alle Verben 
des Beschützens, sowohl aralem, pâdalam, saklem als auch ser-

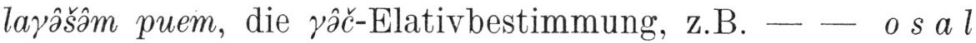

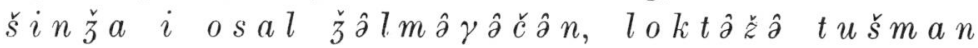

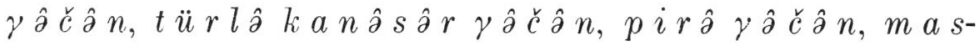
$k a \gamma \hat{\partial} \check{c} \hat{\partial} n$ i $t \ddot{u} r l \hat{\partial} t \ddot{u} r l \hat{\partial} k a i k \gamma \hat{\partial} \check{c} \hat{\partial} n, k u \gamma u \check{z} u m \hat{\partial}$ aralâ! (Porkka-Genetz, 15-16 M-i) '- - bewahre [das Vieh] vor bösem Blick und böser Zunge, vor feindlichen Zauberern, vor jeglicher Störung, vor Wölfen, Bären und aller-

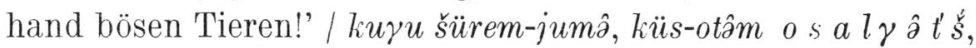

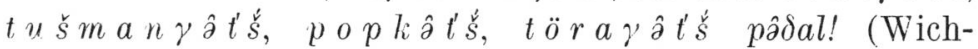
mann V, $29 \mathrm{~S}$ ) 'Grosser šürem-Gott, schütze unsern Opferhain vor dem Bösen, vor Argsinnigen [Menschen], vor den [russischen] Pfarrern und Beamten.'

\section{Der $\delta e c ̌$-Vertretungstyp}

Es gibt insgesamt nur wenige Beispiele hierfür. In ihnen

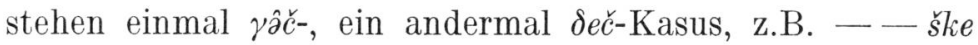

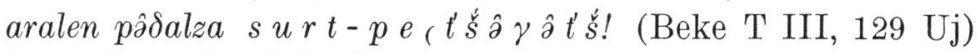
'- - bewache (Plur.), behüte (Plur.) [das Vieh] vor dem Zaun des Hauses!' / tul-aßa, ške serlayâšâm pū tul $\delta e$ (t'šân! (Beke T III, $124 \mathrm{Uj}$ ) 'Feuer-Mutter, behüte mich (du selbst) vor Feuersbrunst (vor Waldbrand[?])!' / Саћлен о с ал де ч нурым, олык-лапымат - - (Ončyko 6/1963, 48 OS) '[Berg], schützend vor dem Bösen das Feld, die Wiese - -'.

\section{Der Vertretungstyp $\gamma \hat{a} \check{c} \sim l e \check{c}$}

In allen Beispielen, unabhängig davon, zu welchem Verb des Beschützens die Trennungskasusform gehört, begegnet von einem Wort mit belebtem wie auch unbelebtem Denotat

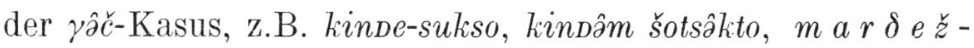

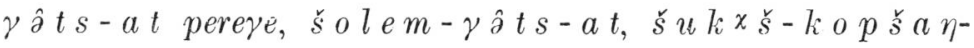

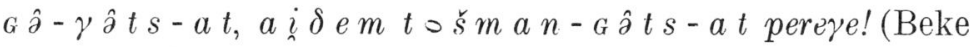
TT, 22 Jt) 'Getreide-Engel, lass' das Getreide wachsen, beschütze es auch vor Sturm, Hagel, vor Würmern, schütze es auch vor feindlichen Menschen!' / tsâße- ${ }^{d} j \circ m \circ m$ komalât: tsâ$\beta \hat{\partial} m \ldots \beta a r a k \chi \breve{s}-k \hat{\jmath} t s-a t m u l-a t$ mndalda! (Beke TT, 23 Jt) 'Den Hühnergött[er]n opfert man [betend]: Die Hühner - - rettet [sie] vor dem Habicht usw.' 


\section{Der $\gamma \hat{\partial} \hat{c}$-Vertretungstyp}

Da in diesem Dialektgebiet eigentlich nur ein Trennungskasus in Gebrauch ist, steht natürlich auch in den diesbezüglichen Fällen stets der $\gamma \hat{\partial} \breve{c}$-Elativ. Belege gibt es wenig, und die stammen alle aus Texten der Schriftsprache, z.B. Кыцә

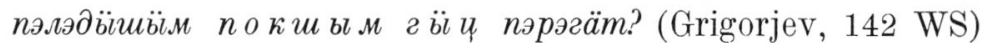
'Wie beschützt man die Blüten [des Apfelbaumes] vor Frost?'

\subsection{Der Trennungskasus bei einem Verb der Errettung, der Verhinderung oder des Ausweichens}

Ein ähnlicher Trennungskasus mit finaler Bedeutung, wie er bei den Verben des Beschützens oben besprochen wurde, kann auch als Bestimmung einiger anderer Verben auftreten. Ein Verb des Rettens z.B. kann natürlich in einem Kontext stehen, der einen typischen lokalen Übergang ausdrückt = 'jemand rettet $\mathrm{X}$ aus A'. Dasselbe Verb kann jedoch auch in einem Satzzusammenhang auftreten, der die Bedeutung hat 'jemand rettet $\mathrm{X}$, damit er nicht nach A gerät'. Der Trennungskasus in einem solchen Ausdruck ist mit den im vorangehenden Kapitel behandelten Verwendungsweisen des Trennungskasus zu vergleichen. In jenen wenigen Kontexten, wo ein solcher Trennungskasus bei einem Verb des Rettens steht, handelt es sich in der Form um einen yấc-Kasus, z.B.

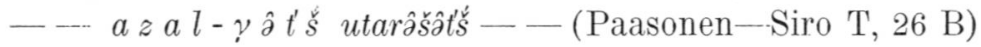
'_- du rettetest [mich] vor dem Tode _ _' / Монденат мо, кузе мый тыйым керем он го г ич утаренам? (Ončyko 6/1963, 15 OS) 'Hast du vergessen, wie ich dich vor dem Galgen rettete?'

In den Texten von WS traten einige Kontexte auf, in denen die Verben der Errettung und des Hinderns eine aus dem Verbalnomen gebildete Elativbestimmung erhielten; hier drückt der Trennungskasus einen Vorgang oder eine Tätigkeit aus, den das Denotat des Objekts nicht zu vollziehen braucht oder deren Gegenstand es nicht wird, z.B. М̈̈̈нь

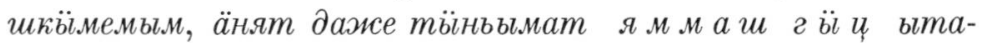
рынем. (Iljakov, 34 OS) 'Ich möchte mich retten, vielleicht auch dich, vor dem Verderben.' / Теве малын мӥць тӓмдан поэмыдам пе ия атлым аш г ӥ цч иӓренам. (Iljakov, 178 
OS) 'Das ist gerade der Grund, weshalb ich zu verhindern versuchte, dass Ihre Dichtung gedruckt würde.' / _ _ d dä тидығы Зоя Георгиевнам халаш кемаш гыц кычен - - (Iljakov, 358 OS) '-.- und dies [die Verschlechterung des Zustandes des Grossvaters] hinderte Z.G. daran, in die Stadt [wohnen] zu gehen.'

Es gibt viel mehr Beispiele für Fälle, wo durch den Trennungskasus mit finaler Bedeutung die Entität ausgedrückt wird, die eine Handlung ausdrückt, deren sich das Denotat des Subjekts eines intransitiven Satzes oder des Objekts eines transitiven Satzes entzieht. In den von mir gesammelten Belegen steht als Trennungskasusform ein Wort, das ein belebtes Wesen oder eine Naturkraft bezeichnet. Anders als in den Bestimmungen der Verben des Beschützens, bei denen die $\gamma \partial \hat{\partial} c ̌-T r e n n u n g s k a s u s$ auch von +Anim-Wörtern in beachtlich starker Verwendung sind, treten als Bestimmungen der anderen Verben regelmässig die habitiv-kognitiven Trennungskasus auf. Beispiele nach Vertretungstypen; für den 4. Vertretungstyp liegen keine sicheren Belege vor:

\section{Der leč-Vertretungstyp}

- — o $\beta \delta a ~ k u \beta a$ šind d’a śilaltân us mak le t'ś. usmak maněs: man kaišât's mele ( $t$ 'ś e m? (Beke M, $506 \mathrm{Up})$ '- - die o $\beta \delta a$ ist [dort], sich vor dem Narren versteckend. Der Narr sagt: Warum verschwandest du vor mir?' / tu śurtâškâ kajen śilân te le ct'śet. (Beke M, $294 \mathrm{Up}$ ) 'In jenes Haus flüch-

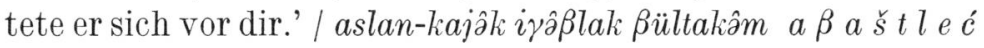
šâlten šândat. (Genetz, $16 \mathrm{P}$ ) 'Die Jungen der Löwin verstecken $\beta$ ültak vor ihrer Mutter.'

\section{Der Vertretungstyp lě̌ $\sim \delta e \check{c}$}

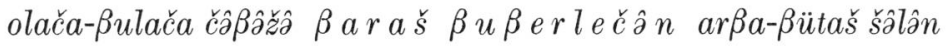
koঠeš_-(Porkka - Genetz, $58 \mathrm{M}-\mathrm{i}$ )' Das bunte Huhn vor dem bösen Habicht in der Spreuscheune sich verbergend weilt _-_'.

\section{Der $\delta e c ̌$-Vertretungstyp}

- — pâkx̌se uDlenam $t u n$ de (t'šs ân. (Beke T III, 160 Uj) ' - - ich konnte kaum vor ihm [vor dem KälteAlten] entfliehen.' / Kызыт ни гӧ де ч нимам от шылте. 
(Ončyko 6/1963, 15 OS) 'Jetzt versteckst du vor niemandem etwas.' / Имне по рмо деч шылыц кудалын. (С̆avajn, 218 OS) 'Das Pferd floh vor den Bremsen.'

\section{Der $\gamma \hat{\partial} c$-Vertretungstyp}

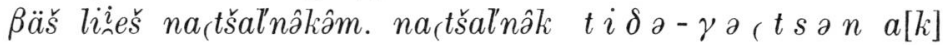
karang. (Beke V, $256 \mathrm{~K}$ ) '[Der Mann] begegnet dem Gouverneur. Der Gouverneur weicht ihm nicht aus.' I — - только

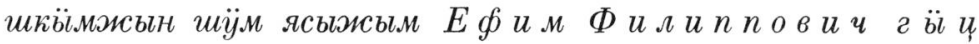
таен моштен. (Iljakov, 236 WS) '_- nur die Sorgen seines eigenen Herzens vor J.F. verbergen könnend.' / Ләнин

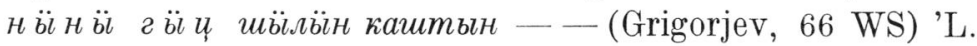
floh sie [die Polizisten] _-

\subsection{Der Trennungskasus als Satzbestimmung}

Ein negatives finales Satzäquivalent mit entsprechender Bedeutung, das in den in den vorangehenden Kapiteln behandelten Kontexten als Bestimmung des Verbs auftritt, kann auch als Satzbestimmung stehen. Dann ist die Trennungskasusform i.a. ein Verbalnomen; auch in dieser Verwendung ist aber ein andersartiges Substantiv nicht ganz unbekannt, wie aus dem letzten Beispiel des 1. Vertretungstyps ersichtlich ist. Als Verbalnomen begegnet in solchen Fällen im gesamten Sprachgebiet das auf -me auslautende Nomen actionis, in $\mathrm{W}$ daneben üblicher auch das auf -maš endende. Als Trennungskasus sind die habitiv-kognitiven Kasus in regelmässigem Gebrauch. Das Subjekt des Satzäquivalents kann durch ein an das Verbalnomen tretendes Possessivsuffix ausgedrückt sein oder durch eine getrennte Nominativ- oder Genitivform; allerdings kann es auch wiedergegeben werden durch irgendein Glied des Hauptsatzes, wenigstens durch dessen Subjekt, Objekt oder Dativadverbial. Beispiele nach Vertretungstypen:

\section{Der leč-Vertretungstyp}

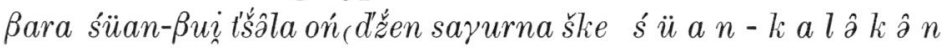
$k$ o $t m \hat{z} l$ e $t^{\prime} \dot{s}$. (Beke T I, $485 \mathrm{JOk}$ ) 'Hierauf besieht sich das "Haupt der Hochzeit" alles und kehrt um, damit die Hoch- 
zeitsgäste nicht zurückbleiben.' I —- - ti pušengâškâ t'śilan malana puraš $t i$ jür le t'ś! (Beke M, $433 \mathrm{Up}$ ) '- — wir alle [müssen] vor dem Regen in diesen [hohlen] Baum hineingehen.'

\section{Der Vertretungstyp lě̌ $\sim \delta e \check{c}$}

ka $i \quad \beta \hat{\partial} \check{c} m \hat{\partial} \delta e \check{c}$ [? $\beta$ oč-] sairak šinžam-— (PorkkaGenetz, $11 \mathrm{M}-\mathrm{i})$ 'Um nicht herunterzufallen, setze ich mich besser - - I oń (d’ẩ̆ktâ mâlam (mâlanem) kornâm jom-

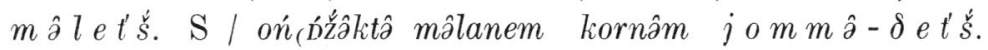
M-i (Wichmann R, 665; im Satz steht in der Version von $\mathrm{M}$ und $\mathrm{Jl} l e c ̌$, in der von $\mathrm{K} \gamma \hat{\partial} \check{c})$ 'Zeig mir den Weg, damit ich mich nicht verirre.'

\section{Der $\delta e \check{c}$-Vertretungstyp}

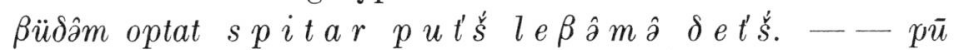

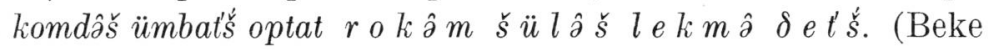
T I, 552 JOü) 'Das Wasser wird (darum) hineingegossen, damit die Terpentinröhre nicht schmelze. - - Auf den Holzdeckel wird Erdreich geworfen, damit die Luft nicht entweiche.' I - - тудо сар ыикелогалме дечын шылын - - туныктышылан кайшым. (Čаvajn, 7 OS)' - damit ich nicht in jenen Krieg geriet, — — ging ich als Lehrer.'

\section{Der Vertretungstyp leč $\sim \gamma \partial \hat{a}$}

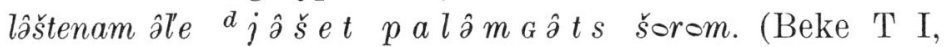
$114 \mathrm{Jt}$ ) 'Ich habe es nur darum in D . . . k verwandelt, damit es deine Familie nicht bemerkt (eigtl. erkennt).' / ko(tso me-

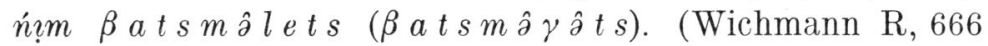
$\mathrm{Jl}$; in den Varianten aus $\mathrm{M}$ und $\mathrm{S}$ desselben Beispielsatzes steht der leč-Kasus, in der Variante aus M-i der deč-Kasus und in der Variante aus $\mathrm{K}$ der $\gamma \hat{\partial} \hat{c}$-Kasus) 'Halte mich fest, damit ich nicht falle.'

\section{Der $\gamma \hat{\partial} \hat{c}$-Vertretungstyp}

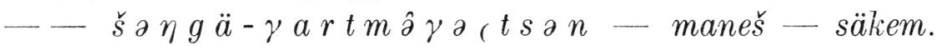
(Beke V, $266 \mathrm{~K}$ ) '—— damit das Gewürm es nicht sticht, [deshalb] breite ich [die Unterhose über das Pferd], sagt er.'

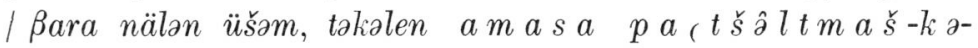


( $t$ s a $n$. (Beke V, $134 \mathrm{~K}$ ) 'Da nahm er einen Schlegel, lehnt ihn an die 'Tür an, damit sie nicht aufspringen kann.' / - -

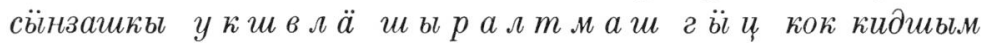
анзыкыла виктен шӥнда. (Iljakov, 312 WS) '- - er streckt seine beiden Hände nach vorn, damit [ihn] die Zweige nicht

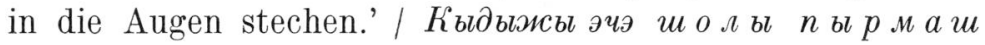
г в̈ь и амасам оролат. (Grigorjev, 118 WS) 'Einige [Bienen] bewachen noch die Tür, damit die Diebe nicht hineinkommen.'

Der Trennungskasus mit finaler Bedeutung kann durch einen negativen Satz ersetzt werden; gute Beispiele hierfür findet man u.a. unter den von Wichmann aus den einzelnen Dialekten gesammelten Sätzen, z.B. tojâ $t u \delta \hat{\partial} n m u m \hat{\partial} l e t ' s$. $\mathrm{S}=t a j \hat{\partial}, t ә \delta \partial^{\partial}$ n ž [es], damit er [es] nicht findet.'

In den östlichsten Dialekten aber kann die negative Trennungskasusform des me-Verbalnomens mit finaler Bedeutung auch durch die Genitivform des $\delta$ âmaš-Verbalnomens ersetzt werden; in dieser Form wird die Negation also angezeigt

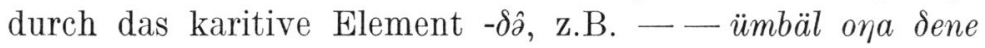
kolatkam petrat šâp rok purtumaš ân. (Beke R, 391 B) '__ sie schliessen den Sarg mit dem Deckel gut zu, damit

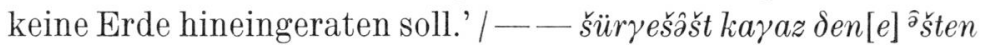
süretâm pâžâktat je $\eta$ pal thâma š ân. (Beke T IV, 184 B) '__ - vors Gesicht binden sie sich Masken (eigtl. ein aus Papier verfertiges Bild), damit sie von niemandem erkannt werden.'

\section{DIE TRENNUNGSKASUSFORM DRÜCKT DAS VERHÄLTNIS EINER TÄTIGKEIT ODER EINES ZUSTANDES ZUR LOKALITÄT AUS}

\subsection{Der Trennungskasus in terminativer Verwendung}

9.1.1. Der Trennungskasus bezeichnet die Grenze des Befindens einer Entität

Als terminative Trennungskasus treten die $\gamma \hat{\partial} \breve{c}$ - und $\breve{c}$-Elative auf. Der eine Grenze ausdrückende Trennungskasus wird oft verstärkt durch die postpositionsartige Nominalform des 


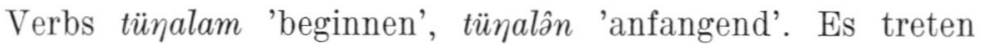
jedoch auch Texte auf, in denen andere Formen dieses Verbs vorhanden sind.

In jenen Konstruktionen, in denen ein terminativer Trennungskasus steht, befindet sich sehr oft auch ein terminativer Wohin-Kasus. Der Wohin-Kasus ist der Form nach ein Illativ, an den die zur Postposition gewordene Nominalform des Verbs šuam 'eintreffen, ankommen' treten kann, šumeš(ke) 'bis'. Andererseits kann der eigentliche Illativ in diesen Kontexten auch ersetzt werden durch z.B. eine Postpositionskonstruktion mit marte 'bis' und jotke 'bis'.

Die terminativen Veränderungskasus können die Grenzen der Dimension einer Entität ausdrücken; auf diese Weise kann man gleichsam den "Seinszustand» der Entität eingrenzen. In einem statischen Satz, der gleichzeitig sowohl einen terminativen Trennungs- als auch Wohin-Kasus enthält, begegnet als Prädikat ein Verb der Ausdehnung oder bloss des

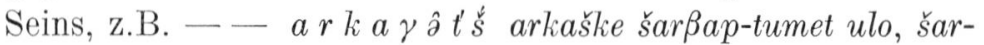
ßap-pištet ulo — - (Paasonen-Siro T, 41 B) '- — von Berg zu Berg sind deine Eichen und deine Linden, in welche ein Bienennest gehöhlt wird - - / $i$ ta $\gamma \hat{\partial} r \hat{\partial} k-k \imath t s \quad i \hat{\partial} l$ iakte alâk ulâ. (Ramstedt, $190 \mathrm{~K}$ ) 'Und unterhalb dieses Berges [eigtl. von diesem Berg an] ist bis an die Wolga eine Wiese.' / T ы ие ч ы н а т корно - - ял воктенысе амбарвлаћ деке иуйна. (Ončyko 6/1963, 71 OS) 'Von dort reicht der Weg zu den neben dem Dorf befindlichen Speichern.' /

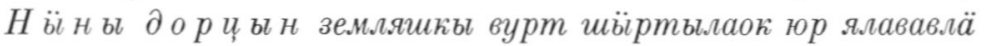
кечалтыныт. (Iljakov, 25 WS) 'Von ihnen [den Wolken] her hingen Regenfransen bis zur Erde wie Litzenzwirn.'

In einem solchen Ausdruck, wo lediglich der Anfangspunkt einer Position mitgeteilt wird, tritt als Prädikat das Verb tünalam 'beginnen' auf, z.B. Туие ч ы н Кумыж корем тӥні алеи. (Ončyko 6/1963, 90 OS) 'An dieser Stelle beginnt die K. - Schlucht.'

Die bisher angeführten Ausdrücke haben statischen Charakter. Die Grenzen der Dimension der Entität können jedoch durch ganz entsprechende Veränderungskasus auch in Kontexten ausgedrückt werden, in denen es sich um die zukünftige 
Lage der Entität handelt. So weisen also die terminativen Konstruktionen keinen formalen Unterschied auf, ob nun die Dimension von hier bis dort mittels eines statischen Prädikats als konstant oder mittels eines dynamischen Prädikats als erst beginnend beschrieben wird. Belege für dynamische

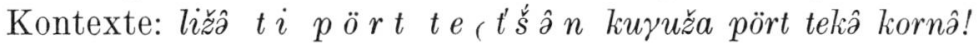
(Beke M, 139 Up) 'Von diesem Hause soll ein Weg zum

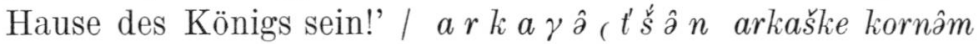
š̈̈̊üm - - (Beke T IV, 285 B) 'Von einem Hügel zum anderen, haute ich einen Weg-_' / par ( $t^{\prime} \dot{s} a \gamma \hat{\partial} t^{\prime} \dot{s} t u ̈-$

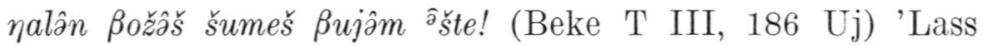
(eigtl. mache) seinen Kopf von der Ähre bis zur Wurzel

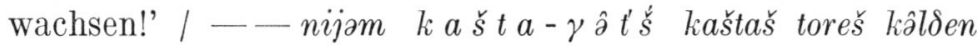
—— (Beke R, 394 B) '—— sie binden von einem Balken zum anderen quer Lindenbast - - '.

9.1.2. Der Trennungskasus bezeichnet das Verhältnis der Position von Entitäten

In den obenstehenden Kontexten ist die Lage einer Entität mittels ihrer Grenzen ausgedrückt. Durch terminative Veränderungskasus kann man aber ausser der Lage einer Entität bezüglich der Lokalität auch das Verhältnis der Lage zweier Entitäten zum Ausdruck bringen; dies geschieht in der Konstruktion "Von $\mathrm{A}_{1}$ nach $\mathrm{A}_{2}$ besteht die Entfernung X». Belege; $\mathrm{zu}$ beachten ist die typische terminative Wohin-Kasuskonstruktion im letzten Kontext: aクaže ulmaš nal bič uštašlieš jald e č. (Sebeok-Ingemann, 65 B) 'Das Feld lag in einer Entfernung von $4-5$ Werst vom Dorf.' / — - jal mündar ogal ulmaš; $t$ u b e č a n kok uštaś-kana ja l b o k te ě. (Sebeok - Ingemann, 70 B) '- - das Dorf war nicht weit weg, von

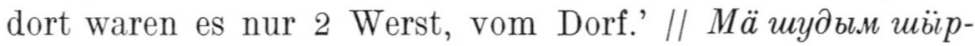

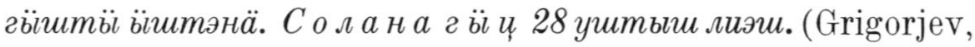
5 WS) 'Wir machen im Wald Heu. Von unserem Dorf sind

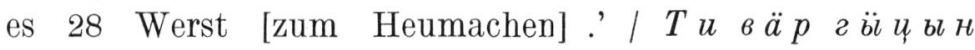
передовой линийышкат вйц уштыли - - ылын. (Iljakov, 275 WS) 'Von diesem Ort zur vordersten Linie - - - waren es

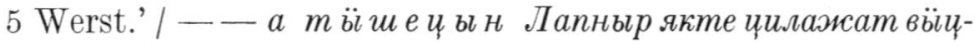


куд уитыи веле лиэи ... (Iljakov, 12 WS)' - - aber von dort sind es bis nach L. nur 5-6 Werst ....

Zur Tiefenstruktur dieser Ausdrücke - nicht immer zur Oberflächenstruktur - gehören regelmässig zwei Entitäten, von denen die eine in der Oberflächenstruktur allgemein in der Form des Trennungskasus, die andere in der des WohinKasus steht. Die Veränderungskasus zeigen in diesen Kontexten einmal die äussersten Grenzen des Gebietes - einer Strecke oder Entfernung - an, das sich zwischen zwei Entitäten befindet, zum andern aber wird auch die Entfernung der Position der Entitäten voneinander ausgedrückt.

9.1.3. Der Trennungskasus bezeichnet die Grenze einer Tätigkeit oder eines Zustandes

Durch die terminativen Veränderungskasus kann auch die Lokalität angezeigt werden, durch die die im Verb ausgedrückte Tätigkeit oder der Zustand begrenzt wird. Im ersten der folgenden Zitate handelt es sich z.B. nicht darum, dass durch das Kehren etwas von einem Ort an einen anderen befördert wird, sondern es geht darum, dass dieses Kehren von irgendwo bis irgendwohin reicht; im zweiten Beleg soll nicht zum Ausdruck gebracht werden, dass das Wasser vom Kopf auf den Schwanz übergeht, sondern dass das Giessen

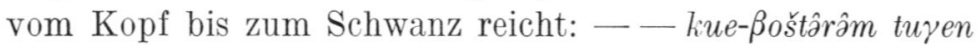

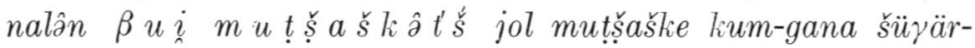
ümbälžsm üštülüt —- (Beke R, 391 B) '- — sie brechen einen Birkenzweig ab, kehren damit vom Kopf [des Toten] bis zu den Füssen das Grab dreimal ab - - / — - šola

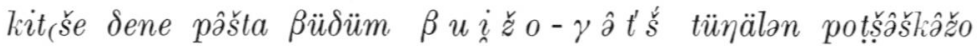
šumeške. (Beke R, 712 B) '- - er giesst mit seiner linken Hand Wasser auf es [= das Füllen], vom Kopf bis zu seinem

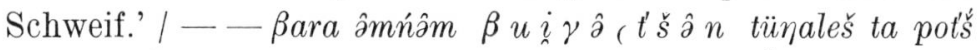
šumeške djayalden kaja olmašs. (Beke T I, 462 Č) '- - [der Mann] streichelt (dann) [damit] das Pferd langsam vom Kopf (eigtl. beim Kopf beginnend) bis zum Schweif.'

Ein solcher Ausdruck kann auch ein nominales Prädikat 


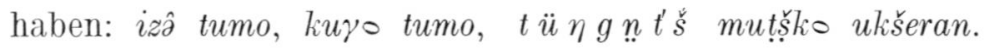
(Wichmann V, 460 B) 'Die kleine Eiche, die grosse Eiche (alle beide) sind sie voll Äste von unten bis zum Wipfel [eigtl. astig vom Wurzelende bis zum Wipfel].'

In allen oben angeführten Beispielen begegnet gleichzeitig ein terminativer Trennungs- wie auch Wohin-Kasus. Der Trennungskasus kann allerdings auch allein auftreten. Auch dann steht als Prädikat häufig tünalam 'beginnen', z.B. К у и е ч тӥні алаи ончыкта. (Ončyko 6/1963, 29 OS) 'Wo man [mit dem Lesen] anfangen soll, zeigt er.' / Тӓ, Миняев дон Ваштаров, литературым пии яратеда, седындон мӥьнь тӥ г й ияда тӥнгалаш решенам. (Iljakov, $49 \mathrm{WS}$ ) 'Ihr, M. und V., liebt sehr die Literatur, deshalb beschloss ich, bei euch anzufangen [mit der Gründung eines Literaturzirkels].'

Oben sind Belege angeführt, in denen die Veränderungskasus eindeutig terminativer Natur sind. An sich gibt es jedoch viele Kontexte, in denen mit Hilfe derselben Trennungs- und Wohin-Kasus sowohl Ankunfts- und Ausgangspunkt einer Entität als auch die Grenzpunkte der durch das Verb ausgedrückten Handlung mitgeteilt werden. Falls der letztgenannte Gesichtspunkt betont ausgedrückt werden soll, kann auch in diesen Ausdrücken tünalân 'anfangend' mit dem Trennungskasus verbunden werden, z.B. Мый шке, Сукар ка з ич тӥніалын, Кумсмарии иумеш нунын дене пьиля куржылм. (С̆avajn, 329 OS) 'Ich selbst angefangen bei

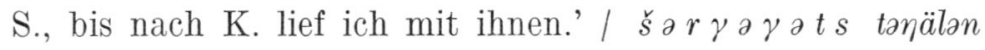
tiškeßek šomeškə ik eঠeməm-ät šəä už. (Wichmann R, $143 \mathrm{~K}$ ) 'Vom Wald angefangen bis nach hier sahen wir keinen Men-

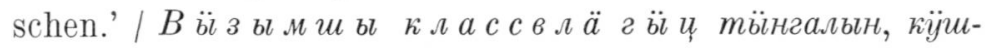
кыла цุила классвлӓшкы кеда - - (Iljakov, 49 WS) 'Geht von den fünften Klassen an nach oben in alle Klassen - - '.

Andererseits kann auch die terminative Beschaffenheit des Trennungskasus mitunter mittels der Postposition šumeš(ke) zum Ausdruck gebracht werden, z.B. Москв а гы и шумешке ені ойльмо қузе шокта.? (C̈аvajn, 156 OS) 'Wie kann man des Menschen Rede bis aus Moskau hören?' 


\subsection{Der Trennungskasus in prolativer Veriendung}

9.2.1. Der Trennungskasus drückt die Lokalität aus, durch die die Position der Entität verläuft

Die Prolativität wird im Tscheremissischen i.a. durch eine prolative Postposition bezeichnet, von denen $\beta$ ošt 'durch,

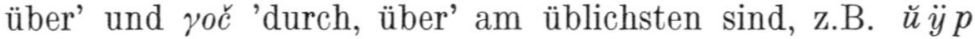
в о шт каяи (Marijsko-russkij slovar, 77 OS) 'durch den Re-

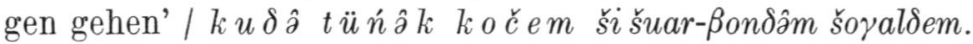
- kečâ. (Porkka-Genetz, 26 M-i) 'Durch das Rauchloch meines Kochhauses stelle ich einen silbernen Mörserstössel. Der Sonnenschein.'

Äusserst allgemein ist aber auch die prolative Verwendung der lokalen Trennungskasus, des $\gamma \partial \hat{\partial} c ̌-$ und des $\check{c}$-Elativs. Die prolativen Trennungskasuskontexte teilen sich grob gesagt in zwei Gruppen. In der einen wird durch den Trennungskasus die Lokalität angegeben, durch welche die Position der Entität verläuft. Beachtenswert ist, dass auch in diesem Fall die Trennungskasus in derselben Weise verwendet werden, unabhängig davon, ob der Ausdruck statisch ist ("Die Position von $\mathrm{X}$ verläuft durch A») oder dynamisch ("Die Position von X wird zum Verlaufen durch A gebracht») (vgl. S. 94). Zunächst Belege für statische, dann für dynamische Kontexte:

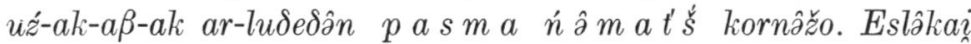
Sene Iźâkaižžn $\beta i$, $t^{\prime} \dot{s} a$ š ojât' $t^{\prime}$ kornâžo. (Beke T IV, 340 B) 'Das Männchen und das Weibchen der Wildente nehmen (Sing.) ihren Weg unter dem Steg [eigtl. der Weg der männlichen und weiblichen Wildente (ist) unter dem Steg hindurch]. Eslâkai-s und Iźâkain-s Weg [führt] hinter den Stall.' / š ü$\gamma \ddot{a} r l \ddot{a} \beta$ oktet'šše korno. (Beke R, 45 B) 'Der Weg [führt] am Friedhof vorbei.' / nem na n jal pokšet'śs n

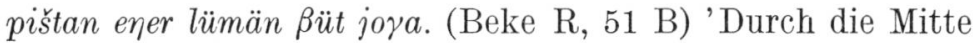
unseres Dorfes fliesst der Fluss pištan ener.' / $K$ y n no $k$ ше ч иь н канаве кӥнчымӧ. (Čavajn, 258 OS) 'Mitten durch

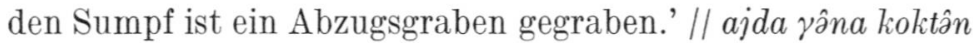

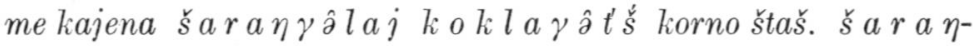

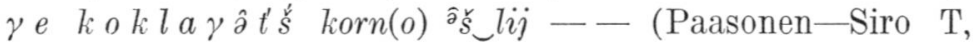
118 B) 'Lasst uns zu zweien gehen zwischen den Weiden einen 
Weg zu machen. Es ist kein Weg zwischen den Weiden ge-

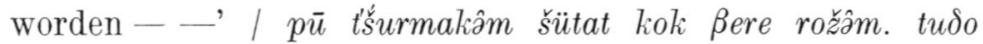

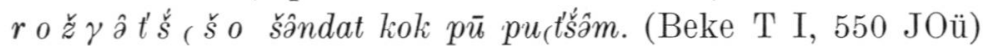
'Diese (eigtl. die Holzröhre) wird an zwei Stellen durchlöchert. In diese Löcher steckt man zwei Holzröhren.' / kerm $\hat{\partial} t^{\prime} \dot{s}$ $\ddot{u} m b a t^{\prime} \dot{s}$ kŝšskat ošmam. (Beke T I, 550 JOü) 'Man streut

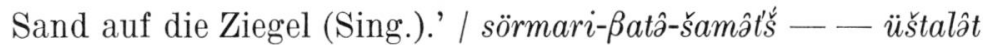

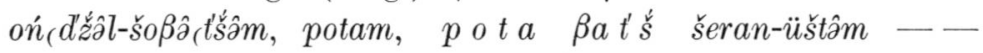
(Wichmann V, 38 S) 'Die Geleitsfrauen — - tun sich um eine Schürze, einen Gürtel, über den Gürtel einen mit Perlen

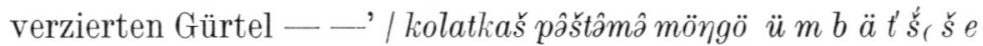
kut Bineram pâštat ške kutušužum kum paț̣̌aš - - (Beke R, 388, B) 'Nachdem sie ihn [den Toten] in den Sarg gelegt haben, legen sie der Länge nach in drei Schichten Leinwand auf ihn _- -' / Памаи шинчамым кӥ дене петыраи, ӱм ба чи е оимам оптаи - - кӥлеш. (Čavajn, 253-254 OS) 'Eine Quellader muss man — - mit Steinen verschliessen, darüber muss man Sand werfen.' / И шїралтымым шылтен от керт. (Ončуko 6/1963, 101 OS) 'Dass über die eine Farbe eine andere gestrichen ist, kannst du nicht verbergen.'

Wie aus den zuletzt angeführten Beispielen hervorgeht, kann die Verwendung des hier behandelten Trennungskasus in der Praxis den zentralen Verwendungsweisen des WohinKasus sehr nahe kommen; das sieht man z.B. an den deutschen Úbersetzungen der Belege. Im Prinzip besteht natürlich auch in diesen Fällen ein Unterschied zwischen den Wohin-Kasus- und den Trennungskasusausdrücken. Während die Wohin-Kasusform ausdrückt, wohin etwas kommt, zeigt die Trennungskasusform an, dass die Position von etwas, was durch ein mit dem Trennungskasus bezeichnetes Gebiet verläuft, dieses gleichzeitig deckt. Im zweitletzten Beispiel drückt der Trennungskasus z.B. aus, dass der Sand über die Quellader reichen muss, während der entsprechende WohinKasus lediglich besagen würde, dass auf die Quellader Sand geschüttet werden muss. 
9.2.2. Der Trennungskasus drückt die Lokalität aus, durch die eine Handlung gerichtet ist

Der prolative Trennungskasus kann ausser dem Durchzugsort der Position einer Entität auch die Lokalität angeben, über die oder durch die hindurch die durch das Verb ausgedrückte Handlung oder der Vorgang gerichtet ist. In den meisten Fällen meines Beispielmaterials - allerdings nicht immer - steht als Bezugswort des prolativen Trennungskasus ein Übergangsverb. Verschiedene Relationsausdrücke bilden wiederum die deutliche Mehrheit der Trennungskasusbestimmungen: es sind Postpositionen oder solche Nomina, die als zweite Komponente eines Kompositums oder als Bezugswort eines Attributs einen Teil des Denotats vom vorangehenden Nomen ausdrücken, oder dann solche Adverben wie 'von oben', 'von unten', durch die die im Verb ausgedrückte Handlung in Höhenrichtung in Beziehung gesetzt wird. Diese Verwendung des Trennungskasus steht also in deutlichem Zusammenhang mit jenen 'Relationsausdrücken', die S. 108-112 behandelt werden.

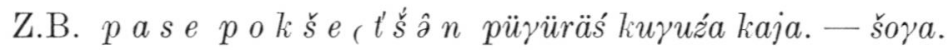
(Beke T IV, 155 B) 'In der Mitte des Feldes geht ein buckliger alter Mann. - Der Pflug.' / kurśśa kuralmaš a $\eta$ a $\beta a t^{\prime}{ }^{\prime}$. (Beke M, 419 Up) 'Laufet um die Wette auf dem

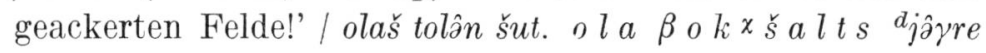
kodalàt. (Beke T I, $340 \mathrm{Jt}$ ) 'Sie gelangen in die Stadt [und] reiten nebeneinander mitten durch die (ganze) Stadt.' / ke(k)-

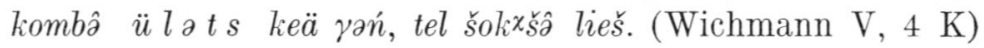
'Wenn die Wildgänse niedrig fliegen, wird der Winter warm.'

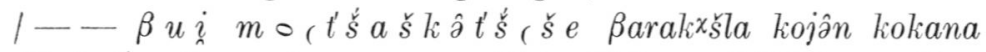

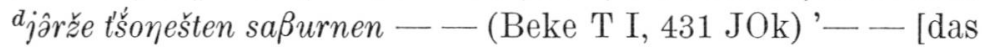
Kind] flog in Gestalt eines Habichts über seinem [= des Mannes] Kopf zweimal im Kreis [herum] -

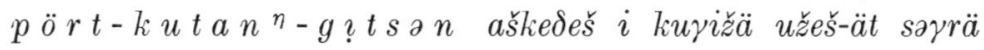
- - (Ramstedt, 179 K) 'Er steigt am Giebel des königlichen Hauses vorbei, und der König erblickt ihn und ruft ihm zu - - / šim kek kašteš ar š ân kü kx š ats-kəts - - (Beke V, $23 \mathrm{~K}$ ) 'Ein schwarzer Vogel fliegt (eigtl. geht) 
in einer Arschin (Elle) Höhe - - / Кожер ан корем покиеч алаша пакман йорта. - Чу! Ончал-я! Те р во ктеч мо тыце кудал эрта? (Ončyko 6/1963, 74 OS) 'Inmitten des tannenreichen Tals läuft träge der Wallach. Aber! Sieh mal! Was läuft neben dem Schlitten so einher?' [Aus einem Gedicht 'Der Hase'].' / Шагавуй тӧр ак кә - - йужнамжьы

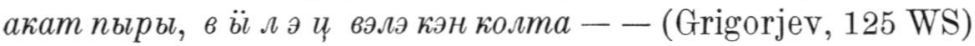
'Der Pflug geht nicht gleichmässig — - manchmal geht er nicht hinein, berührt nur die Oberfläche ——' / By u м в ч а и г ӥ ияо $к-$ - самолетвлӓ чонгештат. (Iljakov, 213 WS) 'Über den Kopf hinweg — - fliegen die Flugzeuge.'

Es gibt auch eine ganze Reihe solcher Kontexte, in denen die Trennungskasusform eine Öffnung bezeichnet, durch die hindurch man geht oder handelt, oder einen Weg, den entlang

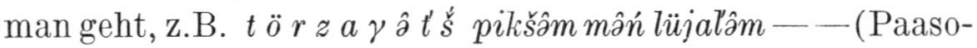
nen-Siro T, 175 B) 'Durch das Fenster schoss ich einen Pfeil - - ' tâje (tâne) puro, maneš, t â ro z ž â ( t'śŝn! (Beke T IV, 413 B) 'Geh du durch dieses Loch hinunter (sagt er)!'

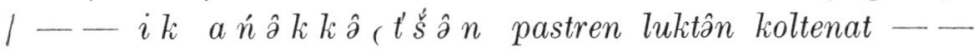
(Paasonen-Siro T, 51 B) '- - aus einer Zauntür [das Vieh] hinaustreiben - - / popšâ o kn a $\gamma$ â č užân - - (Porkka -Genetz, 2 M-i) 'Der Priester sah zum Fenster hinaus - - '

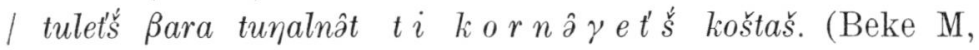
$228 \mathrm{Up}$ ) 'Von der Zeit an begann man auf diesem Weg zu

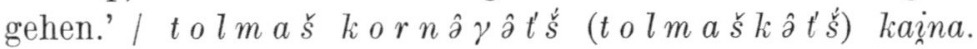
$\mathrm{S} /$ t o l m a šlk $\hat{a} t^{\prime} \dot{s}$ kaina. M-i (Wichmann R, 476) 'Wir gehen denselben Weg, den wir kamen.'

Schliesslich gibt es in gewissem Umfang auch solche Kontexte, in denen die Trennungskasusendung an ein andersartiges Substantiv tritt, in einigen Fällen auch an ein Pronomen. Der prolative Charakter des Trennungskasus kann u.a. durch ein Verb gekennzeichnet werden, das ein Vorbei- oder Hinübergehen bezeichnet; in vielen Fällen zeigt jedoch erst der weitere Textzusammenhang, dass es sich nicht um einen Übergang, ein Verschieben handelt, sondern um ein Hindurchgehen durch etwas. Ich bin jedoch der Ansicht, dass die Zahl jener Nomina, von denen sich ein solcher Trennungskasus bilden lässt, ziemlich begrenzt ist. Ferner kann es interdialektale Unterschiede geben: hierher gehörende Belege habe 
ich vor allem im U-Dialekt sowie in der östlichen Schrift-

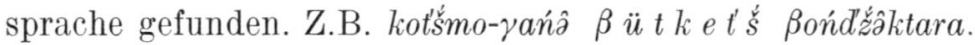
(Beke M, 406 Up) 'Sie [die Trommel] trägt [dich] über jedes

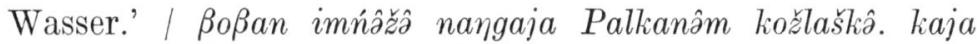

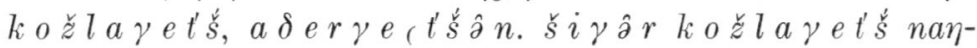
gaja. (Beke M, $255 \mathrm{Up}$ ) ' $\beta$ o $\beta a$ 's Pferd bringt Palkan in den Wald. Es geht durch Wälder und Gestrüpp. Es trägt ihn durch einen (eigtl. engen) Wald.' / $\beta u \beta e r, ~ k u s ̌ s$ t'śs purenat, $t u \check{s}$ e d́ lek! (Beke T III, $84 \mathrm{Uj}$ ) ' $\beta u \beta e r$, wo du hineingefahren (eigtl. hineingegangen) bist, dort komme heraus!' / Тидын годым лаке г ич ч вончыио тарантасбулт гына коио - (Ončyko 6/1963, 53 OS) 'In dieser Zeit wurden die durch die Talschlucht fahrenden geschlossenen Wagen sichtbar. - - '

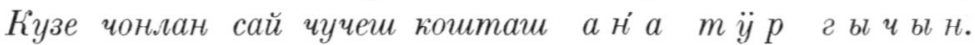
(Čavajn, 26 OS) 'Wie gut ist es doch für meine Seele, am Rand des Ackerstreifens entlang zu gehen!'

In Kontexten, in denen ein Trennungskasus steht, der den Durchgangsort der Übergangsbewegung bezeichnet, kann auch ein Trennungskasus für jenen Ort stehen, von dem etwas weggeht, oder ein Wohin-Kasus für die Stelle, an die etwas hinkommt, z.B. $t u \delta u n$ ü $m b \ddot{a}$ ( $t^{\prime} \dot{s}$ ə $n \check{z} e$ lektâm ro ž $\gamma \hat{\partial}$ ( $t^{\prime} \dot{s} \hat{\partial} n$. (Beke T IV, 407 B) 'Auf ihm (d.h. auf dem Rücken des Schlangenkönigs) [d.h. indem ich über die im Loch liegende Schlange kroch] kam ich aus dem Loch heraus.'

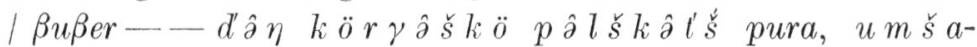

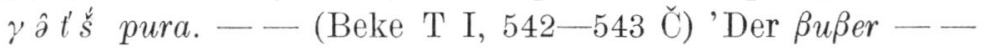
dringt durch Ohren (Sing.) und Mund in die Menschen (Sing.)

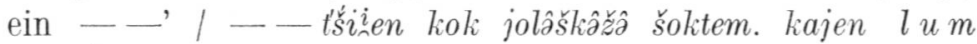
$\beta a t^{\prime} \dot{s} \beta i k$ terk $\hat{z} \ddot{z}$. (Beke M, $551 \mathrm{Up}$ ) '- - er zog auf die beiden Füsse die Siebe. Er ging im Schnee geradeaus heim.'

\section{DIE TRENNUNGSKASUSFORM IN INSTRUMEN-} TALER VERWENDUNG

Aus einigen Textquellen liegen manche Beispielsätze vor, in denen der Elativ als Adverbial des Verbs den Kauf- oder Verkaufspreis anzeigt; z.B. ožalen kok mańitkâts pu- 
tâm. (Beke T I, 298 Jt) 'Er verkaufte ein Pud für zwei Rubel.'

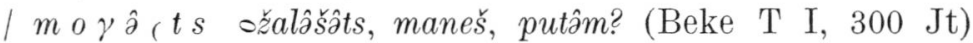
'Zu welchem Preis hast du ein Pud verkauft?' / - $\beta i t l^{\prime} \hat{a}$

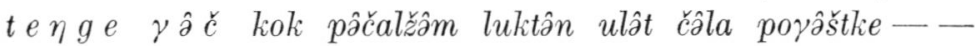
(Porkka-Genetz, $7 \mathrm{M}-\mathrm{i}$ ) ' — - für fünfzig Rubel wurden zwei Jäger mit allen ihren Waren fortgebracht - - '

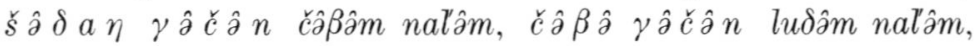
$l u \delta \hat{\partial} \gamma \hat{\partial} \check{c} \partial \hat{n}$ kombâm nalâm -.... (Porkka-Genetz, 3, M-i) 'Für's Weizenkorn bekam ich eine Henne, für die Henne bekam ich eine Ente, für die Ente bekam ich eine Gans - - '.

Üblicher ist jedoch, dass man im Tscheremissischen in dieser Funktion den Dativ oder Lativ verwendet, s. z.B. Alhoniemi, MSFOu 142, 307-309.

\section{DIE TRENNUNGSKASUSFORM IN KAUSALER VERWENDUNG}

Aus dem Dialekt von B habe ich einige Belege verzeichnet, wo die vom Stamm des Verbs ulam 'sein', ulo- oder ulma-, oder von der Negation uke gebildete Elativform als Prädikatsteil einer Art kausalen Satzäquivalents auftritt. Die vom Verb ulam 'sein' gebildete Konstruktion hat positive, die vom Verneinungswort uke 'ist nicht' gebildete negative Bedeutung. Somit verursacht die Endung des Trennungskasus in diesen Fällen nicht dieselbe negative Bedeutung wie bei den S. 81—92

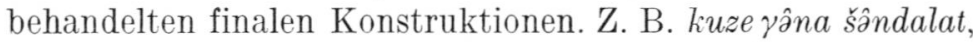

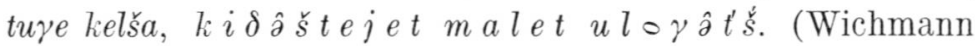
V, 421 B) 'Wie du es [das Scheitelkäppchen] aufsetzest, so steht es [dir], weil [ja doch] Reichtum in deiner Hand ist.'

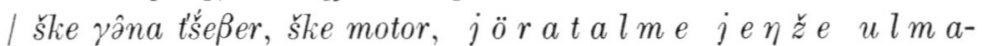
$\gamma \hat{\partial} t^{\prime} \dot{s}$. (Paasonen-Siro T, $100 \mathrm{~B}$ ) 'Er ist schön, er ist munter, weil er eine Geliebte hat.' / olmâšto šin, d'žen t'śapam kâlmalale mânânat o š $t^{\prime} \dot{s} u r k a m$ uk $\hat{\gamma} \gamma \hat{\partial} t^{\prime} \dot{s}$. (PaasonenSiro T, 101 B) 'Auf der Bank sitzend fror mein Fuss, weil ich keinen weissen Strumpf hatte.' / ožno tuluk ârßeze ilaš or a lt $\hat{\partial}$ -

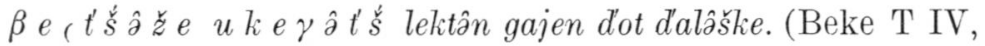
430 B) 'Es ging einmal ein Waisenjunge, da er kein Haus hatte, in ein fremdes Dorf, um [dort] zu leben.' 
Andersartige kausale Trennungskasus sind selten. Aus sporadischen Fällen zu schliessen werden Trennungskasus in gewissem Umfang auch in anderen Dialekten zum Ausdruck der Ursache verwendet; als Trennungskasus kommen dann offenbar die habitiven Kasus in Frage, z.B. $\breve{s}$ o $k x \not{s} \hat{z} l e t^{\prime} \dot{s}$

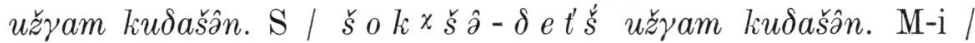

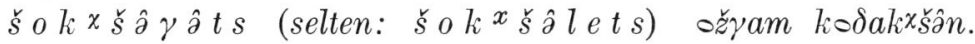

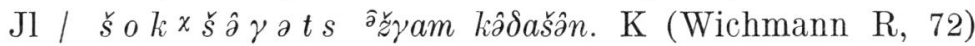
'Wegen der Wärme zog er die Pelze aus.' Erwähnt sei, dass in der Version von M bei diesem Beispiel anstelle des Trennungskasus der Wohin-Kasus šokx̌šlan 'der Hitze wegen' steht. I ти проста гражсданскици шамаквлӓ

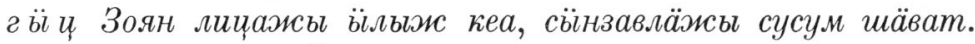
(Iljakov, 268 WS) 'Über diese einfachen Worte über Zivilangelegenheiten wird Z.s Gesicht froh, seine Augen glänzen vor Freude.'

\section{DIE TRENNUNGSKASUSFORM IN TEMPORALER VERWENDUNG}

12.1. Der Trennungskasus drückt aus, nach welcher Zeit die im Satz mitgeteilte Tätigkeit oder der Zustand realisiert wird

Jeder beliebige Vorgang oder Zustand kann in Beziehung gesetzt werden zur Zeit: einerseits kann der Zeitpunkt des Vorgangs oder Zustands ausgedrückt werden, andererseits dessen Dauer.

Die Trennungskasus stehen im Tscheremissischen in zweierlei temporalen Bestimmungen: einmal wird der Zeitpunkt ausgedrückt, nach dessen Verlauf etwas geschieht, zum andern der Zeitpunkt, von dem an etwas geschieht. In der Bedeutung 'in, nach' wird der $\gamma \hat{\partial} c$-Elativ verwendet; die Endung kann an das Wort für den Zeitabschnitt treten, manchmal auch

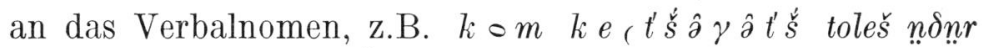
deke. (Beke T I, 664 C) 'In drei Tagen kommt er [der Bär] um das Mädchen.' / arńa kum âtket'ś toryoßoi kaja

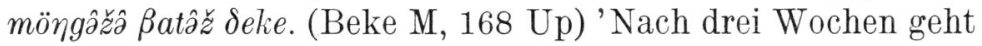
der Kaufmann zu seiner Frau heim.' / $a k \hat{\partial} l \check{z} \hat{\partial} \beta \hat{\partial} t \hat{\partial} m a-$ 


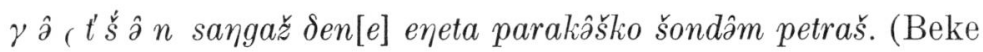
T IV, 446 B) 'Nachdem er den Verstand verloren hatte, drückt[e] er seine Stirn auf ihre Scheide (eig. stützt sich mit der Stirn darauf), um den Abgang des Urins zu verhindern.'

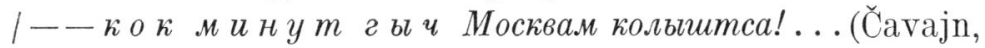
158 OS) ' - - hört (aus dem Radio) in zwei Minuten Mos-

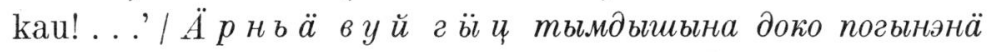
bıльbl - - (Grigorjev, 11 WS) 'Immer nach einer Woche versammelten wir uns [während des Sommers] bei unserem Lehrer - -'.

Am häufigsten wird der Ausdruck mit der temporalen Bedeutung 'nach' mittels des lativen Morphems möngö, meke aus der Nominalform des Verbs gebildet, z.B. maiska to $\beta$ a $r$

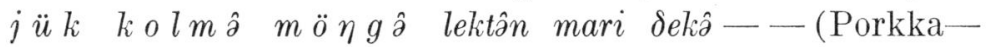
Genetz, 9 M-i) 'Als der Bär den Laut der Axt vernahm, ging er zum Manne - - '. Manchmal können die Morpheme möngö

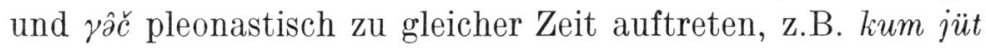

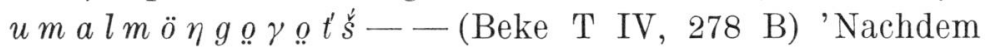
sie drei Nächte hindurch geschlafen hatte - - '.

\subsection{Der Trennungskasus in terminativer Verwendung}

Durch den temporalen, terminativen Trennungskasus wird der Zeitpunkt wiedergegeben, zu dem eine Handlung, ein Vorgang oder Zustand beginnt. Der terminative Trennungskasus wird formal genauso ausgedrückt wie der lokale. In einigen Fällen kann der Ausdruck direkt alternativ als entweder lokal oder temporal aufgefasst werden, z.B. $t u \gamma u D^{-}$ $l a \gamma \hat{\imath} t^{\prime} \dot{s}$ tünalna lištaš. M / $t u \delta \hat{\partial} \quad \gamma u D l a \gamma \hat{\partial} t^{\prime} \dot{s}$ tünalna

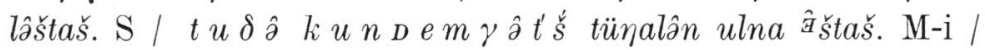

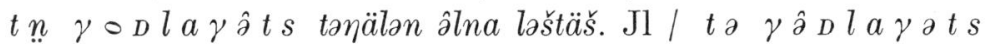

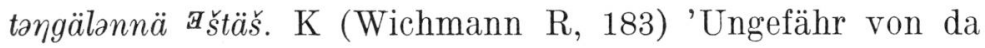
an (von der Zeit od. dem Ort) begannen wir [das] zu tun.' Im zitierten Beleg steht also, wie in vielen anderen Beispielen für den terminativen Trennungskasus, das Verb tünalam 'beginnen'. Zu beachten ist allerdings, dass sein Auftreten in Kontexten mit einem temporalen terminativen Trennungskasus auch dann nicht unumgänglich ist, wenn gleichzeitig 
kein terminativer Wohin-Kasus im Kontext steht (vgl. S. 93), z.В. П е р в ы й ч и сла г ӥ и, как Ваштаров толеи, пӓиам ӥитаи токем ванцеда. (Iljakov, 115 WS) 'Vom ersten Tag an, wenn V. [zur Arbeit] kommt, werden Sie bei mir arbeiten.'

Recht häufig gehört auch zu temporalen terminativen Trennungskasuskontexten gleichzeitig ein Wohin-Kasus. Auch er hat bis auf geringe Unterschiede dieselbe Form wie der entsprechende lokale Wohin-Kasus (vgl. S. 92-96, s. auch Alhoniemi, MSFOu 142, 272-275). An der genannten, die WohinKasus behandelnden Stelle meiner Arbeit finden sich auch einige Beispiele mit Trennungskasus; hier weitere Belege: - 1919 ий январь г и ч тӥніалын, 1955 ий марте Яков Алексеевич әре туныктымо пашаште ыитен. (Onс̌у ko 6/1963, 93 OS) '- - vom Januar d.J. 1919 angefangen bis zum Jahre 1955 leistete J.A. ununterbrochen Unterrichtsarbeit.' /

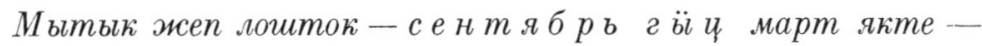
Ондрикан Раманьц - - рассказвлӓжсы гӥц Миколай дӓ - - Bикторат иукым керальл илӓнышты нӓлыныт. (Iljakov, 40 WS) 'In der kurzen Zeit — vom September bis zum März - erhielten M. und V. für sich viel Nützliches aus den Erzählungen von O.R.'

$\mathrm{Zu}$ beachten ist aber, dass in den Fällen, wo mehrere mittels Terminativkonstruktion ausgedrückte Zeitabschnitte aufeinander folgen können, der terminative Wohin-Kasus ersetzt werden kann durch einen Genitiv-Instruktiv mit der Endung -әิn, z.В. И й а ы ч $и \breve{u} ы н$ жсап әрта, IIIыже покта кеніежым... (C̆avajn, 20 OS) 'Von einem Jahr zum andern vergeht die Zeit, der Herbst verfolgt den Sommer. . .' (Ein zweites Beispiel bei Alhoniemi, MSFOu 142, 274). Die Tiefenstruktur eines solchen Ausdrucks ist "von der Zeit D zur Zeit D + wiederholt»; zum Ausdruck dieser Beziehungen wären eigentlich die Morpheme D $\gamma \hat{\partial} \breve{c}-\mathrm{D}$ ške + $(\hat{\partial}) n$ notwendig. Da z.B. in dem zitierten Ausdruck nur die Morpheme D $\gamma \hat{a} c ̌$ - D (人) $n$ stehen, ist in der Oberflächenstruktur also sowohl Lativität als auch die Wiederholung gleichsam durch ein (â)n-Morphem ausgedrückt. 
13. DIE TRENNUNGSKASUSFORM GIBT DIE LOKALITÄT AN, VON WO AUS DER IM SATZ AUSGEDRÜCKTE ZUSTAND ODER DIE TÄTIGKEIT VERURSACHT WIRD

Als Ausgangspunkt unserer Betrachtung soll folgender Satz dienen: - - тӓгї вычыдеок олица гйи ик окня севалеи. (Iljakov, 246 WS) '- - jemand schlägt von der Strasse her unerwartet [zur Überraschung für die im Zimmer Anwesenden] das Fenster ein.' In diesem Kontext drückt die Trennungskasusform zweifelsohne eine Lokalität aus, doch existiert zwischen dem Denotat der Trennungskasusform und dem des Objekts nicht das von der Relationsregel vorausgesetzte lokale Verhältnis: der Trennungskasus sagt nichts aus über die Position des Denotats des Objekts. Dagegen wird durch die lokale Bestimmung der Ort angezeigt von wo aus die im Verb beschriebene Handlung verursacht wird. Meistens sind solche Kontexte transitiv, doch sind intransitive nicht unbekannt. Auch der lokale Trennungskasus des nächsten intransitiven Satzes bezeichnet nicht den Ort, von dem sich die Entität entfernt, sondern so wie die Bestimmung im obigen Satz die Lokalität, von wo aus die Handlung des Verbs verursacht wird: $B \ddot{b и л е ~ и ~ ы л ~ к р е д а л а и ~ к у и т ы л ь ы ~}$ azbı - - (Iljakov, 117 WS) 'Von ausserhalb [eigtl. oberhalb] der Kolchose kann man nicht leicht [gegen Veränderungen] kämpfen ——'.

In den zitierten Beispielen steht der Trennungskasus bei einem Verb der Tätigkeit; er kann aber auch den Ort angeben, von wo aus ein Zustand verursacht wird: $k u \delta \hat{\jmath}$ er $\beta e z ́ \hat{z} \quad k \ddot{u} p-$

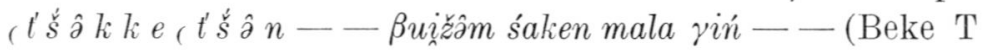
III, 430 Up) 'Das (eigtl. jenes) Kind, das den Kopf vom Polster — - herunterhängen lässt ——'.

Meist gibt die Trennungskasusform indirekt auch den Aufenthaltsort des Denotats des Handelnden wieder, doch ist es deutlich nicht die primäre Aufgabe der hierher gehörenden Trennungskasus, die Lokalität irgendeiner Entität anzuzeigen; dies geht u.a. aus dem folgenden Beleg hervor: $k \ddot{o} r \gamma \hat{\partial}$ -

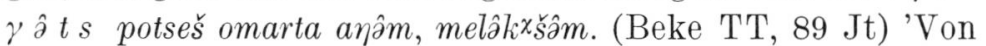


innen öffnet er die Öffnung des Bienenstockes [auf den er erst den Sack gesetzt hat], den Deckel.'

Als Trennungskasus werden in solchen Ausdrücken regelmässig der $\gamma \hat{\partial} \hat{c}$ - und der $\check{c}$-Elativ verwendet; die Trennungskasusform kann neben dem genauen Ort auch die Richtung

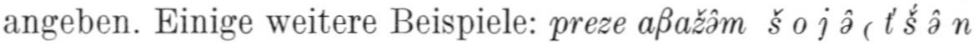
šupšeš kân-—oń ( $d^{\prime} \dot{z}^{2} \hat{a} t^{\prime} \check{s}$ šupšeš kân-—(Beke T IV, 386 B) 'Wenn das Kalb von hinten [an den Zitzen] seiner Mutter saugt — - Wenn es [aber] von vorne saugt - - '

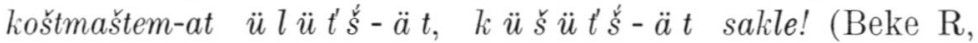
709 B) 'Unterwegs beschütze mich von unten, von oben!' /

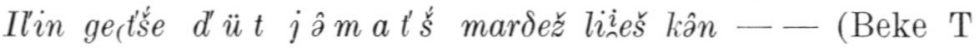
III, $67 \mathrm{Uj}$ ) 'Wenn am Eliastage der Wind von Norden her

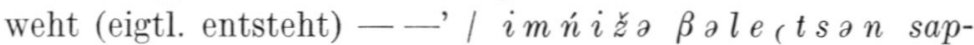

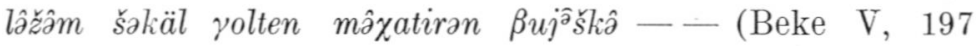
K) 'Von seinem Pferd aus stiess er sein Schwert in den Kopf

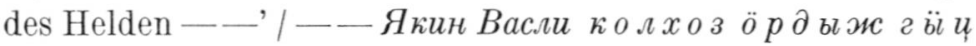
худа пӓшавлӓэмым вида. (Iljakov, 177 WS) '-— V. J. lenkt seine Sabotage von ausserhalb der Kolchose.' / В е с в в е и bи н Ваштаров докь Павыл Павльч пижеда - - (Iljakov, 137 WS) 'Von der anderen Seite greift P.P. den V. an [mit Fragen] - - '.

Als eigenes Ganzes sind die entsprechenden Trennungskasusbestimmungen bei Verben der Sinneswahrnehmung zu behandeln. S. 46 stehen Beispiele für den Satztyp »jemand sieht, hört X aus A», z.B. 'hört Nachrichten aus Moskau'. In einem solchen Ausdruck wird also der Ausgangspunkt des Reizes durch die elativische Lokalitätsbestimmung wiedergegeben. Bei den Verben der Sinneswahrnehmung steht aber auch oft ein solcher lokaler Trennungskasus, der zum Ausdruck bringt, von wo aus die Sinneswahrnehmung stattfindet; der Satztyp lautet dann »jemand betrachtet, hört X von

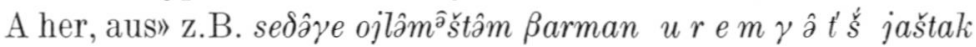
kolâšt šoyen. (Paasonen-Siro T, 15 B) 'So ihren Reden [,die im Zimmer geführt wurden,] heimlich lauschend stand Barman

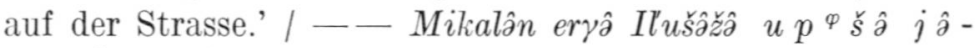

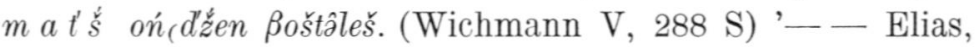
Michaels Sohn, lacht, unter der Mütze hervorblickend, auf.' 


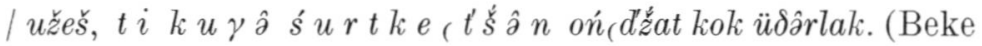
M, 280 Up) 'Er sieht, aus diesem grossen Hause schauen zwei Mädchen heraus.' / - - изивлӓ иїдейымыла дӓ тамам вычымыла $\ddot{y} л$ ы и кӥшкыла анжат. (Iljakov, $190 \mathrm{WS})$ '- - die Kleinen schauen verwundert und wie auf etwas wartend von unten nach oben.'

Die Kontexte, die die Handlung einer Person von irgendwoher wiedergeben, lassen sich nicht immer von jenen unterscheiden, wo die Verschiebung einer Entität von einer Lokalität ausgedrückt wird. Im folgenden Satzzusammenhang z.B. hat der Trennungskasus gleichzeitig diese beiden Funktionen: т ышә и шанымыюсым сирэн-сирэн колта ылын. (Grigorjev, 66 WS) 'Von dort [aus seinem Versteck] schrieb Lenin seine Ideen.' Hier wird also einmal zum Ausdruck gebracht, von wo aus Lenin handelte, und zum andern, von wo die von Lenin schriftlichen niedergelegten Ideen anderswohin gelangten.

\section{DIE TRENNUNGSKASUSFORM BEZEICHNET DEN PUNKT DER ENTITÄT, WORAUF SICH DER IM SATZ AUSGEDRÜCKTE ZUSTAND ODER DIE TÄTIGKEIT BEZIEHT}

Mit Hilfe des lokalen Trennungskasus kann auch die Stelle ausgedrückt werden, auf die sich der im Verb bezeichnete Zustand, die Handlung oder der Vorgang bezieht. Der in solchen Kontexten mit dem Trennungskasus bezeichnete "Ort» ist im allgemeinen der Teil eines grösseren Ganzen. Im Satz kinde-sokor - - šeleš pokx šalts ân Dâk- (Beke TT, 62 Jt) 'Bekommt der Brotlaib — - in der Mitte einen Sprung _ _' z.B. wird nicht allgemein die Lokalität des Aufspringens wiedergegeben, sondern ausdrücklich, dass dieser Sprung in der Mitte des Brotes entsteht. So geht es bei diesen Ausdrücken i.a. um eine ähnliche Relativierung wie bei den S. 99-100 behandelten Prolativ-Ausdrücken. Ein solcher Ausdruck mit einem Prolativ z.B. wie or em pokše $t^{\prime} \dot{s} \hat{\jmath} n$ kaje! (Beke T I, $502 \mathrm{JOk}$ ) 'Geh in der Mitte der 
Strasse!' kann entsprechend ausgelegt werden, indem sich das Gehen auf den mittleren Teil der Strasse bezieht.

Konstruktionsmässig weisen jene Kontexte, in denen ein Trennungskasus die Stelle eines Zustandes, einer Handlung oder eines Geschehens anzeigt, mehrere Typen auf. Im Zusammenhang mit intransitiven Verben wird die Gesamtheit i.a. durch das Subjekt ausgedrückt. Als Prädikat begegnet ein Verb, das den Zustand oder die Zustandsveränderung angibt; Belege liegen u.a. von Verben mit folgender Bedeutung vor: 'sich verändern', 'trocknen', 'gefrieren', 'vergilben', 'abbrechen', 'zerspringen', 'sich anhängen', 'sich erhängen', 'hängen, aufgehängt sein'. Beispiele: šurno ü $m b \ddot{a} t$ 'ś kanä koyarya - - (Beke T IV, 180 B) 'Nur die Oberfläche des Getreides wird versengt - - / šürtö $\beta i t^{\prime} \check{s}^{k} \hat{\partial} z \beta e r-$ $\gamma \hat{\partial} t^{\prime} \dot{s}$ kürles. (Beke T IV, $162 \mathrm{~B}$ ) 'Der Faden reisst an der dünnen Stelle.' / tolšâla saplâkeš $\breve{s} \ddot{u} z ̌ z \hat{z} t s$ piktalten $i$ kolen. (Beke T I, 133 Jt) 'Auf dem Heimweg (eigtl. zurückkommend) verwickelte sich ihr Hals in die Zügel und [sie] erstickte.' / o $\beta \delta a k u e \beta u j \hat{\jmath}$ što ke(tsa ü $p k \hat{\partial}$ ( $t s \hat{\partial} n$. (Beke T I, $105 \mathrm{Jt}$ ) 'Der o $\beta \delta a$ hängt bei den Haaren im Wipfel der Birke.' / Икмыняржын шӥргыжё пеле г и ч катлен. (Ončyko 6/1963, 67 OS) 'Bei einigen waren die Gesichter [auf dem Foto] in

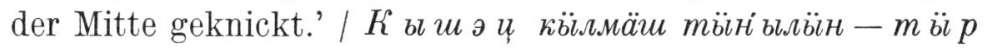
г в̈ и, по ки э и?? (Grigorjev, $50 \mathrm{WS}$ ) 'Wo fängt [der See] an zu

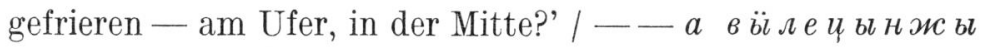
- - вашталтдеок кодын. (Iljakov, $245 \mathrm{WS}$ ) '- - aber äusserlich — - blieb er unverändert.'

In derartigen Kontexten kann auch ein nominales Prädikat auftreten, i.a. ein Adjektiv, aber - falls das letzte Zitat der folgenden Beleggruppe hierher gehört - manchmal auch ein

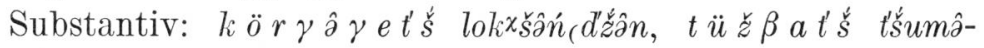
raš. (Beke T III, $392 \mathrm{Up}$ ) 'Innen ist sie [die Mauer] glatt, eigtl. abgeschnitzt, aussen ist sie gewölbt.' / šürtö $k \circ z$ et'ś $\beta$ âśkâž $t \circ \check{z}$ et'ś kürleš. (Beke T I, $379 \mathrm{JOk}$ ) 'Wo das Garn dünn ist, dort reisst es.' / tumo, $t u m-\ddot{u} m b a t^{\prime} \dot{s}$ šolo, šol$\ddot{u} m b a t^{\prime} \dot{s}$ piśte, piśt-ümbat'ś kue. - ter. (Beke T I, 387 JOk) 'Eiche, auf der Eiche ist Ulme, auf der Ulme Linde, auf der Linde Birke. - Der Schlitten.' 
In einigen Fällen wiederum steht als Prädikat an sich ein Wortgefüge, bestehend aus einem bedeutungsleeren Verb und einem Subjekt. Dann drückt z.B. das Attribut des Subjekts die Gesamtheit aus; so steht z.B. im folgenden Kontext als Prädikat šârka li̊eš 'die Blüte kommt, fängt an zu blühen', und die Gesamtheit wird ausgedrückt durch das Attribut

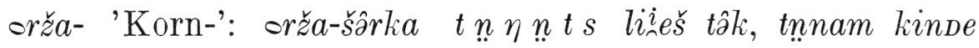

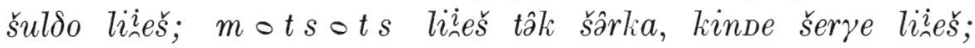
$k \hat{a} \delta a l t s \hat{\partial} n l i i_{n}^{i} e s ̌ t a ̂ k, k a ̂ \delta a l$ ak liieš. (Beke TT, $55 \mathrm{Jt}$ ) 'Fängt die Kornblüte unten an der Ähre an, so wird das Brot billig; blüht sie an der Spitze, so wird das Getreide teuer; blüht sie von der Mitte an, so hat es auch den Mittelpreis.'

In Sätzen mit Objekt zeigt die Trennungskasusform ihrerseits den Teil oder Punkt des Denotats des Objekts an, worauf sich die im Verb zum Ausdruck gebrachte Handlung bezieht. Als Prädikat der Hunderte von hierher gehörenden Kontexten begegnet eine grosse Anzahl verschiedener Verben. Üblich sind u.a. die folgenden Bedeutungen: 'schlagen', 'schiessen', 'treten', 'zerschlagen', 'verbrennen', 'bedecken', 'zerstampfen', 'giessen', 'sägen', 'brechen', 'essen', 'picken', 'beissen', 'kneifen', 'streichen', 'liebkosen', 'kehren', 'aufhängen', 'binden', 'gefangen nehmen' usw., z.B. po č $k \hat{z} \check{c}$ peren yolden mera$\eta \hat{\partial} m$ - - (Porkka-Genetz, 1 M-i) 'Auf den Schwanz schlug

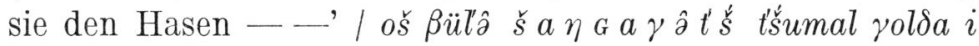
pirâ kola. (Wichmann V, $168 \mathrm{M}-\mathrm{i}$ ) 'Die weisse Stute tritt den Wolf [mit dem Huf] an die Stirn, und der Wolf stirbt.' I

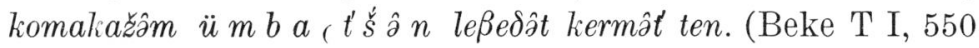
JOü) 'Man deckt den Ofen auch oben ringsherum mit Zie-

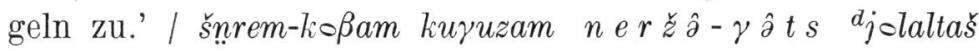
kâlešs. (Beke TT, $16 \mathrm{Jt}$ ) 'Der šṇrem-Alten [und] dem šnnremAlten muss man die Nase abbrennen.' / azäm don djengämdž

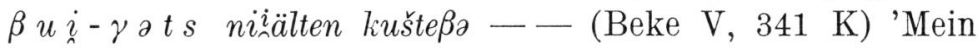
älterer Bruder und seine Frau haben mich erzogen, indem sie meinen Kopf streichelten - - / lâktân kazažam, ä $r \delta$ a lo- $\gamma$ a ( $t$ s an šâral rolten. (Beke V, $121 \mathrm{~K}$ ) 'Da zog [der Mann] das Messer und stiess es zwischen die Schenkel [des Bären].' / - -Эчан- - весыюиым нер су з о г ы ч мушкынda. (Čavajn, 127 OS) '- - E. — — schlägt den anderen mit 
der Faust an die Nasenwurzel.' / Йьван-вате - - Йыванылм пулы и г в ч ше куча. (Čavajn, 171 OS) 'J.s Frau - -

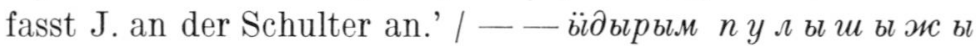
г ӥь ц йірзаи тӥвналеш. (Iljakov, 337 WS) '- - er beginnt das Mädchen an der Schulter zu schütteln.'

Auch in einigen Satztypen, die ein kognitives Verhältnis ausdrücken, begegnet eine entsprechende Elativbestimmung,

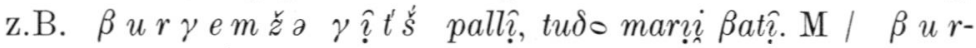

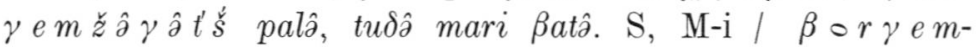

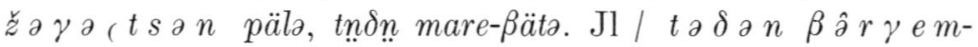

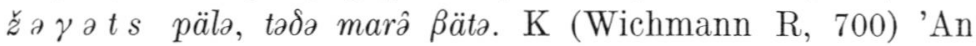
ihrem Kleid kann man erkennen, [dass] sie eine Mari-Frau ist.' Hier drückt die Elativbestimmung also den Punkt aus, den man zuerst identifiziert und worauf dann das Erkennen der Ganzheit erfolgt. In einem solchen Ausdruck sind die Verhältnisse im Prinzip die gleichen wie in dem Ausdruck folgender Bedeutung: "X schlägt $\mathrm{Y}$ an Punkt A tot»; der Schlag bezieht sich also auf Punkt A an Y, und darauf folgt der Tod von Y.

Einige Kontexte mit einem typischen Transitivverb als Prädikat haben jedoch überhaupt kein Objekt, sondern das das Ganze bezeichnende Wort steht als Attribut der Trennungskasusform, oder auf die Gesamtheit verweist ein an die Trennungskasusform getretenes Possessivsuffix. Belege: - -

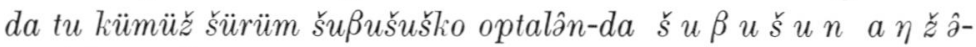

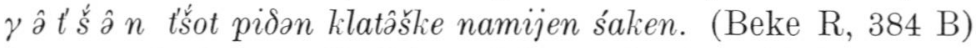
'_- - und sie goss die Schüssel Suppe in einen Schlauch und band die Öffnung jenes Schlauches fest zu, trug ihn in den

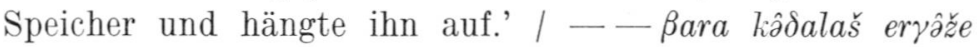

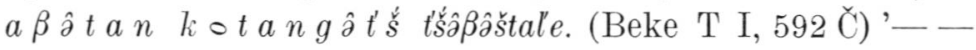
der mittlere Sohn kniff (dann) den Hahn in den Steiss.' /

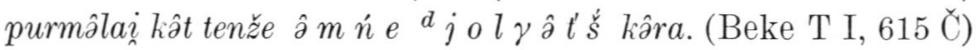
'Mit der Rechten schlägt er die Füsse (Sing.) des Pferdes.' /

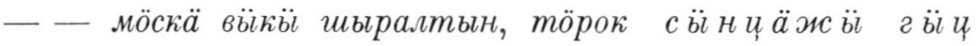
пыикыл колтән. (Grigorjev, $120 \mathrm{WS}$ )' - - die Biene griff den Bären an, stach ihn direkt ins Auge.'

Eine derartige Verwendung kann ein gewisses Zwischenstadium in der Entwicklung bedeuten, wo sich der Trennungs- 
kasus zu einem direkten Rektionskasus einiger transitiver Verben entwickelt. Anzeichen in dieser Richtung sind vorhanden. Z.B. enthält der folgende Kontext wenigstens in der Oberflächenstruktur kein auf das Ganze hinweisendes Wort, und der Gedanke wirkt konstruiert, dass sich der Sprecher das Fenster z.B. als Teil des Hauses gedacht habe und das die Gesamtheit bezeichnende Wort in seiner Rede nur weggelassen habe (vgl. weiter oben das letzte Beispiel von Beke V): pandâm nälan o G ń a $\gamma$ ats pären. (Beke V, $286 \mathrm{~K}$ ) 'Er nahm einen Stock und klopfte am Fenster.'

\section{DIE TRENNUNGSKASUSFORM DRÜCKT DIE ENTITÄT AUS, DIE DER IM SATZ AUSGESPRO- CHENE ZUSTAND BETRIFFT}

Vor allem in Gebeten gibt es reichlich Kontexte mit einem Trennungskasus, deren Konstruktion folgendermassen aussieht: als Prädikat eine Imperativform vom Verb puem 'geben' als Objekt ein abstrakter Begriff wie 'Segen', 'Schutz', 'Gesundheit' - als Trennungskasusbestimmung ein Wort, das ausdrückt, in Bezug worauf der durch das Objekt ausgedrückte Begriff gewünscht wird. Unabhängig vom belebten oder unbelebten Charakter des Denotats steht als Trennungskasusform stets der $\gamma \hat{\partial} \check{c}$-Elativ oder eine Postpositionskonstruktion mit ümbač 'von oben her'. Belege: mülkx̌s-jumo,

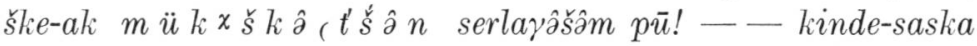

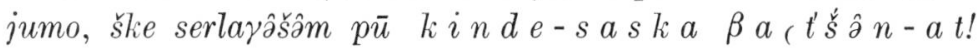
(Beke T III, 119 Uj) 'Bienengott, behüte du selbst die Bienen! - - Getreideblüten-Gott, behüte du selbst auch die

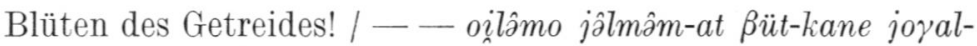
taren $\ddot{a} r-m o-\gamma \hat{a} t^{\prime} \dot{s}-a t$ jönọm-ät puźa! (Beke R, $705 \mathrm{~B}$ ) '_- - machet unsere Sprache leichtfliessend wie das Wasser, wenn wir sprechen, gebet uns in allem Glück [eigtl. Weis-

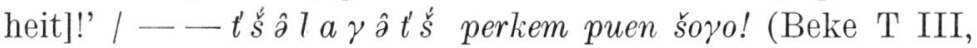
$121 \mathrm{Uj})$ ' - - gib in allem Segensfülle!' / mük $x_{s}$-ōn, $m \ddot{u} k \times s$ $\beta a$, t'š̀ ân tažam pū!, manât. (Beke T III, $130 \mathrm{Uj}$ ) 'Fürst der Bienen, gib [du selbst] den Bienen Gesundheit! (sagt man).' 
Wie man sieht, ist der Trennungskasus in den einzelnen Beispielen sehr unterschiedlich ins Deutsche übersetzt; im letzten Beleg sogar durch einen habitiven Dativ. Es ist jedoch offenbar, dass in all diesen Belegen ein TrennungskasusAdverbial steht, das in der herkömmlichen Satzlehre als sog. Verhältnisbestimmung bezeichnet wird. Es kann somit sein, dass der genaue Bedeutungsinhalt dieser Belege etwas komplexer wäre als die aus den Textsammlungen stammenden deutschen Übertragungen vermuten lassen. Vergleichen wir z.B. die folgenden Kontexte miteinander: suksem, serlayâšâm $p \bar{u}$ - - (Beke T III, $142 \mathrm{Uj}$ ) 'Mein Engel, erbarme dich

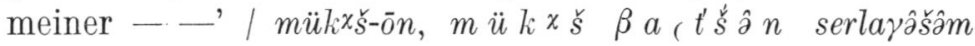
pū!, manât. (Beke T III, $130 \mathrm{Uj}$ ) 'Bienenfürst, erbarme dich der Bienen (schone sie)! (sagt man).' Sie unterscheiden sich strukturell nur darin, dass der letzte Beleg eine ümbačPostpositionskonstruktion enthält, die im ersteren fehlt. Aus der Übersetzung des ersteren Beispiels geht hervor, dass der Schutz sich auf den Sprecher beziehen soll; die U̇bersetzung ist zweifellos richtig, da der im Gebet stehende Imperativ des Verbs puem, zu dem keine Dativbestimmung gehört, i.a. implizit auf eine zugunsten des Sprechers oder der Gruppe des Sprechers geschehende Handlung, auf die Behütung, hinweist. Die Übersetzung des zweiten Beispiels weist jedoch keine solche Bedeutung auf; dennoch ist anzunehmen, dass auch in diesem Beispiel das Verb puem einen Hinweis auf eine speziell zugunsten des Sprechers geschehende Handlung enthält; das Beispiel dürfte also ungefähr folgendermassen zu deuten sein: ' — — gib [uns] hinsichtlich der Bienen Schutz!'

Falls diese Auslegung der Belege richtig ist, kann man die Verwendung des Trennungskasus in den genannten Kontexten von der ursprünglichen Bedeutung des Kasus her verstehen: der Ursprung derartiger Ausdrücke läge also in einem Kontext folgender Art: $\mathrm{X}$ gibt $\mathrm{Y}$ an $\mathrm{B}$ aus A». Diesem Schema entspricht offenbar u.a. der folgende, ebenfalls in einem Gebet auftretende Kontext, wo durch einen Dativ zum Ausdruck gebracht wird, dass es in diesem Fall nicht um einen Übergang zugunsten des Sprechers geht: - - porâ

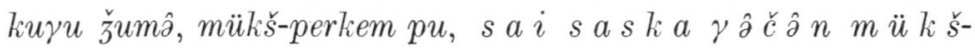


l a n mü-perkem pu! (Porkka-Genetz, $16 \mathrm{M}-\mathrm{i})$ '- - verleihe guter, grosser Gott, Reichtum an Bienen, verleihe den Bienen eine Fülle von Honig aus guten Blumen.'

Die folgenden Belege weichen ihrer Struktur nach von den oben zitierten ab. Dennoch enthalten sie offenbar einen entsprechenden "Trennungskasus des Verhältnisses»: porâ kuүu

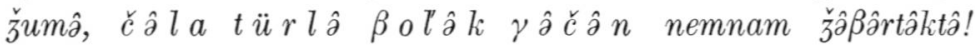
(Porkka-Genetz, 16 M-i) 'Grosser, guter Gott! Erfreue uns mit allerlei verschiedenartigen Haustieren!' / môlande-ōn, ške arale, manât, $p$ as u jâ $r \gamma \hat{\partial} t^{\prime} \grave{s}_{\text {! }}$ (Beke T III, $130 \mathrm{Uj}$ ) 'Fürst der Erde, behüte [du selbst] das Feld ringsumher!' An sich ist das Verb aralem 'beschützen' bedeutungsmässig jedoch identisch mit dem Wortgefüge serlayâšâm puem 'Schutz geben'; so gehört das zuletzt zitierte Beispiel in der Tiefenstruktur eindeutig mit den früher angeführten zusammen. Das Verb jâßârtâktem 'erfreuen' enthält wiederum die Bedeutung 'Freude geben, bringen'; der strukturelle Unterschied zwischen dem Kontext mit persönlichem Objekt ('jemanden erfreuen') und dem mit Sachobjekt ('jemandem Freude bereiten') entspricht genau dem Unterschied, der z.B. zwischen den Ausdrücken pukšem 'füttern' + Akk. und kočkâšŝm puem 'Essen geben' + Dat. herrscht. Mit anderen Worten enthält das Verb jẩßartâktem u.a. sowohl die Bedeutungsmerkmale vERURSACHEN + zustand; in den früheren Beispielen wurden diese semantischen Merkmale nur durch verschiedene Wörter wiedergegeben, durch das Verb puem und durch ein getrenntes Objekt.

Erwähnt sei, dass bei dem Verb jâß̧ิrtâktem 'erfreuen' statt dem Trennungskasus auch der Postpositionsausdruck mit Sene 'mit' stehen kann: - - tu $\delta \hat{\partial}$ perke $\delta$ e n $\hat{\partial}$ nemnam ว̌ẩßârtâktâ! (Porkka-Genetz, 19 M-i) '- - mit diesem Reichtum erfreue uns!' In den Gebeten findet man - zum selben Prädikat gehörend - $\gamma \hat{a} c$-Bestimmungen verschiedener Funktionen sogar in unmittelbarer Nähe voneinander. Im folgenden Zitat z.B. gehören die beiden ersten Elative zu den hier untersuchten Fällen; sie drücken aus, für wen um Schutz gebeten wird (der dem Betenden selbst zugute kommt), die beiden folgenden wiederum, vor welcher Wirkung der Betende bittet geschützt zu werden (diese Verwendungs- 
weisen des Trennungskasus sind S. $81-88$ behandelt wor-

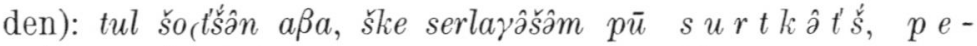

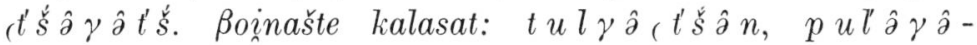

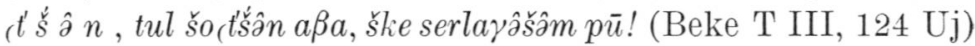
'Feuergebärende (schaffende?) Mutter, behüte das Haus, den Zaun. Man sagt während des Krieges: Vor dem Feuer, vor der Kugel behüte mich (du selbst), rette mich, feuergebärende (schaffende[?]) Mutter!'

16. DIE TRENNUNGSKASUSFORM IN DISTRIBUTIVER VERWENDUNG

In einigen Kontexten steht an der Stelle des Subjekts oder Objekts der $\gamma \hat{\partial} c ̌$-Trennungskasus, z.B. mâjâ šin (dž́em koGlaštâ

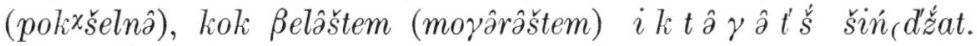

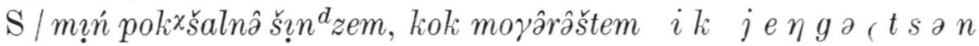
š?n $n^{d} z \ddot{a t}$. Jl (Wichmann R, $800 \mathrm{Jl}$ ) 'Ich sitze in der Mitte, auf

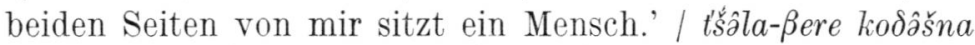

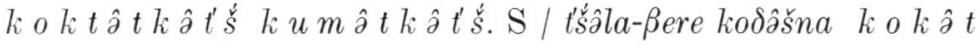
kumâtkât'š. M-i / Bezd'e kodâšna koktâtkâts ko-

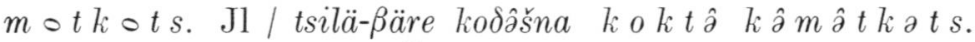
K (Wichmann R, 433) 'Überall haben wir je zwei oder drei

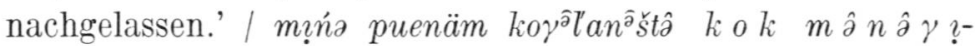
$t$ s a n (Ramstedt, $52 \mathrm{~K}$ ) 'ich gab jedem von ihnen zwei Eier'.

Diese Trennungskasusbestimmungen haben distributiven Charakter. Ein die Stelle des Subjekts einnehmender $\gamma \partial \hat{c}{ }^{-}$ Trennungskasus - der offensichtlich selten ist — drückt aus, wieviele Denotate des Subjekts die durch das Verb (und eventuell dazu gehörende Bestimmungen) bezeichnete Position oder Tätigkeit betrifft. Der die Stelle des Objekts einnehmende Trennungskasus teilt wiederum meistens mit, auf wieviele einzelne Denotate sich die Tätigkeit des Denotats eines jeden Subjekts richtet; in diesen Ausdrücken hat das Subjekt mehrere Denotate. Wie aber aus dem zuletzt angeführten Beispiel ersichtlich ist, kann das distributive $\gamma \partial \hat{\partial}$ - $^{-}$ Objekt auch in einem Ausdruck mit einem singularischen Subjekt auftreten: dann zeigt sich die Distributivität darin, dass das Denotat des Subjekts die auf das pluralische Denotat 
des $\gamma \hat{\partial} c ̌$-Objekts gerichteten Handlungen getrennt vollzieht. Der distributive $\gamma \hat{a} c$-Trennungskasus kann aber auch als adverbiale Bestimmung auftreten: - - lupšten $k u m k a$ n a gə ̌̌ čučeš — - (Sebeok-Ingemann, 77 B) ' - - er schlägt mit der Peitsche beide [den Bräutigam und die Braut] dreimal - -

Ich habe den distributiven $\gamma \hat{\partial} c$-Kasus ausführlich in dem Vortrag behandelt, den ich auf dem Zweiten Finnougristenkongress hielt. In dem Zusammenhang habe ich auch versucht, die Geschichte der distributiven Verwendung des Elativs zu klären. Der Ausdruckstyp ist meines Erachtens aus dem Ausdruck meinige geben, nehmen o.dgl. die Anzahl X von Y» entstanden, indem das Zahlwort, das die Anzahl X angibt, aufgrund der syntaktischen Verschiebung als Attribut des die $\gamma \hat{\partial} c$-Trennungskasusform aufweisenden $\mathrm{Y}$ aufgefasst wurde. S. die Erklärung und weitere Beispiele in Alhoniemi, Congressus secundus, Pars I, 7-16.

\section{DIE TRENNUNGSKASUSFORM ZUR BEGREN- ZUNG EINER ANZAHL ODER MENGE}

S. 92-96 war die Rede von der lokalen Verwendung des terminativen Trennungskasus, S. 104-105 von seiner temporalen Verwendung. Formal derselbe terminative Trennungskasus kann aber auch zum Ausdruck der untersten Grenze einer Anzahl oder einer Menge verwendet werden. In allen in diesen Zusammenhang gehörenden, an sich wenigen Beispielen tritt gleichzeitig auch eine die Obergrenze anzeigende terminative Postpositionskonstruktion auf.

Alle von mir verzeichneten Beispiele sind so geartet, dass der terminative Ausdruck gleichsam auf das Subjekt oder Objekt hinweist. Das Besondere ist jedoch, dass dieses Subjekt oder Objekt auch unausgedrückt bleiben kann, wobei der gleichsam als deren Bestimmung im Satzzusammenhang fungierende Terminativausdruck in der Oberflächenstruktur sein nicht ausgedrücktes Bezugswort vertreten kann. Z.B. Пӧръенं влакьм, латкандаи ий г ич тӥніалын, витле ияи марте, мобилизоваен нан' гаеныт. (Čavajn, 118 OS) 'Die Män- 
ner, von den 18- bis zu den 50jährigen, wurden in den Kriegrsdienst geführt.' / ik omarta mükš pua $i k$ putk $\hat{\jmath} t^{\prime} \dot{s}$ kok put jotân. (Beke T IV, 272 B) 'Ein Bienenstock ergibt ein bis

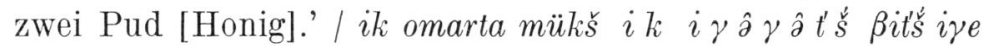
jotân oj əิra ik kenežlan. (Beke T IV, 266 B) 'Ein [einziger] Bienenstock lässt während eines Sommers ein bis fünf Bienen[schwärme] ausfliegen.' / Г ен н р а л г ӥ и тйінгалын, рядовой салтак якте техень мужество доно кредалыт гйнь - (Iljakov, 246 WS) 'Wenn [die Männer] vom General biz zum einfachen Soldaten mannhaft kämpfen - - '.

\section{DIE TRENNUNGSKASUSFORM IN KOMPARATI- VER VERWENDUNG}

Die genuine Bildungsweise des Komparativs im Tscheremissischen besteht darin, dass der den Vergleichspunkt ausdrückende Trennungskasus an das zu steigernde Adjektiv bzw. die Partikel tritt. Zu den komparativen Partikeln zähle ich u.a. die folgenden: $\beta$ ara 'danach, später', ońčâč 'früher, vor', ožno 'id.' In meinem anlässlich des Dritten Finnougristenkongresses gehaltenen Vortrag habe ich nachgewiesen, dass bei der Komparation die habitiv-kognitiven Trennungskasus in Gebrauch sind. Dennoch begegnen in dieser Funktion auch ausserhalb des $7 е \check{c}$-Gebietes - u.a. in beiden Schriftsprachen - die erstarrten, aus den Pronominalstämmen tâ- 'dieser' sowie tu- 'jener' gebildeten leč-Kasus tâlě̆ und tuleč. In $\mathrm{K}$ und in WS begegnen in der Komparation als Ausnahmen auch die aus den Pronomina ti- W 'dieser' und tə- W 'jener' abgeleiteten nicht-habitiven tišec W und təšec W. Sonst begegnen nur wenige Ausnahmen von der nach Gebieten unterschiedenen Verwendung der habitivkognitiven Trennungskasus. Einige Beispiele:

\section{Der leč-Vertretungstyp}

ti ple t'śs jöśọ paša uke. (Wichmann R, $322 \mathrm{M}$ ) 'Eine schwierigere Arbeit als diese gibt es nicht.' Ein exzeptioneller ঠeč-Trennungskasus kommt in der Quelle Sebeok-Ingemann vor, mit Ausnahme des an die Partikel ßara 'später, nach' 
tretenden leč-Kasus, sowie in zwei drei Beispielen aus dem Dialekt B, von denen das eine folgendermassen lautet: - n a lm et te t'ś ožno akšâm kürlün oillo! (Beke T IV, 372 B) '_ _ bestimme den Preis im voraus (eigtl. vor dem Kauf)!'

2. Der Vertretungstyp lěc $\sim \delta e \check{c}$

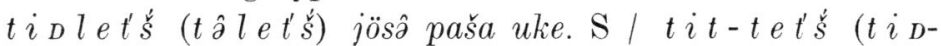
le t'ś) jösâ paša uke. M-i (Wichmann R, 322) 'Eine schwierigere Arbeit als diese gibt es nicht.'

\section{Der $\delta e \check{c}$-Vertretungstyp}

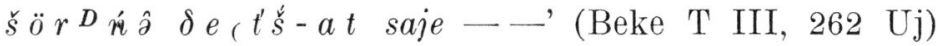
'Besser als Gold - - '. Dennoch tritt an die Partikel $\beta$ ara

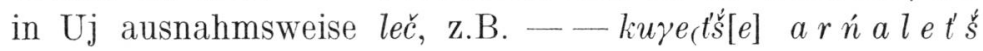
ßara kuškâżmân — - (Beke T III, $176 \mathrm{Uj}$ ) '- — am Dienstag nach der Osterwoche - - '.

4. Der Vertretungstyp lě̌ $\sim \gamma \hat{\partial} \check{c}$

ti $\delta$ an l e ts jasâ päšä uke. (Wichmann R, $322 \mathrm{Jl}$ ) 'Eine schwierigere Arbeit als diese gibt es nicht.' / m?n $t \underline{n} \delta n n \gamma n t s$ (od. $t \underline{n} \delta \underline{n} l$ e ts) (šku) pajan âlam. (Wichmann R, $321 \mathrm{Jl}$ ) 'Ich bin (viel) reicher als er.'

\section{Der $\gamma \hat{\partial} \hat{c}$-Vertretungstyp}

ti l e ts jasâ $\beta \ddot{a} s \ddot{a} u k e$. (Wichmann R, $322 \mathrm{~K}$ ) 'Eine schwierigere Arbeit als diese gibt es nicht.' / tadə piš jažon ə̌štəš,

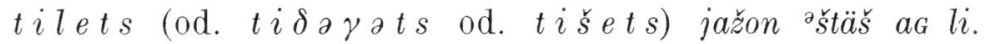
(Wichmann R, $319 \mathrm{~K}$ ) 'Er machte [es] recht gut, [desto] besser kann man [es] nicht machen.'

Weitere Beispiele sowie eine ausführlichere Behandlung der komparativen Trennungskasus s. im Artikel Alhoniemi, Congressus tertius, Pars I, 463-469.

19. DIE TRENNUNGSKASUSFORM IN VERBINDUNG MIT NICHT-KOMPARATIVISCHEN PARTIKELN

Die in dieses Kapitel gehörenden Kontexte teilen sich in zwei Gruppen. Zu den Partikeln mit der Bedeutung 'insge- 
heim' jâšt, jəßərt W, šolâp und šâp(ak) sowie zur Postposition posna 'getrennt' gehört stets der habitiv-kognitive Trennungskasus. Hier folgt nur ein Beleg für jeden Vertretungstyp, weitere Beispiele s. Alhoniemi, MSFOu 150, 17-18.

\section{Der leč-Vertretungstyp}

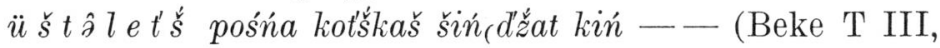
$453 \mathrm{Up})$ 'Wenn du dich ohne Gürtel zum Essen setzt - - '.

\section{Der Vertretungstyp lě $\sim \delta e \check{c}$}

$k \hat{a} t-t e t^{\prime} \dot{s}$ posna tolaša. M-i / ki D let'śs posna tolasa. S (Wichmann R, 264) 'Ohne Hände [eigtl. als Handloser] müht er sich ab, mit Mühe tut er etwas.'

3. Der $\delta e \breve{-}$-Vertretungstyp

- - ынде мый $m$ ый дече т посна илен ом керт. (Čavajn, 112 OS) ' — — jetzt kann ich nicht leben ohne dich.'

4. Der Vertretungstyp lě̌ $\sim \gamma \hat{\partial} \check{c}$

a kodom aresta pašt am lets pasna pua - - (Beke T I, 38 Jo) 'Was er [ihnen] aber gab (eigtl. gibt) ohne sich zu bekreuzigen —- '.

5. Der $\gamma \hat{\partial} \hat{c}$-Vertretungstyp

$\beta \ddot{a} t$ ə $\tilde{z} \gamma$ ? $t$ s a $n$ basna (Ramstedt, $96 \mathrm{~K}$ ) 'getrennt von seiner Frau'.

Die zweite Gruppe besteht aus den Partikeln, die 'entfernt (von etwas)' bedeuten. Zu diesen Partikeln können offenbar ebensogut lokale wie habitiv-kognitive Trennungskasus gehören; neben den habitiv-kognitiven Kasus treten in ihrer Verbindung im gesamten Sprachraum auch $\gamma \hat{\partial} \hat{c}$ - und $\check{c}$-Elative auf. Da ich auch diese Fälle bereits früher behandelt habe (s. Alhoniemi, MSFOu 150, 18-19), begnüge ich mich hier mit sehr wenigen Beispielen.

1. Der leč-Vertretungstyp

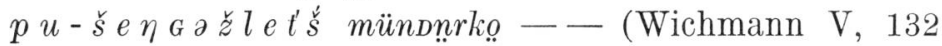
M) 'Weit vom Baum —- $/ /-\ldots \operatorname{mer} a \eta-j a l-\gamma \hat{\partial} t^{\prime} \dot{s}$ 


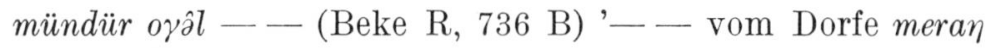
nicht weit — - '

2. Der Vertretungstyp leč $\sim \delta e \check{c}$

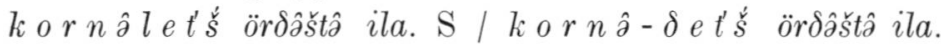
M-i (Wichmann R, 192) 'Er lebt abseits vom Wege.' //

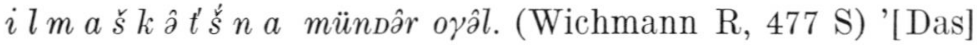
ist nicht weit von unserem Wohnort.'

3. Der $\delta e \check{c}$-Vertretungstyp

- — коллектив деч ӧрдыштӧ - - (Ončyko 6/1963 OS) ' - - abseits vom Kollektiv ——' // - - m ви ие ч тора —— (Ončyko 6/1963, 71 OS) '- — weit von hier ——'.

4. Der Vertretungstyp lě̌ $\sim \gamma \hat{\partial} \breve{c}$

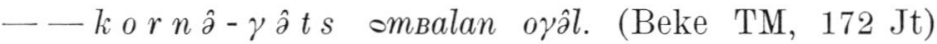
'— - nicht weit von dem Wege.'

5. Der $\gamma \hat{a} \hat{c}$-Vertretungstyp

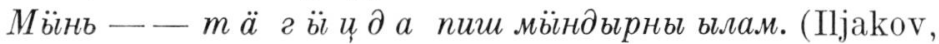
365 WS) 'Ich — - bin sehr weit von Euch.'

20. DIE TRENNUNGSKASUSFORM DER GANZHEIT, VERBUNDEN MIT EINEM NOMEN, DAS EINEN TEIL BEZEICHNET

Die Grenze zwischen den Fällen, wo der die Gesamtheit anzeigende Trennungskasus als Bestimmung z.B. eines Verbs der Loslösung oder des Trennens zu deuten ist, und jenen, wo er deutlich zu einem Nomen gehört, das einen Teil ausdrückt, lässt sich oft äusserst schwer ziehen. Adnominale Trennungskasus, die ohne Zweifel in diesen Zusammenhang gehören, habe ich eigentlich nur aus den Schriftsprachen aufgezeichnet. Dort begegnet in beiden Schriftsprachen der

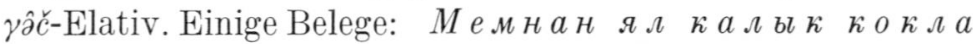
г ве ч иктат тудым пален огыл - - (Čavajn, 284 OS) 'Niemand von den Leuten unseres Dorfes kannte ihn _- 
( Ну н ын н коклла г ич ч нылле утла ен'жылан Советский Союз Герой лймым пуымо. (Onс̌уko 6/1963, 52 OS) 'Über 40 von ihnen wurde der Titel eines Helden der Sowjetunion verliehen.' / Н у н ын н ко к $л$ а г ы ч иктыжат олам ужын огыл улмаи. (Ončyko 6/1963, 65 OS) 'Keiner von ihnen hatte

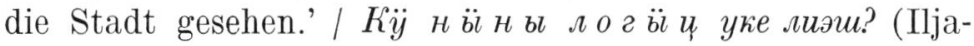
kov, $216 \mathrm{WS}$ ) 'Wer von ihnen geht zugrunde?'

In den folgenden Beispielen steht allerdings als Prädikat ein Verb, das im allgemeinen eine Trennungskasusbestimmung erhält; es kann jedoch sein, dass auch in diesen Fällen die Trennungskasusform in erster Linie adnominal zu deuten ist. In den Beispielen aus drei Dialekten steht der $\gamma \partial \hat{a} c$-Kasus, in den Belegen aus M dagegen der leč-Kasus; dies wäre eine Ausnahme, auch wenn der Trennungskasus als Bestimmung des Verbs stehen würde (in dem Beispiel aus $\mathrm{S}$ haben wir

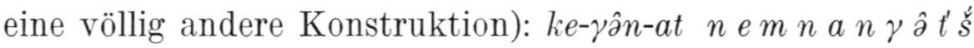

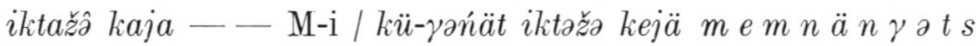

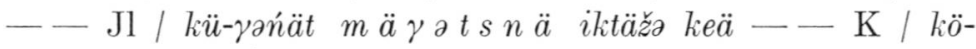
yiń-at me le et'šn a kaja - - M (Wichmann R, 439) 'Einer von uns geht - - '. Weitere Beispiele für Fälle, in denen der $\gamma \hat{a} \check{c}$-Kasus möglicherweise als adnominal auszulegen ist, s. Alhoniemi, MSFOu 150, 19-20.

\section{1. ÜBER SYNTAKTISCH ERSTARRTE TRENNUNGS- KASUSFORMEN}

Typisch für die syntaktisch erstarrte Kasusform ist u.a., dass sie in der Satzstruktur an einer Stelle stehen kann, wo sie überhaupt nicht oder wenigstens nicht ohne Veränderung der Satzstruktur ersetzt werden kann durch entsprechende Kasusformen anderer Wörter. Im Tscheremissischen begegnen auch erstarrte Trennungskasusformen. Auffallend ist, dass es sich in den von mir durchgearbeiteten Texten dabei regelmässig um $\check{c}$ - oder $\gamma \hat{a} \grave{c}$-Kasus handelt. Der leč-Kasus begegnet nur in den pronominalstämmigen tulečla oder tulečlan, deren Bedeutung u.a. 'von da an, (nicht) mehr' (z.B. Beke T IV, 82, $100 \mathrm{M}$ ) ist, in denen nach dem Trennungskasusmorphem noch 
ein zweites Flexionselement steht.

In vielen Fällen entspricht die erstarrte Kasusform formal genau der lebenden; Bedeutung und Verwendung sind jedoch andere. In den von mir benutzten Textquellen begegneten u.a. die folgenden lexikalisierten Trennungskasusformen; ich begnüge mich damit, nur eine Belegstelle anzugeben und nur die dort auftretende Bedeutung zu nennen: Berč 'wegen' (Wichmann R, $71 \mathrm{~K}$ ); яра әыч 'umsonst' (Čavajn, 272 OS); кокла гыч 'vorzeitig' (Ončyko 6/1963, 86 OS); kоže(t'šân 'wie' (Beke T I, 620 Č); luyut's 'vorzeitig' (Beke R, 392 B); nüzßßetsən 'mittlerweile' (Ramstedt, $196 \mathrm{~K}$ ); on (Dzâts 'zuerst' (Beke T I, $166 \mathrm{Jt}$ ); patška(tsan 'zuletzt' (Wichmann R, 620 K); šenget'šsn 'dann' (Beke T IV, $100 \mathrm{M}$ ); škevet'šs (šâ 'von selbst'

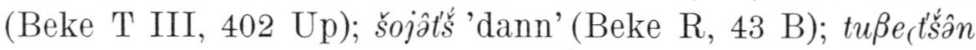
'danach' (Beke T IV, 435 B); tušet'ś 'so' (Beke T III, 47 Uj); uүut's 'wieder' (Beke T IV, 235 B); ümßat's 'zusätzlich' (Wichmann, R 612 M-i).

Alho Alhoniemi 


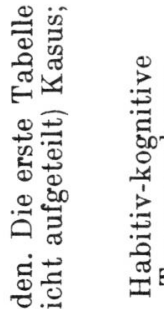
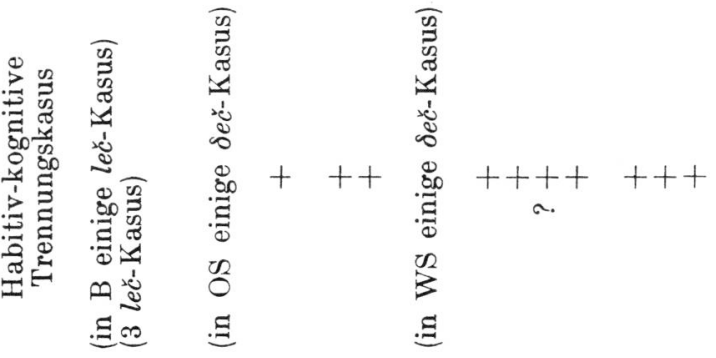

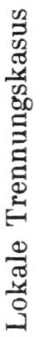

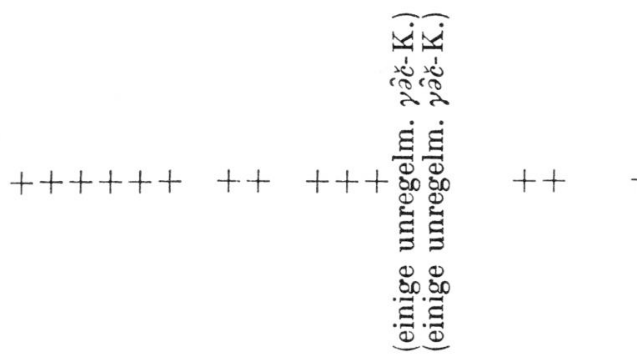

$++++++++++++$

電

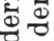

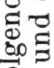

$\stackrel{0}{x}$

赵苛

to $x$

$30 \stackrel{3}{3}$

들 중

ฮี

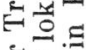

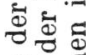

8000

들

덩

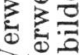

芩苋

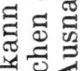

댕.

\%

สิ

5.

$\stackrel{\Xi}{\leftrightarrows}$

记.

运.

$\infty_{0}$

告

욜 $\vdots \vdots \vdots \vdots \vdots \vdots \vdots \vdots$ ㄹ

옳 원

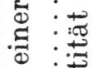

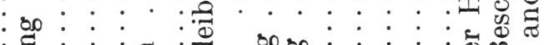

क्षे

800 : : 舟 过

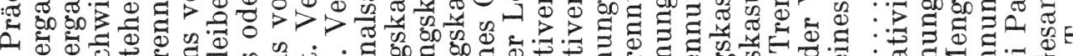
ص

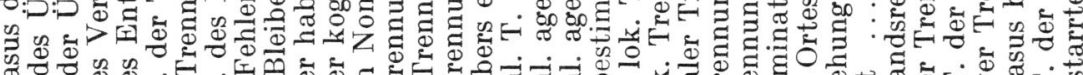

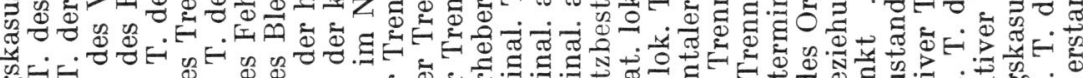

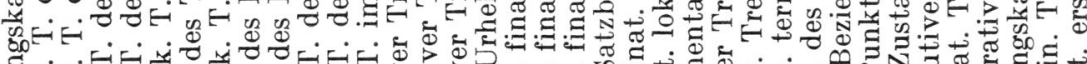
范

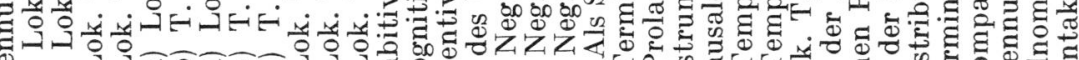

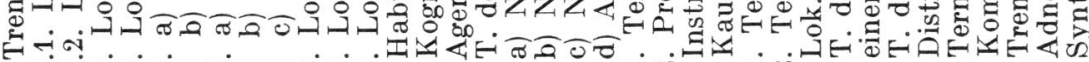
N

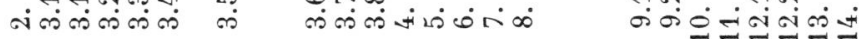
வ 


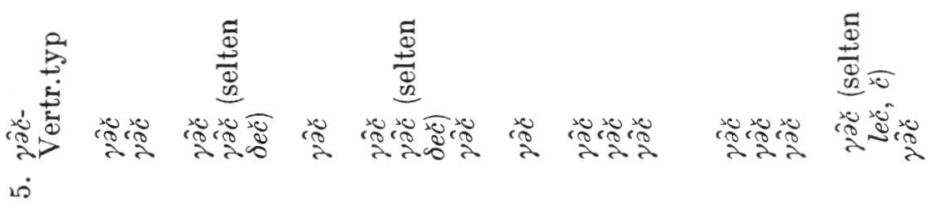

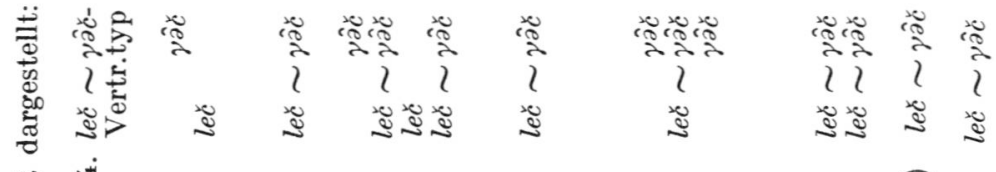
: ष्ष

竞

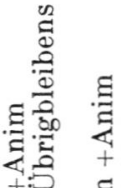

$\because$

落

ल)

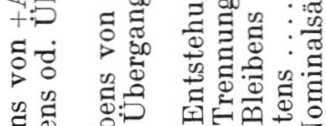

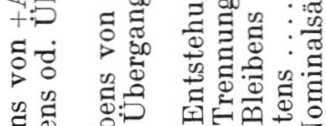

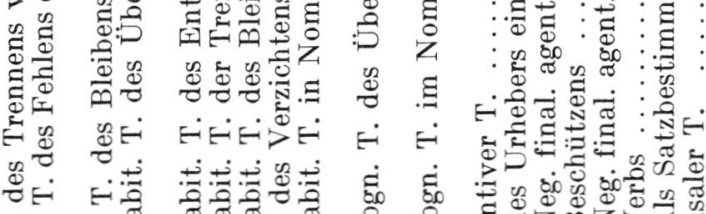

เั้

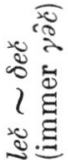

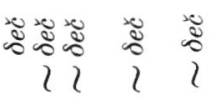

$\approx$

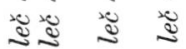

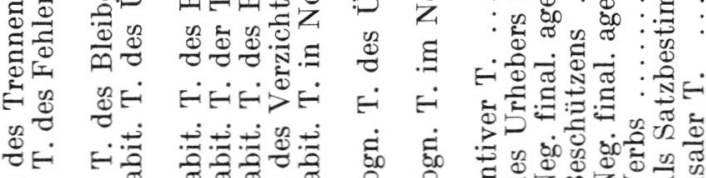

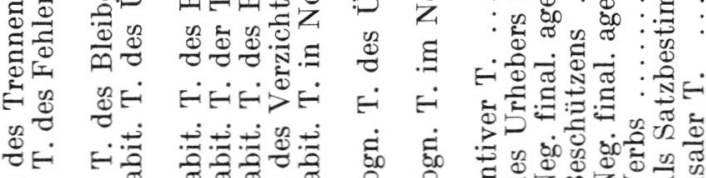

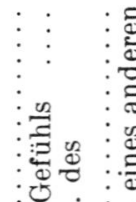

:

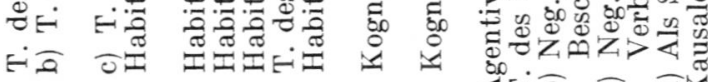

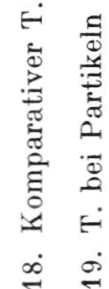

$\Xi$ 


\title{
Literatur und Abkürzungen
}

\author{
Textquellen
}

Beke $\mathrm{M}=$ Tscheremissische Märchen, Sagen und Erzählungen gesammelt und herausgegeben von ÖDön BeKE. MSFOu 76. Helsinki 1938.

Beke $\mathrm{R}=$ Texte zur Religion der Osttscheremissen. Von Öрӧм Bеке. Sonderabdruck aus Anthropos, Band 29, 1934. Wien 1934.

Beke T I, T III, T IV = Tscheremissische Texte. Gesammelt und herausgegeben von Ö. BЕке. Band I, Budapest 1957. Band III und Band IV, Budapest 1961.

Beke $\mathrm{TM}=$ Tscheremissische Märchen aus dem Kreise Jaransk. Gesammelt und herausgegeben von ÖD ÖN BEKE. Sonderabdruck aus Õpetatud Eesti Seltsi Aastaraamat 2, 1937. Tartu 1939.

Beke $\mathrm{TT}=$ Tscheremissische Texte zur Religion und Volkskunde. Gesammelt und herausgegeben von Ö̈ӧN BЕке. Oslo Etnografiske Museum, Bulletin 4. Oslo 1931.

Beke $\mathrm{V}=$ Volksdichtung und Gebräuche der Tscheremissen (Maris). I. Band. Gesammelt und herausgegeben von ÖDöN BEKE. Budapest 1951.

Čavajn $=$ С. ЧАВАЙН Ойпого. Иошкар-Ола 1957.

Genetz $=$ Ost-tscheremissische Sprachstudien von Dr. Arvid Genetz.

I. Sprachproben mit deutscher Uebersetzung. JSFOu 7. Helsinki 1889.

Grigorjev $=$ П. Г. ГРИГОРЬЕВ У вашталтыш ик и тышәньмӹкӹ лыдаш. Москоа 1927.

Iljakov $=$ Н. ИЛЬЯКОВ Эдемвлӓ дӓ ивлӓ. Роман. Козьмодемьянск 1957.

Izi bolševik-vlak = Изи большэвик-влак. Турлӧ ойлымаш дән почәламут кнага. Моско 1927.

Ončyko 6/1963 = Ончыко. Литературно-художественный общественно-политический журнал. 6/1963. Йошкар-Ола 1963.

Paasonen-Siro $\mathrm{T}=$ Tscheremissische Texte gesammelt von $\mathrm{H}$. PAAsonen. Herausgegeben von PaAvo Siro. MSFOu 78. Helsinki 1939.

Paasonen-Siro W $=$ H. PAasonens ost-tscheremissisches Wörterbuch. Bearbeitet und herausgegeben von PaAvo Siro. Helsinki 1948. Porkka-Genetz $=$ Volmari PorkкA's tscheremissische Texte mit 
Übersetzung. Herausgegen von Arvid Genetz. JSFOu 13. Helsingfors 1895 .

Ramstedt $=$ Bergtscheremissische Sprachstudien von G. J. Ramstedt. MSFOu 17. Helsingfors 1902.

Sebeok - Ingemann $=$ An Eastern Cheremis Manual. Phonology, Grammar, Texts and Glossary. By Thomas A. Sebeok and Franges J. IngEMann. The Hague 1961.

Wichmann $R=$ Die unveröffentlichten Sätze, die YrJö Wichmann aus fünf tscheremissischen Dialekten aufgeschrieben hat. Die Sätze sind die gleichen, die Antal Reguly seinerzeit aus einer Mundart aufschrieb und die József Budenz in NyK 3 veröffentlichte. Manuskript (im Besitz der Finnisch-Ugrischen Gesellschaft, Helsinki).

Wichmann $\mathrm{V}=$ Volksdichtung und Volksbräuche der Tscheremissen. Herausgegeben von YrJö Wighmann. MSFOu 59. Helsinki 1931.

\section{Sonstige Literatur}

Alhoniemi, Congressus secundus, Pars I = Alho Alhoniemi Über die distributive Verwendung der tscheremissischen Postposition $\gamma \partial \hat{\partial t}$. Congressus secundus internationalis Fenno-ugristarum. Helsinki 23. -28. VIII. 1965. Pars I. Helsinki 1968.

Alhoniemi, Congressus tertius, Pars $\mathrm{I}=$ Alho Alhoniemi Zum Gebrauch der Woher-Kasus in der marischen Komparation. Congressus tertius internationalis Fenno-ugristarum. Tallinnae habitus 17. - 23. VIII 1970. Pars I. Tallinn 1975.

Alhoniemi, FUF $38=$ Alнo Alнoniemi Über die Form des zu Verbalnomina tretenden Objekts im Tscheremissischen. FUF 38. Helsinki 1970.

Alhoniemi, MSFOu 142 = Alho Alhoniemi Über die Funktionen der Wohin-Kasus im Tscheremissischen. MSFOu 142. Turku 1967.

Alhoniemi, MSFOu $150=$ Alho Alhoniemi Über einige nichtadverbale Verwendungsweisen der Woher-Kasus im Tscheremissischen. MSFOu 150. Helsinki 1973.

Alhoniemi, Sananjalka $10=$ A. Alhoniemi Suomen ja tšeremissin kielen suuntasijajärjestelmien funktionaalisesta rakenteesta [Über die funktionale Struktur der Richtungskasussysteme im Finn. und Tscher.]. Sananjalka 10. Turku 1968.

Alhoniemi, Sananjalka $17=$ Alнo Alнoniemi Eräistä suomen kielen paikallissijojen keskeisistä käyttötavoista [Über einige charakteristische Verwendungsweisen der finnischer Lokalkasus]. Sananjalka 17. Turku 1975.

Bartens, Kaasussyntaksi $=$ RAIJA BARTEns Inarinlapin, merilapin ja luulajanlapin kaasussyntaksi [Die Kasussyntax des Inari-, Seeund Lulelappischen]. MSFOu 148. Helsinki 1972.

FUF $=$ Finnisch-ugrische Forschungen. Helsinki $1901-$. 
Galkin, Istor. Grammatika I = И. С. ГАЛКИН Историческая грамматика марийского языка. Морфология, часть I. Йошкар-Ола 1964.

Grusov, Fonetika = Л. П. ГРУЗОВ Историческая грамматика марийского языка. Введение и фонетика. Йошкар-Ола 1969.

Hakulinen, $\mathrm{SKRK}^{3}=$ LAURI HAKULINEN Suomen kielen rakenne ja kehitys. Kolmas, korjattu ja lisätty painos. [Struktur und Entwicklung der finnischen Sprache. Dritte, überarbeitete und vermehrte Auflage.] Keuruu 1968.

Itkonen, Vir. $1960=$ ERK I IткоNEN Tšeremissin kielen sanaliittojen suhteesta yhdyssanoihin ja taivutusmuotoihin [Über das Verhältnis von Wortverbindungen zu Komposita und Flexionsformen im Tscheremissischen]. Virittäjä 1960. Helsinki 1960.

JSFOu = Journal de la Société Finno-ougrienne. Helsinki 1886-.

Kangasmaa-Minn, Acta = Eeva KangasmaA-Mrnn Tšeremissin kaksoisobjekti [Das doppelte Objekt im Tscheremissischen]. Acta Universitatis Tamperensis. Ser. A. Vol. 26. Tampere 1969.

Kangasmaa-Minn, MSFOu 139 und 146 = Eeva KangasmaA-Minn The Syntactical Distribution of the Cheremis Genitive. I MSFOu 139. Turku 1966. II MSFOu 146. Helsinki 1969.

Lyons, Introduction $=$ JоHN LYONs Introduction to Theoretical Linguistics. Cambridge 1971.

Marijsko-russkij slovaŕ = Марийско-русский словарь. Москва 1956. McCawley, Prelexical Syntax = James D. McCawley Prelexical Syntax. Semantic Syntax. Edited by Pieter A. M. Seuren. Oxford 1974. MSFOu = Mémoires de la Société Finno-ougrienne. Helsinki 1890-. NyK = Nyelvtudományi Közlemények. Budapest 1862-.

Sadeniemi, Tietolipas $18=$ Matti SAdeniem I Kielenkäytön kysymyksiä [Fragen des Sprachgebrauchs]. Tietolipas 18. Helsinki 1960. Savatkova-UCajev, Grammatičeskij ocerk = Марийско-русский словарь. С приложением краткого грамматического очерка марийского языка (А. САВАТКОВА-3. УЧАЕВ). Москва 1956.

Siro, Lokalkasus = Die finnischen Lokalkasus als Bestimmungen des Verbums. Untersuchungen zur finnischen Syntax. Von PaAvo Siro. Annales Universitatis Turkuensis. Series B. Tom. 57. Turku 1956.

Wichmann, FUF $9=$ YrJö Wichmann Über eine Art »Rhotazismus» im Tscheremissischen. FUF 9. Helsinki 1909-1911.

\section{Dialekte und Schriftsprachen}

$$
\begin{aligned}
& \mathrm{B}=\text { Dialekt von Birsk } \\
& \check{\mathrm{C}}=\text { Dialekt von Čeboksary } \\
& \mathrm{J}=\text { Dialekt von Jaransk }
\end{aligned}
$$




$$
\begin{aligned}
& \mathrm{Jl}=\text { Jaransker Dialekt von Lumpanur } \\
& \mathrm{Jo}=\text { Jaransker Dialekt von Otjukowo } \\
& \mathrm{Jt}=\text { Jaransker Dialekt von Turšo-Mučakš } \\
& \mathrm{Ju}=\text { Jaransk-Uržumer Dialekt von Upša } \\
& \mathrm{JO}=\text { Dialekt von Joškar-Ola } \\
& \mathrm{JOk}=\text { Joškar-Olaer Dialekt von Kükš-nur } \\
& \text { JÖ̈= Joškar-Olaer Dialekt von Ǔšütj-tür } \\
& \mathrm{K}=\text { Dialekt von Kozmodemjansk } \\
& \mathrm{M}=\text { Dialekt von Malmyž } \\
& \mathrm{M}-\mathrm{i}=\text { Dialekt von Morki } \\
& \mathrm{O}=\text { Osttscheremissisch (allgemein) } \\
& \mathrm{OS}=\text { Osttscheremissische Schriftsprache } \\
& \mathrm{P}=\text { Dialekt von Perm } \\
& \mathrm{S}=\text { Dialekt von Sernur } \\
& \mathrm{U}=\text { Dialekt von Uržum } \\
& \mathrm{Uj}=\text { Uržumer Dialekt von Jadykbyljak } \\
& \mathrm{Up}=\text { Uržumer Dialekt von Petrušin } \\
& \mathrm{Us}=\text { Uržumer Dialekt von Sabujal } \\
& \mathrm{Uś}=\text { Uržumer Dialekt von Śükśâ } \\
& \mathrm{W}=\text { Westtscheremissisch (allgemein) } \\
& \mathrm{WS}=\text { Westtscheremissische Schriftsprache }
\end{aligned}
$$




\section{Inhalt}

1. EINLEITUNG $\ldots \ldots \ldots \ldots \ldots \ldots \ldots \ldots \ldots \ldots \ldots \ldots \ldots \ldots \ldots \ldots$

2. DIE TRENNUNGSKASUSFORM ALS GLIED EINES PRÄDIKATIVEN VERHÄLTNISSES $\ldots \ldots \ldots \ldots \ldots \ldots \ldots \ldots$

2.1. Das Verhältnis ist total .................. 9

2.2. Das Verhältnis ist partial ................. 14

3. DIE TRENNUNGSKASUSFORM ALS GLIED EINES LOKALEN VERHÄLTNISSES $\ldots \ldots \ldots \ldots \ldots \ldots \ldots \ldots$

3.1. Der Trennungskasus bei einem Verb des lokalen Übergangs 20 3.1.1. Der Trennungskasus drückt die Lokalität aus .... 20

3.1.2. Der Trennungskasus drückt die Richtung aus .... 25

3.2. Der Trennungskasus bei einem Verb des Verschwindens .. 27

3.3. Der Trennungskasus bei einem Verb des Entstehens ..... 28

3.4. Der Trennungskasus bei einem Verb der Trennung oder der Loslösung . ..................... 30

3.5. Der Trennungskasus bei einem Verb des Bleibens ..... 35

3.6. Der Trennungskasus bei einem Verb der habitiven Verände-

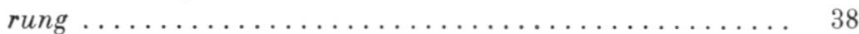

3.7. Der Trennungskasus bei einem Verb der kognitiven Veränderung .............................. 42

3.8. Der Trennungskasus in Nominalsätzen sowie in Sätzen mit'sein' ........................ 50

4. DIE TRENNUNGSKASUSFORM ALS GLIED EINES HABITIVEN VERHÄLTNISSES $\ldots \ldots \ldots \ldots \ldots \ldots \ldots 2$

4.1. Der Trennungskasus bei einem Verb des habitiven Übergangs 55

4.2. Der Trennungskasus bei einem Verb des Entstehens ..... 62

4.3. Der Trennungskasus bei einem Verb der Trennung oder der

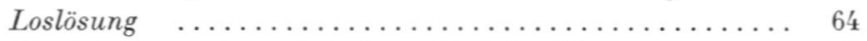

4.4. Der Trennungskasus bei einem Verb des Bleibens ....... 65

4.5. Der Trennungskasus bei einem Verb des Verzichtens . . . 66

4.6. Der Trennungskasus in Nominalsätzen sowie in Sätzen mit

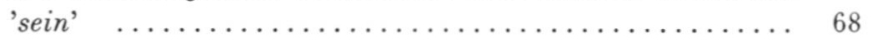

5. DIE TRENNUNGSKASUSFORM ALS GLIED EINES KOGNITIVEN VERHÄLTNISSES ............. 71

5.1. Der Trennungskasus bei einem Verb der Veränderung .. 73

5.2. Der Trennungskasus in Nominalsätzen sowie in Sätzen

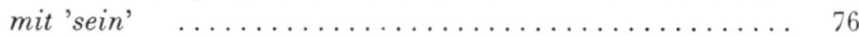

6. DIE TRENNUNGSKASUSFORM DRÜCKT DAS AGENS 


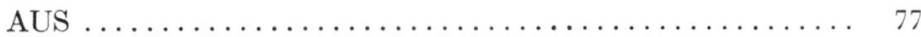

7. DIE TRENNUNGSKASUSFORM DRÜGKT DEN URHEBER EINER EMPFINDUNG AUS $\ldots \ldots \ldots \ldots \ldots \ldots 78$

8. DIE TRENNUNGSKASUSFORM IN FINALER VERWENDUNG .............................. 81

8.1. Der Trennungskasus bei einem Verb des Beschützens .... 81

8.2. Der Trennungskasus bei einem Verb der Errettung, der Verhinderung oder des Ausweichens ............. 88

8.3. Der Trennungskasus als Satzbestimmung ........... 90

9. DIE TRENNUNGSKASUSFORM DRÜCKT DAS VERHÄLTNIS EINER TÄTIGKEIT ODER EINES ZUSTANDES ZUR LOKALITÄT AUS . ................. 92

9.1. Der Trennungskasus in terminativer Verwendung ....... 92

9.1.1. Der Trennungskasus bezeichnet die Grenze des

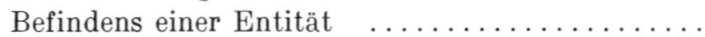

9.1.2. Der Trennungskasus bezeichnet das Verhältnis der Position von Entitäten ....................

9.1.3. Der Trennungskasus bezeichnet die Grenze einer Tätigkeit oder eines Zustandes ...............

9.2. Der Trennungskasus in prolativer Verwendung ...........

9.2.1. Der Trennungskasus drückt die Lokalität aus, durch die die Position der Entität verläuft ...........

9.2.2. Der Trennungskasus drückt die Lokalität aus, durch die eine Handlung gerichtet ist .........

10. DIE TRENNUNGSKASUSFORM IN INSTRUMENTALER VERWENDUNG ......................... 101

11. DIE TRENNUNGSKASUSFORM IN KAUSALER VER-

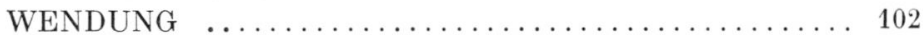

12. DIE TRENNUNGSKASUSFORM IN TEMPORALER VER-

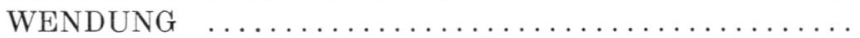

12.1. Der Trennungskasus drückt aus, nach welcher Zeit die im Satz mitgeteilte Tätigkeit oder der Zustand realisiert wird

12.2. Der Trennungskasus in terminativer Verwendung ......

13. DIE TRENNUNGSKASUSFORM GIBT DIE LOKALITÄT AN, VON WO AUS DER IM SATZ AUSGEDRÜCKTE ZUSTAND ODER DIE TÄTIGKEIT VERURSACHT WIRD

14. DIE TRENNUNGSKASUSFORM BEZEICHNET DEN PUNKT DER ENTITÄT, WORAUF SICH DER IM SATZ AUSGEDRÜCKTE ZUSTAND ODER DIE TÄTIGKEIT

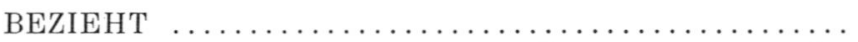

15. DIE TRENNUNGSKASUSFORM DRÜGKT DIE ENTITÄT AUS, DIE DER IM SATZ AUSGESPROCHENE ZUSTAND BETRIFFT

16. DIE TRENNUNGSKASUSFORM IN DISTRIBUTIVER VERWENDUNG 
17. DIE TRENNUNGSKASUSFORM ZUR BEGRENZUNG EINER ANZAHL ODER MENGE ............ 116

18. DIE TRENNUNGSKASUSFORM IN KOMPARATIVER

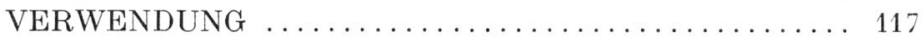

19. DIE TRENNUNGSKASUSFORM IN VERBINDUNG MIT NICHT-KOMPARATIVISCHEN PARTIKELN _...... 118

20. DIE TRENNUNGSKASUSFORM DER GANZHEIT, VERBUNDEN MIT EINEM NOMEN, DAS EINEN TEIL BE-

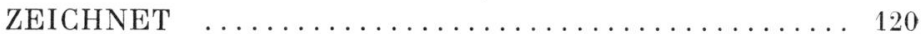

21. ÜBER SYNTAKTISCH ERSTARRTE TRENNUNGSKA-

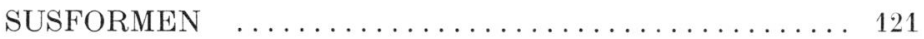

22. TABELLEN ÜBER DIE VERWENDUNG DER TREN-

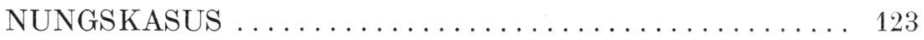

LITERATUR UND ABKÜRZUNGEN . . . . . . . . . . . 125 Textquellen ........................... 125

Sonstige Literatur . . . . . . . . . . . . . . . . . 126

Dialekte und Schriftsprachen ............... 127 